\title{
WestVirginiaUniversity
}

THE RESEARCH REPOSITORY @ WVU

Graduate Theses, Dissertations, and Problem Reports

2017

\section{North-East Indian Monsoon Rainfall Variability over Southeastern Peninsular India}

Jothiganesh Shanmugasundaram

Follow this and additional works at: https://researchrepository.wvu.edu/etd

\section{Recommended Citation}

Shanmugasundaram, Jothiganesh, "North-East Indian Monsoon Rainfall Variability over Southeastern Peninsular India" (2017). Graduate Theses, Dissertations, and Problem Reports. 6616.

https://researchrepository.wvu.edu/etd/6616

This Dissertation is protected by copyright and/or related rights. It has been brought to you by the The Research Repository @ WVU with permission from the rights-holder(s). You are free to use this Dissertation in any way that is permitted by the copyright and related rights legislation that applies to your use. For other uses you must obtain permission from the rights-holder(s) directly, unless additional rights are indicated by a Creative Commons license in the record and/ or on the work itself. This Dissertation has been accepted for inclusion in WVU Graduate Theses, Dissertations, and Problem Reports collection by an authorized administrator of The Research Repository @ WVU.

For more information, please contact researchrepository@mail.wvu.edu. 


\title{
North-East Indian Monsoon Rainfall Variability over Southeastern Peninsular India
}

\author{
Jothiganesh Shanmugasundaram \\ Dissertation submitted \\ to the Eberly College of Arts and Science \\ at West Virginia University
}

in partial fulfillment of the requirements for the degree of

Doctor of Philosophy in

Department of Geology and Geography

\author{
Eungul Lee, Ph.D., Chair \\ Amy E. Hessl, Ph.D. \\ Trevor Harris, Ph.D. \\ Nicolas Zégre, Ph.D. \\ Govindarajalu Srinivasan, Ph.D. \\ Department of Geology and Geography
}

Morgantown, West Virginia

2017

Keywords: Northeast Indian Monsoon, Southeastern India, Ocean-Atmosphere interaction, Moisture transport processes, Climate change adaptation Copyright 2017 Jothiganesh Shanmugasundaram 


\section{ABSTRACT \\ North-East Indian Monsoon Rainfall Variability over Southeastern Peninsular India \\ Jothiganesh Shanmugasundaram}

North-East Indian Monsoon rainfall (NEIMR) during October-December is of immense socio-economic importance to the agriculture dependent population in the southeastern peninsular India. NEIMR is subject to extreme year-to-year and intraseasonal variability that needs to be understood to enhance climate resilience. An understanding of NEIMR variability and the physical processes behind this variability would help to improve the predictability of NEIMR variation over the southeastern peninsular of India. An insight into past societal responses to monsoon variability would be a great lesson for adapting to future climate challenges. This dissertation seeks to examine the intra-seasonal variability of NEIMR and its driving ocean-atmospheric conditions, and simultaneously understand the past societal responses to these conditions. In so doing the research addresses some of the key scientific knowledge gaps in NEIMR and provides recommendations on how to respond to monsoon variability.

The investigation of intra-seasonal variability of pentad NEIMR using the Hidden Markov Model indicated the presence of three dominant rainfall 'states' in the southeastern peninsular of India: wet, coastal wet, and dry. These three rainfall states are associated with distinct atmospheric circulation and surface temperature. The wet conditions are characterized by enhanced cyclonic activities and increased moisture convergence at $850 \mathrm{hPa}$ over the Indian southeastern peninsular and its neighboring oceanic regions - the Bay of Bengal and Indian Ocean. In contrast, the dry conditions are associated with anticyclonic circulation and the reduced moisture convergence at 850 hPa.

The examination of ocean and atmospheric conditions associated with wet NEIMR conditions over the southeastern peninsular of India revealed that sea surface temperatures (SSTs) significantly increased over the Bay of Bengal during all the 
simultaneous and lagged time steps. The SSTs were significantly increased over the equatorial western Indian Ocean during the lag-2, -3 , and -4 time steps before the occurrence of wet NEIMR conditions. At the same time, the latent heat fluxes (LHF) decreased over the Bay of Bengal (all time steps) and increased over the Indian Ocean (same and lags-1 and -2). The differences in the relationships with wet NEIMR between SST and LHF over the two ocean basins are possibly due to the differing atmospheric moisture demands and lower level winds. The investigation of moisture transport processes indicates that moisture transport was dominant over the lower atmospheric levels (1000 to $850 \mathrm{hPa})$. The moisture from the equatorial Indian Ocean region was transported to the moisture-abundant Bay of Bengal region through westerly anomalies and subsequently the moisture was carried to the southeastern peninsular of India through strong cyclonic circulation.

An investigation of instrumental and proxy climatic data sets between 500 and $2010 \mathrm{CE}$ indicates that the period between $\sim 850$ and $\sim 1300 \mathrm{CE}$, a time of frequent $\mathrm{El}$ Niño-like conditions, was associated with a substantial increase in NEIMR, whereas South-West Indian monsoon rainfall (SWIMR) suffered substantial deficits. The spatial pattern and chronology of water harvesting infrastructure developed under Chola rule indicate that these features were concentrated in the NEIMR-receiving regions of southeastern India and that their construction peaked during El Niño-dominated intervals. Overall, enhanced NEIMR conditions and adaptation strategies practiced in the Chola's territory, combined with less favorable climatic conditions over the neighboring kingdoms, appears to have underpinned the well-documented political and economic strengths of the Chola Kingdom. I infer that the water management infrastructure promoted by the Chola rulers helped to buffer the consequences of climatic extremes in later history, whether from droughts (e.g. the El Niño-related mega-drought of 18761878) or floods (because the reservoirs contained surplus runoff).

Overall, the spatio-temporal characterization of the three rainfall states, and the ocean and atmospheric processes associated with the wet NEIMR conditions over the southeastern peninsular of India could provide a valuable scientific input for enhancing rainfall predictability, which is of huge socioeconomic value to agriculture and water 
resource management sectors in the Indian southeastern peninsular. Further, the lessons from the past would be a valuable input for adapting to future climate challenges in the southeastern peninsular of India. Especially for the planners and policymakers who would gain from restoring value to the existing tank system as a means of managing climatic risk in Southern India, and for ensuring the related goals of food security, food sovereignty, and urban flood hazards are suitably managed within a "capable" landscape. 


\section{Dedication}

To my wife Ancy for being very supportive on all my endeavors.

To my father and mother for what I am.

To all my teachers, friends, and well-wishers. 


\section{Acknowledgments}

I express my heartfelt thanks to all the faculty, colleagues, and friends at West Virginia University for their support during my doctoral degree. I first acknowledge my advisor Dr. Eungul Lee for molding me into a climatologist with strong fundamentals and background on monsoon climate and its driving land-ocean-atmospheric processes. Dr. Lee trained me to acquire skills in programming, tools, and models required for investigating climate research questions as an independent researcher. Dr. Lee's directions and feedbacks on my research greatly helped me to develop my scientific inquiry skills, data analysis, and scientific writing. Especially, the discussions with my advisor during the weekly lab meetings were very beneficial for my research progress. I learnt from Dr. Lee that a planned and systematic way of working greatly helps to succeed in academic and research career. I am grateful for the funding opportunity Dr. Lee has provided me to work as a research assistant in his climatology lab that contributed to a valuable research experience on the inter-disciplinary projects in climate applications. I feel fortunate and excited that I had a chance to work with Dr. Lee for my doctoral research.

I express my sincere thanks to my committee members. I learnt teaching methods, creativity in research, getting insights from scientific papers, impacts of scientific research, and scientific writing skills from Dr. Amy Hessl, especially during my graduate coursework. Dr. Hessl encouraged me and gave me opportunity to earn experience in guest lectures in undergraduate classes while I was working as a graduate assistant with her during my first semester. That led me to give many guest lectures for various undergraduate classes as well as to teach a part of physical geography coursework as a full-time instructor. Dr. Trevor Harris made it possible for me to learn advanced geovisualization techniques such as 'Computer Assisted Virtual Environments' and innovative methods of exploring spatial data analysis techniques through his coursework. Dr. Harris was the one who taught me to ask the right question rather than finding a correct answer to a wrong question. I learnt how a person could be passionate about one's field of interest from Dr. Nicolas Zégre as he is a hydrologist and river rafting enthusiast. 
Nicolas was the one who helped me to build my fundamentals on the water cycle in the climate processes and scientific communication skills. I am grateful to Dr. Srinivasan Govindarajalu, at the Regional Integrated Multi-Hazard Early Warning System who encouraged me to pursue the $\mathrm{PhD}$ degree and provided guidance throughout the program as a well-wisher and my dissertation committee member. Dr. Srinivasan was always there to guide me on Indian climate system and monsoon dynamics from his vast experience.

I am grateful to Dr. Yanni Gunnell, Department of Geography, Univ Lyon Lumière, France, for his guidance and directions on exploring the societal response to climate variability in South India, and participating as co-author of a paper coming out of my Ph.D research. Thanks to Dr. Balaji Rajagopalan from the Department of Civil, Environmental, and Architectural Engineering at University of Colorado Boulder, for his input and comments on the links between ENSO and the Indian monsoon, and on monsoon impacts in the agriculture sector.

I express my sincere gratitude to the West Virginia University, especially to the Department of Geology and Geography for giving me the opportunity to pursue my doctoral degree in Geography, and for two years funding through a departmental teaching assistantship. Thanks to Dr. Brenden McNeil, Joshua Lohnes, and Christabel Devadoss, with whom I worked as a teaching assistant and it was a valuable learning experience for me. Thanks to Lee Ann Nolan for her kind support and feedback which helped me to improve my teaching skills. During my research assistantship, I had a chance to work with Dr. Heather Basara on the heat wave project in the Chickasaw nation which was a rewarding inter-disciplinary research experience. I am thankful to Dr. Basara for her insightful comments and suggestion during the project which enhanced my critical thinking on climate application related projects. Thanks to Rahama Bieda for her research support while working with heat wave project. I thank all my professors with whom I had chance to work with them or got feedback from them during my doctoral degree, Dr. Tim Warner, Dr. Brent McCusker, Dr. Bradley Wilson, Dr. James Harner, Dr. Ann Oberhauser, Dr. Karen Culcasi, Dr. Yong-Lak Park, Dr. Jonathan Hall, Dr. Maria Perez, Dr. Aaron Maxwell. Thanks to Hope Stewart for her administrative support and Randy 
Crowe for his technical support at Brooks Hall. My heartfelt thanks to A. R. Subbiah from the Regional Integrated Multi-Hazard Early Warning System for Africa and Asia, from whom I got a lot of insights and background knowledge about the socioeconomic importance of the North East Indian Monsoon for the state of Tamil Nadu. I am grateful to my friend Itesh Dash who introduced GrADS and SHELL scripting to me that helped me a lot to carry out data analysis during my doctoral degree.

I would like to thank my colleague Yaqian He from the Department of Geology and Geography at West Virginia University. Yaqian was always there in our lab to discuss about the data analysis, interpreting results, and to ask critical questions that helped me a lot. Yaqian would give her comments and feedbacks on my research findings and on my manuscript. Thanks to Dr. Huming Luo who helped me to understand the Hidden Markov Model and Power Spectrum Analysis. Thanks are also due to my department colleagues Alex Dye, John Burkhart, Fang Fang, Jennifer Smith, Dave Kneiter, Jim Schindling, Kevin Kuhn, Frank Lafone, Matthew Purtill, Park Muhunda, Thomas Brown, Barb MacLennan, Chris Ramezan, Maingi Solomon, Joyce Muthoni, Deborah Kirk, Luis Andrés Guillen, and Amber Williams for their feedback and support during my course work, comprehensive exams and research. I would like to thank Andrea Bebell from Department of English; Jennie Zhu and Pragya Srivastava from the Department of Geology and Geography at West Virginia University for their editorial corrections and comments. I am grateful to all my friends and well-wishers, Suresh Rathinam, Premavalli Shanmugam, Subra Natarajan, Saravanan Kolandaivelu, Vikas Agrawal, Aditya Jakka, Vikram Jakka, Sashank Shabineevasu, Vishnu Padmanaban, Jayaram Subramaniam, Kumarendran, Praween M., Hari Hara Sudhan Lakshman, Apporva Ravishankar, Shobit Singh, Swathi Reddy Shetty, Srikanth Gattu, Danushya Ramachandran, David Murad, and the Devadoss family for their support during my doctoral degree. Finally, I thank all my family members for their continued support during my doctoral degree. 


\section{Table of Contents}

1 Introduction ........................................................................................................................ 1

2 Rainfall variability over the southeastern peninsular of India .............................6

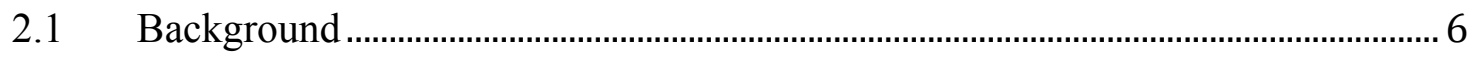

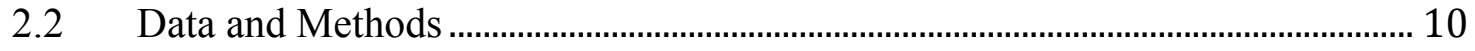

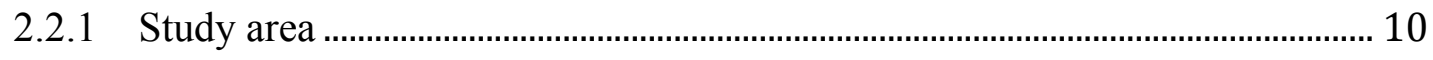

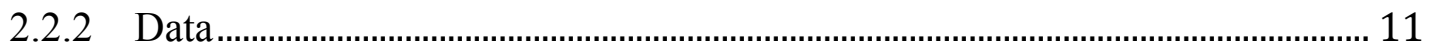

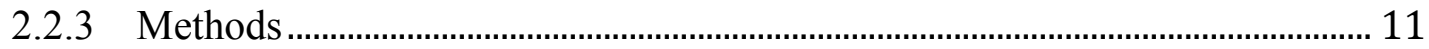

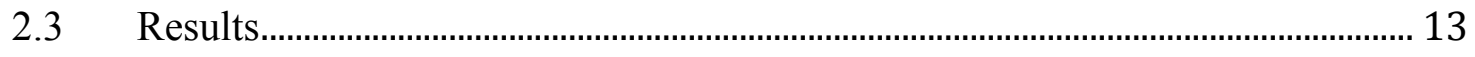

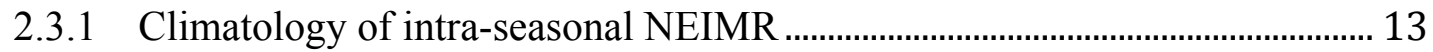

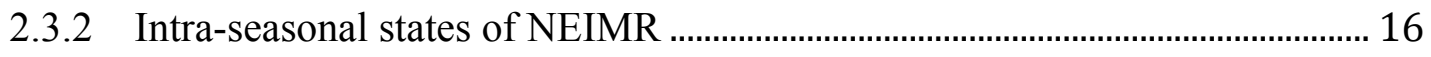

2.3.3 Atmospheric circulation and surface temperature conditions for the rainfall states 24

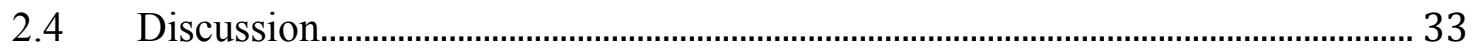

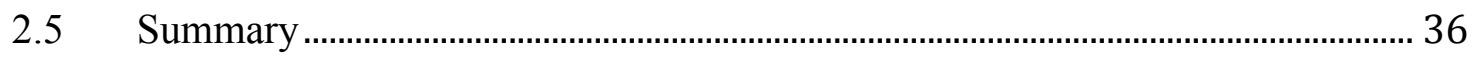

3 Ocean and atmospheric conditions associated with NEIMR .............................38

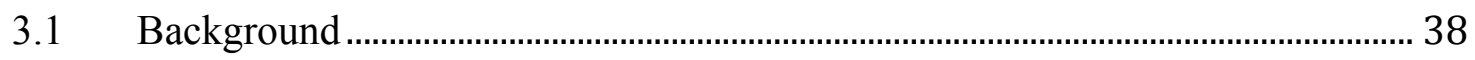

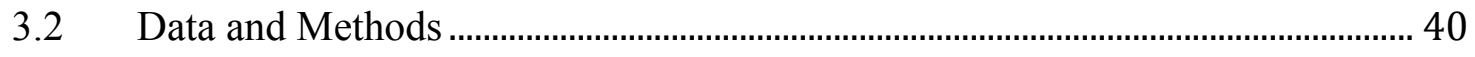

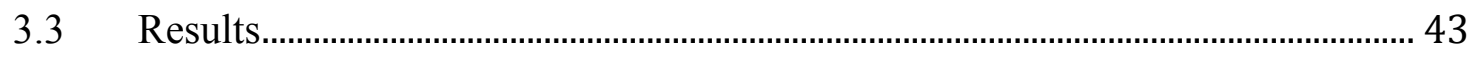

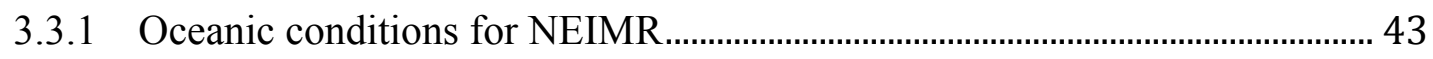

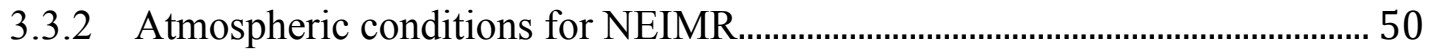

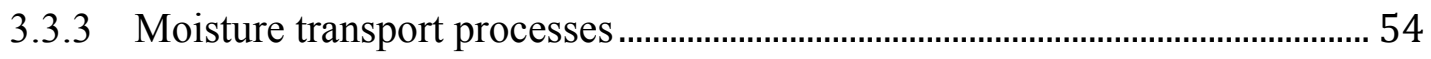

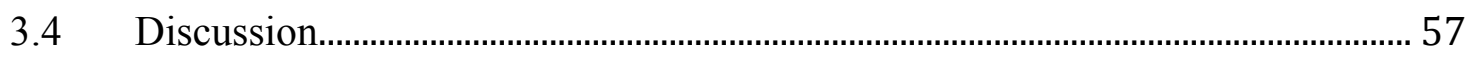

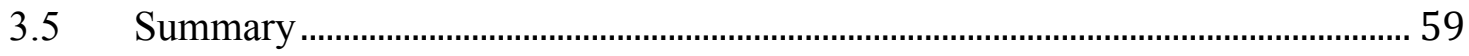

4 Lessons from the past for adapting to the monsoon variability in the future ... 61

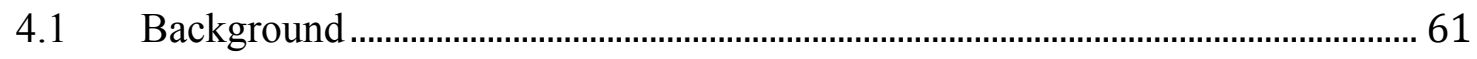

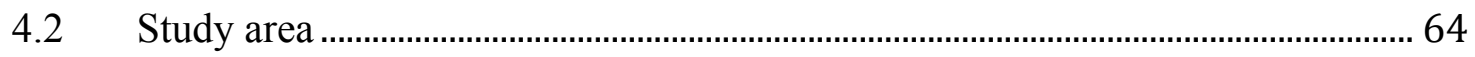

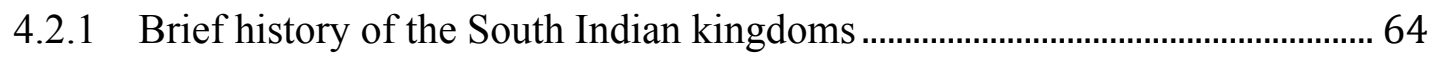


4.2.2 Landscapes of the Chola Kingdom: temples and tanks......................................6 66

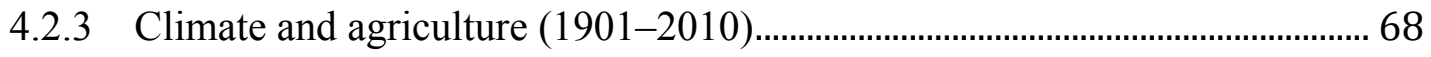

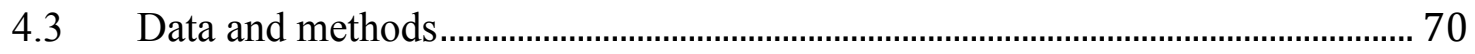

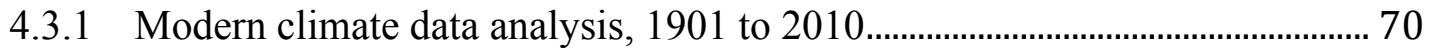

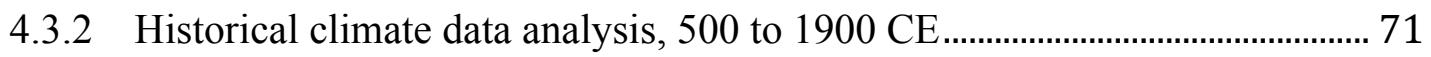

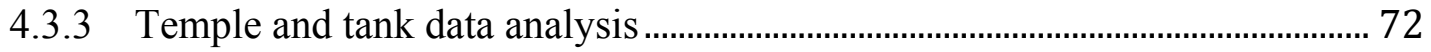

4.3.4 Exploring the societal response to changing climate in the recent

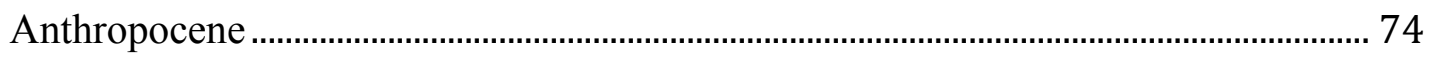

4.4 Climatic variability during the modern and historical periods .............................. 75

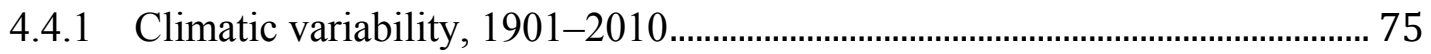

4.4.2 Relationship between rainfall and the SOI, 1901-2010................................. 78

4.4.3 Climatic variability, 500-1900 CE....................................................................... 79

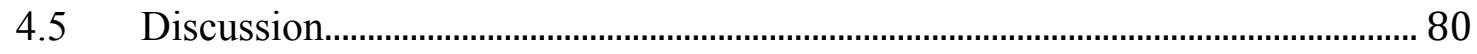

4.5.1 Potential causes for the rise of the Chola Kingdom ............................................ 80

4.5.2 Societal response to climatic challenges during the Anthropocene ................. 86

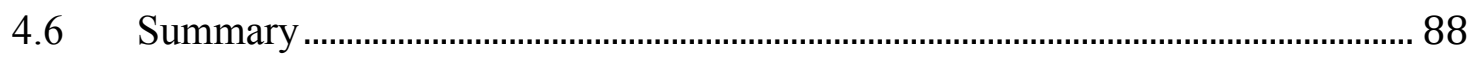

5 Dissertation conclusion ................................................................................91

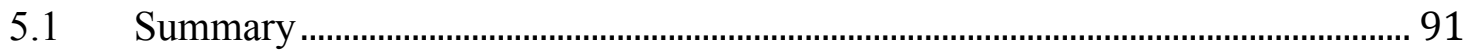

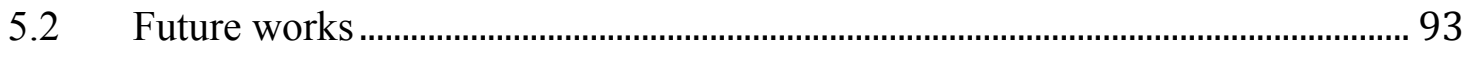

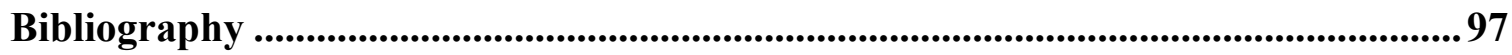




\section{List of Tables}

Table 2.1 Probability of transitions between the rainfall states from the 3-state HMM...21

Table 3.1 Spearman correlation coefficient of NEIMR, averaged over the southeastern India $\left(77.5^{\circ}\right.$ to $80.25^{\circ} \mathrm{E}, 8^{\circ}$ to $16^{\circ} \mathrm{N}$ ), with SST and LHF (simultaneous and lagged time steps), averaged over the Bay of Bengal $\left(80^{\circ}\right.$ to $95^{\circ} \mathrm{E}, 8^{\circ}$ to $\left.19^{\circ} \mathrm{N}\right)$ and equatorial western Indian Ocean $\left(56^{\circ}\right.$ to $76^{\circ} \mathrm{E}, 3^{\circ} \mathrm{S}$ to $\left.5^{\circ} \mathrm{N}\right)$ regions during the months of Oct-Dec for the period 1985 to 2014 . All the correlation coefficient values are significant at the $99 \%$ level ( $p$ value $<0.01$ ), except the value of lag-4 LHF over the equatorial western Indian Ocean

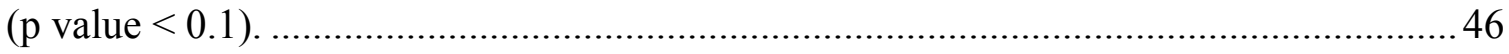

Table 4.1 Chronology of Chola Kingdom rulers........................................................ 74

Table 4.2 Rainfall characteristics over the capital cities of the kingdoms of South India 76 


\section{List of Figures}

Figure 1.1 Map showing (a) geography and topography of the southern peninsular of India, (b) seasonal accumulated rainfall during October to December months ( $\mathrm{mm}$ ), (c) percentage of annual rainfall received during October to December months, (d) rainfall variation by pentad (five days period) from Jan to Dec, over the study domain (77.580.25E and 8-16N), and (e) same as (d), but for Sep to Dec

Figure 2.1 Map showing (a) geography and topography of peninsular India and (b) percentage of annual rainfall received during October to December months. The study region is outlined in the rectangle in (b).

Figure 2.2 Rainfall variability over the NEIMR domain of $77.5-80.25^{\circ} \mathrm{E}$ and $8-16^{\circ} \mathrm{N}$ during the months of October to December for the years of 1982-2014. (a) daily rainfall variability, and (b) pentad rainfall variability

Figure 2.3 Rainfall (mm/day) variation by pentad from Jan. to Dec., over the study domain $\left(77.5-80.25^{\circ} \mathrm{E}\right.$ and $\left.8-16^{\circ} \mathrm{N}\right)$, (b) Same as (a), but for Sept. to Dec., (c) Longitudinal cross-section $\left(77-81^{\circ} \mathrm{E}\right)$ of wind vectors $(\mathrm{m} / \mathrm{s})$ area-averaged over $8-16^{\circ} \mathrm{N}$ during Jan. to Dec., (d) Latitudinal cross-section $\left(8-16^{\circ} \mathrm{N}\right)$ of wind vectors area-averaged over $77-81^{\circ} \mathrm{E}$ during Jan. to Dec., (e) Longitudinal cross-section $\left(77-80.25^{\circ} \mathrm{E}\right)$ of pentad rainfall area-averaged over $8-16^{\circ} \mathrm{N}$ during Jan. to Dec., (f) Latitudinal cross-section (8$16^{\circ} \mathrm{N}$ ) of pentad rainfall area-averaged over $77.5-80.25^{\circ} \mathrm{E}$ during Jan. to Dec, (g) Same as (e), but for Sept. to Dec., and (h) Same as (f), but for Sept. to Dec.

Figure 2.4 Bayesian Information Criterion (BIC) scores for 1-18 NEIMR state models classified by the Hidden Markov Model (HMM). Horizontal dotted line indicates the lowest BIC score and vertical line indicates its corresponding state model.

Figure 2.5 Mean pentad NEIMR (mm/day) for the six rainfall states.

Figure 2.6 (a) Grid locations considered for the HMM modelling, (b) mean pentad NEIMR (mm/day) and (e) occurrence probabilities from the 3-state model, for the State1 , (c and $\mathrm{f}$ ) and (d and $\mathrm{g}$ ) are as (b and e), but for the State-2 and State-3, respectively. Anomalies of rainfall amounts during (h) State-1, (i) State-2, and (j) State-3 from the seasonal mean climatology.

Figure 2.7 Seasonal OND rainfall ( $\mathrm{mm} /$ day) for the years with enhanced frequencies of (a) State-1 (1987, 1997, 2005 and 2010), (b) State-2 (1982, 1989, 2001, ad 2014), and (c) State-3 (1988, 1992, 1995, and 2002). (d, e, f) are same as (a, b, c) but show the anomalies from the seasonal mean climatology.

Figure 2.8 Year-to-year variations in occurrences of the three rainfall states based on the Viterbi algorithm during 1982-2014. X-axis is pentad number from 56 (03-08 Oct.) to 73 (27-31 Dec.) and Y-axis is years from 1982 to 2014.

Figure 2.9 Inter-annual variations of (a) frequency of rainfall states (numbers), and (b) seasonal mean rainfall during OND ( $\mathrm{mm} /$ day). Vertical dotted lines indicate the highest 5 years of NEIMR during 1982-2014. 
Figure 2.10 Seasonal climatology during OND for (a) surface air temperature $\left({ }^{\circ} \mathrm{C}\right),(\mathrm{b})$ mean sea level pressure $(\mathrm{hPa})$ and surface winds (vectors, $\mathrm{m} / \mathrm{s}),(\mathrm{c})$ vorticity $(10-5 \mathrm{~s}-1)$ and winds $(\mathrm{m} / \mathrm{s})$ at $850 \mathrm{hPa}$, and $(\mathrm{d})$ moisture convergence at $850 \mathrm{hPa}\left(\mathrm{gkg}^{-1} \mathrm{~s}^{-1}\right) \ldots \ldots \ldots . .25$

Figure 2.11 Surface air temperature $\left({ }^{\circ} \mathrm{C}\right)$ - Mean climatology of (a) State-1, (b) State-2, (c) State-3, and the anomaly from the NEIMR seasonal climatology of (d) State-1, (e) State2 , and (f) State-3. The green lines in (d), (e), and (f) indicate the region significant at 95\% level. 27

Figure 2.12 Mean sea level pressure $(\mathrm{hPa})$ and surface winds $(\mathrm{m} / \mathrm{s})$ - Mean climatology of (a) State-1, (b) State-2, (c) State-3, and the anomaly from the NEIMR seasonal climatology of (d) State-1, (e) State-2, and (f) State-3. The green lines in (d), (e), and (f) indicate the region significant at $95 \%$ level.

Figure 2.13 Vorticity (10-5 s ${ }^{-1}$; shaded) and winds (m/s) at $850 \mathrm{hPa}$ - Mean climatology of (a) State-1, (b) State-2, (c) State-3, and the anomaly from the NEIMR seasonal climatology of (d) State-1, (e) State-2, and (f) State-3. The green lines in (d), (e), and (f) indicate the region significant at $95 \%$ level

Figure 2.14 Moisture convergence $\left(\mathrm{gkg}^{-1} \mathrm{~s}^{-1}\right)$ at $850 \mathrm{hPa}$ level - Mean climatology of (a) State-1, (b) State-2, (c) State-3, and the anomaly from the NEIMR seasonal climatology of (d) State-1, (e) State-2, and (f) State-3. The green lines in (d), (e), and (f) indicate the region significant at $95 \%$ level.

Figure 2.15 Wind velocity (shaded; $\mathrm{m} / \mathrm{s}$ ) and direction (vector; $\mathrm{m} / \mathrm{s}$ ) at the $200 \mathrm{hPa}$ level (a) Seasonal climatology, and anomaly from the seasonal climatology of (b) State-1, (c) State-3. The green lines in (b) and (c) indicate the region significant at 95\% level........ 35

Figure 3.1 The spearman correlation coefficients between NEIMR $(\mathrm{t})$ and SSTs of the simultaneous ( $\mathrm{t}$ ) and the lagged pentads at the (b) lag-1 (t-1), (c) lag-2 (t-2), (d) lag-3 (t3), and (e) lag-4 (t-4) pentads during the months of Oct-Dec for the period 1985 to 2014. The thick black lines indicate the significant regions at the $95 \%$ confidence level.

Figure 3.2 The spearman correlation coefficients between NEIMR (t) and latent heat flux of the simultaneous ( $\mathrm{t}$ ) and the lagged pentads at the (b) lag-1 (t-1), (c) lag-2 (t-2), (d) lag-3 (t-3), and (e) lag-4 (t-4) pentads during the months of Oct-Dec for the period 1985 to 2014 . The thick black lines indicate the significant regions at the $95 \%$ confidence level.

Figure 3.3 Geographical extent of the (a) southeastern peninsular India, (b) Bay of Bengal, and (c) equatorial western Indian Ocean.

Figure 3.4 Composite differences of SSTs $\left({ }^{\circ} \mathrm{C}\right)$ at (a) the simultaneous pentad and the lagged pentads of (b) lag-1, (c) lag-2, (d) lag-3, and (e) lag-4 between the wet NEIMR conditions (pentads exceeding $90^{\mathrm{th}}$ percentile) and the seasonal climatology during the months of Oct-Dec for the period 1985-2014. The thick black lines indicate the significant regions at the $95 \%$ level.

Figure 3.5 Composite differences of latent heat flux $\left(\mathrm{Wm}^{-2}\right)$ at (a) the simultaneous pentad and the lagged pentads of (b) lag-1, (c) lag-2, (d) lag-3, and (e) lag-4 between the wet NEIMR conditions (pentads exceeding $90^{\text {th }}$ percentile) and the seasonal climatology 
during the months of Oct-Dec for the period 1985-2014. The thick black lines indicate the significant regions at the $95 \%$ level.

Figure 3.6 Vertical cross sections of composite differences of specific humidity $\left(10^{4}\right.$ $\mathrm{kg} / \mathrm{kg}$ ) at the simultaneous and lagged pentads between the wet NEIMR conditions and the seasonal climatology during the months of Oct-Dec for the period 1985 to 2014 over the (a) Bay of Bengal $\left(80^{\circ}\right.$ to $95^{\circ} \mathrm{E}, 8^{\circ}$ to $\left.19^{\circ} \mathrm{N}\right)$ and (b) equatorial western Indian Ocean $\left(56^{\circ}\right.$ to $76^{\circ} \mathrm{E}, 3^{\circ} \mathrm{S}$ to $\left.5^{\circ} \mathrm{N}\right)$ regions. The thick lines in (b) indicate the significant regions at the $95 \%$ level. The entire region in (a) is significant at the $95 \%$ level.

Figure 3.7 Composite differences of specific humidity $\left(10^{4} \mathrm{~kg} / \mathrm{kg}\right)$ averaged over 1000 , 925 , and $850 \mathrm{hPa}$. at (a) the simultaneous pentad and the lagged pentads of (b) lag-1, (c) lag-2, (d) lag-3, and (e) lag-4 between the wet NEIMR conditions (pentads exceeding $90^{\text {th }}$ percentile) and the seasonal climatology during the months of Oct-Dec for the period 1985-2014. The thick black lines indicate the significant regions at the $95 \%$ level........52

Figure 3.8 Composite differences of wind magnitude (m/s; shaded) and direction $(\mathrm{m} / \mathrm{s}$; vectors) averaged over 1000,925 , and $850 \mathrm{hPa}$, at (a) the simultaneous pentad and the lagged pentads of (b) lag-1, (c) lag-2, (d) lag-3, and (e) lag-4 between the wet NEIMR conditions (pentads exceeding $90^{\text {th }}$ percentile) and the seasonal climatology during the months of Oct-Dec for the period 1985-2014. The thick black lines indicate the significant regions at the $95 \%$ level.

Figure 3.9 Composite differences of moisture convergence $\left(10^{-4} \mathrm{~kg} \mathrm{~m}^{-1} \mathrm{~s}^{-1}\right.$; shaded) and moisture transport vectors $\left(\mathrm{kg} \mathrm{m}^{-1} \mathrm{~s}^{-1}\right)$ for the same pentad at (a) 1000 , (c) 850 and (e) 700 $\mathrm{hPa}$, and for the lag-1 pentad at (b) 1000, (d) 850 and (f) $700 \mathrm{hPa}$, between the wet NEIMR conditions and the seasonal climatology during the months of Oct-Dec for the period 1985-2014. The thick black lines indicate the significant regions at the $95 \%$ level for moisture convergence.

Figure 3.10 Composite differences of Vertical Integrated Moisture flux (VIMF) convergence $\left(10^{-3} \mathrm{~kg} \mathrm{~m}^{-2} \mathrm{~s}^{-1}\right.$; shaded) and moisture transport vectors $\left(\mathrm{kg} \mathrm{m}^{-1} \mathrm{~s}^{-1}\right)$, integrated from 1000 to $850 \mathrm{hPa}$, during (a) same, (b) lag-1, and (c) lag-2 pentads, between the wet NEIMR conditions and the seasonal climatology during the months of Oct-Dec for the period 1985-2014. (d), (e), and (f) are same as in (a), (b), and (c), but for vorticity $\left(10^{-5} \mathrm{~s}^{-1}\right)$ and wind vectors $(\mathrm{m} / \mathrm{s})$ averaged over the three pressure levels of 1000 , 925 , and $850 \mathrm{hPa}$. The thick black lines indicate the significant regions at the $95 \%$ level for (a, b, and c) VIMF and (d, e, and f) vorticity.

Figure 3.11 Schematic diagrams, (a) illustration and (b) flowchart, of the ocean and atmosphere processes over the equatorial western Indian Ocean and the Bay of Bengal, driving wet NEIMR conditions over the southeastern India.

Figure 4.1 Geography and chronology of kingdoms in South India. (a) Map showing topography, rivers and capital cities of the South Indian kingdoms (compiled after Schwartzberg 1992), and (b) Status of South Indian kingdoms at 50-year intervals during the period 250-1500 CE (after Schwartzberg 1992). The blue rectangular box represents the golden age of the Chola Kingdom, between 850 and $1280 \mathrm{CE}$ 
Figure 4.2 Temples and tanks in Cuddalore district, Tamil Nadu. (a) Nataraja temple and its tank in Chidambaram, and (b) Veeranam Lake in Sethiyathope (Photo by Shanmugasundaram Jothiganesh, 2015).

Figure 4.3 Modern rainfall distribution in peninsular India. (a) Seasonal mean of SouthWest Indian Monsoon Rainfall (1901 to 2010) and of $850 \mathrm{hPa}$ wind vectors (1948 to 2010) from June to September, and (b) Seasonal mean of North-East Indian Monsoon Rainfall (1901 to 2010) and of $850 \mathrm{hPa}$ wind vectors (1948 to 2010) from October to December. Rainfall data (in units of $\mathrm{mm} /$ season) were obtained from the Climate Research Unit (Harris et al. 2013) and wind vectors (in unit of $\mathrm{m} / \mathrm{s}$ ) were calculated using $\mathrm{u}$ - and v-winds from the National Center for Environmental Prediction (NCEP) reanalysis data (Kalnay et al. 1996). .68

Figure 4.4 Temporal variability of modern SWIMR and NEIMR over the capital cities of the Chola and other kingdoms of South India. Rainfall quantity (1901-2010 CE) is in $\mathrm{mm} / \mathrm{month}$. The t-test for a two-sample difference of the means in SWIMR and NEIMR time series rejects the null hypothesis (mean differences of SWIMR and NEIMR are equal to zero), and the p-values are significant at $99 \%$ for all six of the cities......

Figure 4.5 Scatterplots of (a) SOI vs. NEIMR index, and (b) SOI vs. SWIMR index (1901-2010). Positive values indicate a wetter, and negative values a drier, phase of NEIMR and SWIMR. Vertical dashed lines at -7 to 7 position the lower and upper limits of a normal period; values less than -7 indicate an El Niño period; values greater than 7 correspond to a La Niña period. Red lines running diagonally in the plots represent the trend line of the data points.

Figure 4.6 Rainfall deviation ( $\mathrm{mm} /$ month) during El Niño years from the climatological normal (a) SWIMR season, and (b) NEIMR season. Significant regions at the $95 \%$ level were contoured.

Figure 4.7 Time series of monsoon variability (500 to $1900 \mathrm{CE}$ ) based on three different geologic proxies. (a) SOI, after Yan et al. (2011), (b) Oxygen isotope values $(\delta 180)$, a proxy for the South-West Indian Monsoon Index, as elaborated by Sinha et al. (2007) from speleothem geochemistry at Dandak caves, and (c) South Asian Monsoon Index after Shi et al. (2014). Vertical lines are lower and upper time brackets of the golden age of the Chola Kingdom (850-1280 CE) and horizontal dashed lines are means of each time series.

Figure 4.8 Spatial distributions of temple and tank construction works in South India. Maps show the number of temples constructed in each modern district between 850 and 1280 CE. C1 to C9: successive Chola periods as given in Table 4.1 


\section{List of Abbreviations}

$\begin{array}{ll}\text { BCE } & \text { Before Common Era } \\ \text { BIC } & \text { Bayesian Information Criterion } \\ \text { BOB } & \text { Bay of Bengal } \\ \text { CE } & \text { Common Era } \\ \text { CRU } & \text { Climate Research Unit } \\ \text { ENSO } & \text { El Niño Southern Oscillation } \\ \text { EWIO } & \text { Equatorial Western Indian Ocean } \\ \text { HMM } & \text { Hidden Markov Model } \\ \text { IMD } & \text { India Meteorological Department } \\ \text { IPCC } & \text { Intergovernmental Panel on Climate Change } \\ \text { ITCZ } & \text { Inter-Tropical Convergence Zone } \\ \text { LHF } & \text { Latent Heat Flux } \\ \text { MSLP } & \text { Mean Sea Level Pressure } \\ \text { NCEP } & \text { National Center for Environmental Prediction } \\ \text { NEIMR } & \text { North East Indian Monsoon Rainfall } \\ \text { NOAA } & \text { National Oceanic and Atmosphere Administration } \\ \text { OND } & \text { October, November, and December } \\ \text { PlaSim } & \text { Planet Simulator } \\ \text { SAMI } & \text { South-Asian Monsoon Index } \\ \text { SOI } & \text { Southern Oscillation Index } \\ \text { SST } & \text { Sea Surface Temperature } \\ \text { SWIMI } & \text { South-West Indian Monsoon Index } \\ \text { SWIMR } & \text { South West Indian Monsoon Rainfall } \\ \text { WHOI } & \text { Vertically Integrated Moisture Flux } \\ \text { Woods Hole Oceanographic Institution }\end{array}$




\section{Introduction}

More than half the world's population resides in the Asian monsoon climate region (Chen 2006). Agrarian-based societies have developed in these monsoon regions because of abundant solar radiation and rainfall, which are two essential ingredients for successful agriculture (Webster et al. 1998). The monsoon over South Asia is driven by two distinct seasonal wind patterns: south-westerlies during the summer season (May to September) and north-easterlies during the winter season (October to February). The monsoonal wind transports moisture from the ocean to land areas that brings rainfall during the summer monsoon season (Krishnamurthy and Kinter 2003). The ocean and atmosphere interaction causes variability in monsoon systems over space and time. The monsoon rainfall variability that can result in extreme wet or dry regional conditions can adversely impact agricultural yields, water resources, and infrastructure (Singh et al. 2014). As the monsoon rainfall variability is of major socio-economic importance, understanding the causes of monsoon rainfall variability and its predictability has received attention among the climate research community.

India has two distinct monsoon rainfall seasons, the South-West Indian Monsoon Rainfall (SWIMR) season during the months of June to September and the North-East Indian Monsoon Rainfall (NEIMR) season during the months of October to December. Except for the southeastern peninsular of India, the majority of the Indian land mass receives its annual rainfall during the SWIMR season (Krishnamurthy and Kinter 2003). The major rainfall receiving regions ( $>500 \mathrm{~mm} / \mathrm{season}$ ) during the NEIMR season are confined to the eastern side of the Western Ghats and Eastern Ghats (Figures 1a and 1b). The entire Tamil Nadu and parts of Andhra Pradesh receive the majority of its annual rainfall ( $>60 \%$ along the coastal belt and $>30-40 \%$ over the land mass far from the coast) during the NEIMR season (Figures 1c, 1d, and 1e). All over India, the regions benefiting from NEIMR are lesser when compared to SWIMR. Thus, the NEIMR has received equally less attention compared to SWIMR. 
(a)

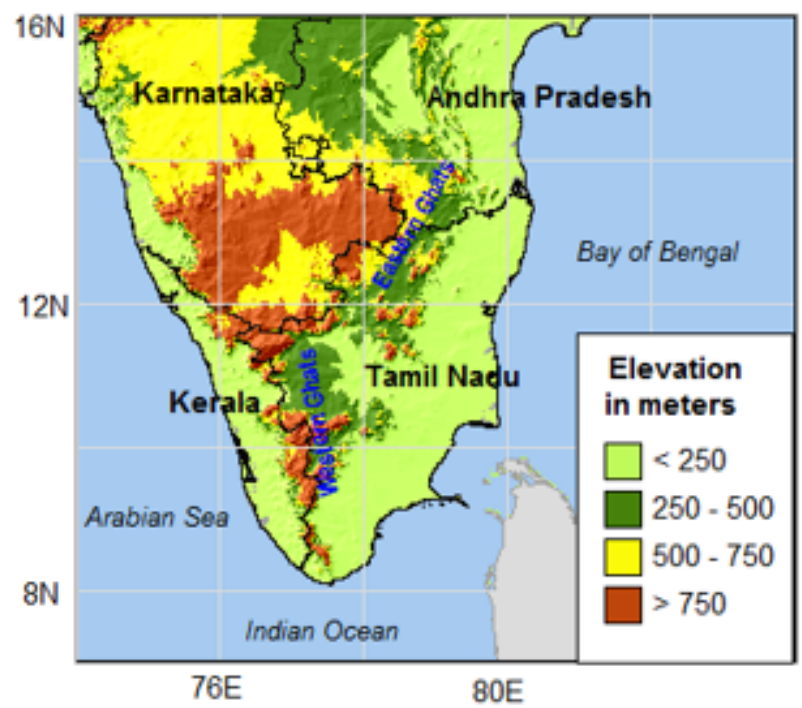

(c)

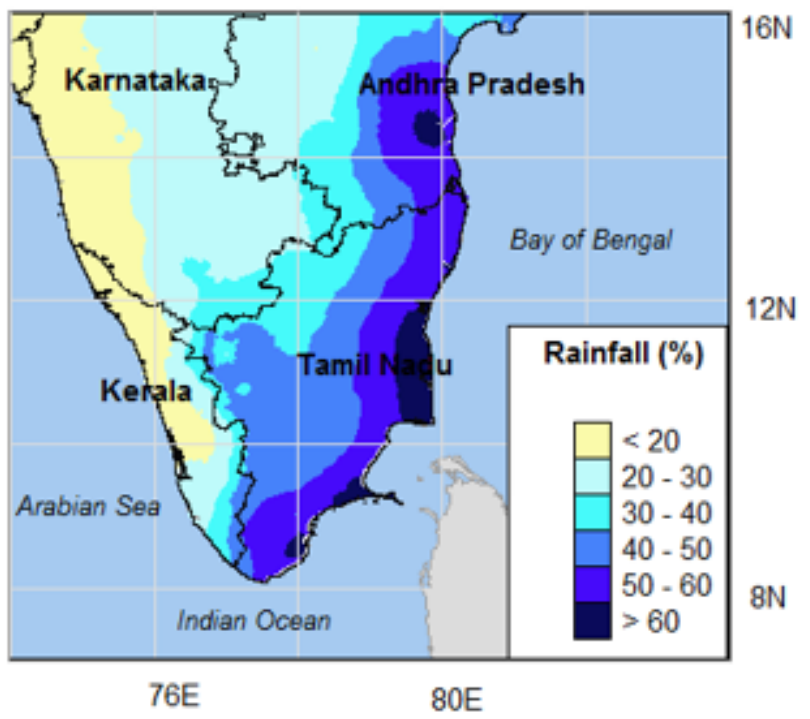

(b)
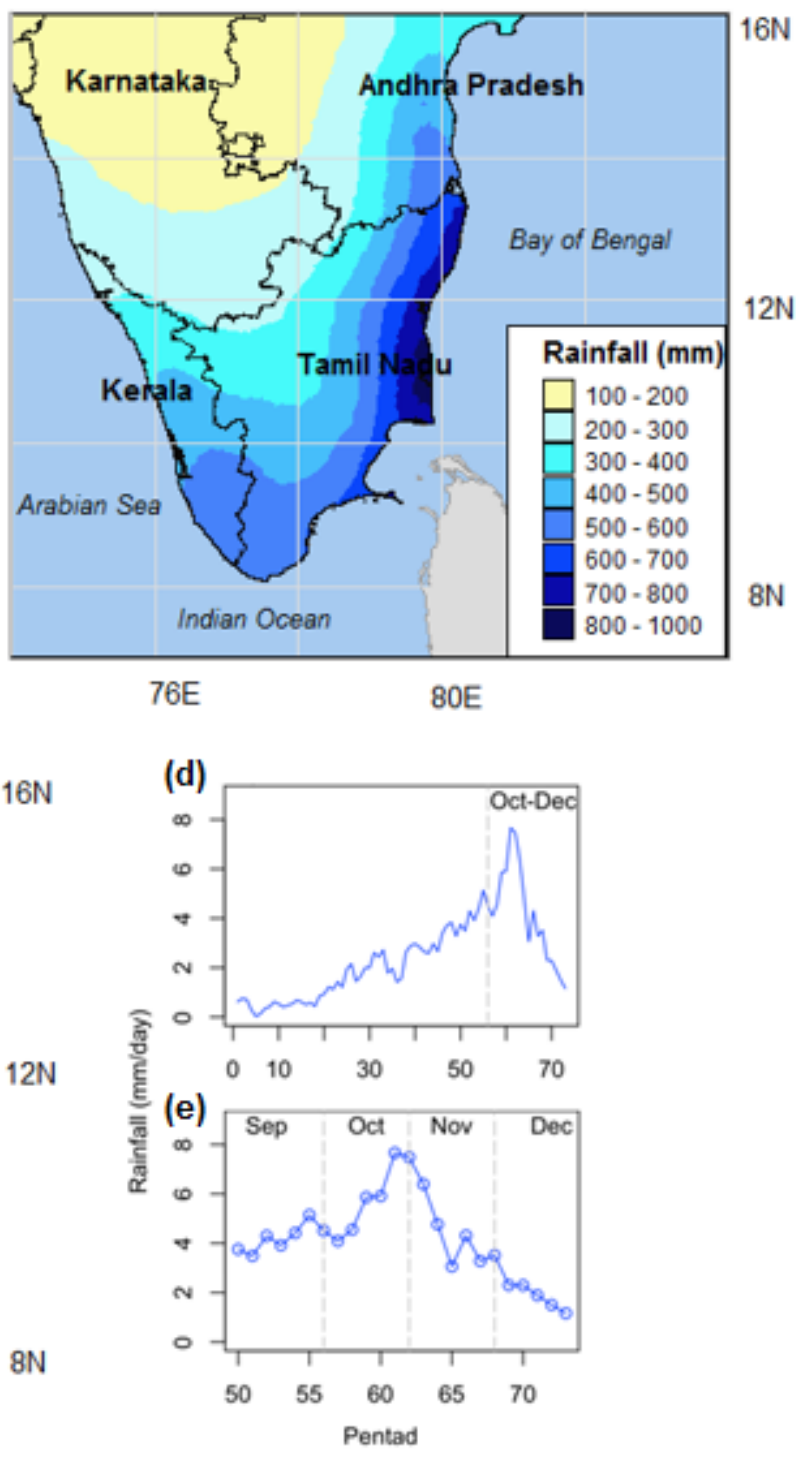

Figure 1.1 Map showing (a) geography and topography of the southern peninsular of India, (b) seasonal accumulated rainfall during October to December months $(\mathrm{mm}),(\mathrm{c})$ percentage of annual rainfall received during October to December months, (d) rainfall variation by pentad (five days period) from Jan to Dec, over the study domain (77.580.25E and 8-16N), and (e) same as (d), but for Sep to Dec

The water requirements for the agriculture sector in Tamil Nadu and parts of Andhra Pradesh are heavily dependent on NEIMR. Around 31 million rural people depend on the agriculture sector for their livelihoods in Tamil Nadu (DES 2013). The NEIMR deviation from normal conditions increases the vulnerability of the agricultural sector and thereby experiences socioeconomic impacts over the NEIMR dominated regions (Rajeevan et al. 
2012). From 2000-2012, Tamil Nadu experienced three severe drought years (2001, 2002, and 2012) and two excessive rainfall years (2008 and 2011) and each had a socioeconomic impact on Tamil Nadu. The drought in 2001-2002 caused a loss of \$1.2 billion in agricultural production and the 2012 drought accounted for a loss of approximately 2.2 billion US\$ in agriculture production (DAC 2013, UNDP 2013). The monsoon failure impacts the agricultural sector and increases socioeconomic issues through the cascading impacts observed on agro-processing industries, employment opportunities, poverty rates, urban migration, price inflation, state relief budget, and the state economy. The above normal NEIMR in the year 2011 caused an economic loss of 250-333 million US\$ in the coastal districts of Tamil Nadu (DAC 2013). The impacts during the years of excessive monsoon are more complex depending on the specific episode, causing more physical damages on building and road infrastructures due to flooding and strong winds from the intensified monsoon activity. The immense socioeconomic importance of NEIMR highlights the need to understand NEIMR variability and its influential climate drivers.

The NEIMR over the southern peninsular of India is highly variable across space and through time (Rajeevan et al. 2012). The NEIMR is associated with the formation of a trough of low, cyclonic circulation, easterly waves, depressions and cyclonic storms over the Bay of Bengal (Balachandran et al. 2006). The heat and moisture fluxes over the adjoining ocean waters (Bay of Bengal and Indian Ocean), and also those over the land areas of peninsular India, show a strong association with seasonal NEIMR variability (Prasanna and Yasunari 2008, George et al. 2011). The ocean and atmospheric conditions responsible for altering these moisture sources could be major factors contributing to NEIMR variability. Hence, studying the ocean and atmospheric interactions is important to understand the drivers behind the NEIMR variability. The NEIMR research in the past was heavily focused on inter-annual variability, and the seasonal or monthly rainfall time series of NEIMR missed some key intra-seasonal variations or behavior of extreme rainfall events. From the end-users' perspective, seasonal NEIMR quantity is of less value compared to intra-seasonal variation, because agriculture and hydrological operations require rainfall information at an intra-seasonal time-scale for informed decision-making (Gunnell et al. 2007). Moreover, farmers and decision makers in the 
agricultural sector and planning agencies require accurate intra-seasonal rainfall forecast information for decision making in order to minimize and manage climate-associated risks in the agricultural sector. Although understanding intra-seasonal rainfall variability over peninsular India has a scientific and societal relevance, there are only limited studies available on the intra-seasonal variability of NEIMR (Charlotte et al. 2012, Rajeevan et al. 2012).

Future climate change is likely to challenge society's ability to adequately manage water resources, particularly in the developing world. The response of past societies to climatic variability, particularly in terms of water management (Gunnell et al 2007), can provide useful insights into the timing and scale of response to future events. Dearing et al. 2015 have highlighted the importance of understanding the socio-ecological system dynamics of the past for the sustainable management of landscapes in the future. The rural population of South India was heavily dependent on monsoon rainfall for meeting the water requirements of its agriculture (Krishna Kumar et al. 2014, DoE 2006, Parthasarathy et al. 1988). A perspective on societal resilience in the Anthropocene to extreme climatic events in the past in the South India would be valuable for the people to adapt to varying monsoon climates. Therefore, investigating the societal responses of a complex hierarchical society to past climate change over the South Indian region would provide insights for preparing for future climate change.

The overarching goal of this dissertation is to examine the intra-seasonal variability of NEIMR, the NEIMR variability driven by ocean-atmospheric conditions, and understanding past societal responses to address some of the key scientific knowledge gaps in NEIMR and also to provide recommendations on responding to monsoon variability. The specific research questions to address this objective are as follows:

1. How to characterize the spatio-temporal variation of pentad-mean NEIMR over the southeastern peninsular of India into fewer discrete rainfall states? What are the atmospheric circulation and surface temperature conditions linked to the identified rainfall states? (Chapter 2)

2. What are the oceanic and atmospheric conditions that are associated with pentad NEIMR variation over the southeastern peninsular of India? How is the 
atmospheric moisture, linked to the wet NEIMR conditions, transported from the surrounding oceans to the southeastern peninsular India? (Chapter 3)

3. What are the lessons learnt from the ancient and pre-modern societal responses to NEIMR variability in the past in adapting to monsoon variability under climate change? (Chapter 4) 


\section{Rainfall variability over the southeastern peninsular of India}

\subsection{Background}

NEIMR occurs during the months of October to December and contributes up to $70 \%$ of the annual rainfall over the southeastern peninsular of India (Krishnamurthy and Kinter 2003). The southeastern peninsular receives rainfall from the South-West Indian monsoon rainfall (SWIMR) season during the months of June to September, but this is less significant $(<30 \%$ ) when compared to NEIMR (Prasanna and Yasunari 2008, Rajeevan et al. 2012). During the NEIMR season, the east coast of the southern peninsular of India received maximum rainfall ( $>50 \%$ of annual rainfall), compared to the interior parts of the peninsular $(30-40 \%$ of annual rainfall) (Srinivasan and Ramamurthy 1974, Raj 2012, Rajeevan et al. 2012; also see Figure 2.1(b)). NEIMR is critical for water requirements in the region, as the excess (flood) and deficient (drought) NEIMR conditions increase the vulnerability of the agricultural sector and thereby gives rise to several socioeconomic impacts (Kripalani and Kumar 2004, George et al. 2011). For instance, the 2001-2002 drought caused an estimated loss of 1.2 billion US\$ in agriculture production and the 2012 drought accounted for a loss of approximately 2.2 billion US\$ in agriculture production (DAC 2003, UNDP 2013). On the other hand, the 2011 excessive NEIMR condition caused an economic loss of 250-333 million US\$ in the coastal districts of Tamil Nadu (DAC 2003). Investigation into the spatio-temporal variation of NEIMR can provide crucial information for climate forecasting and risk management in the southeastern peninsular of India, whereas NEIMR has been seldom studied (Rajeevan et al. 2012). 
(a)

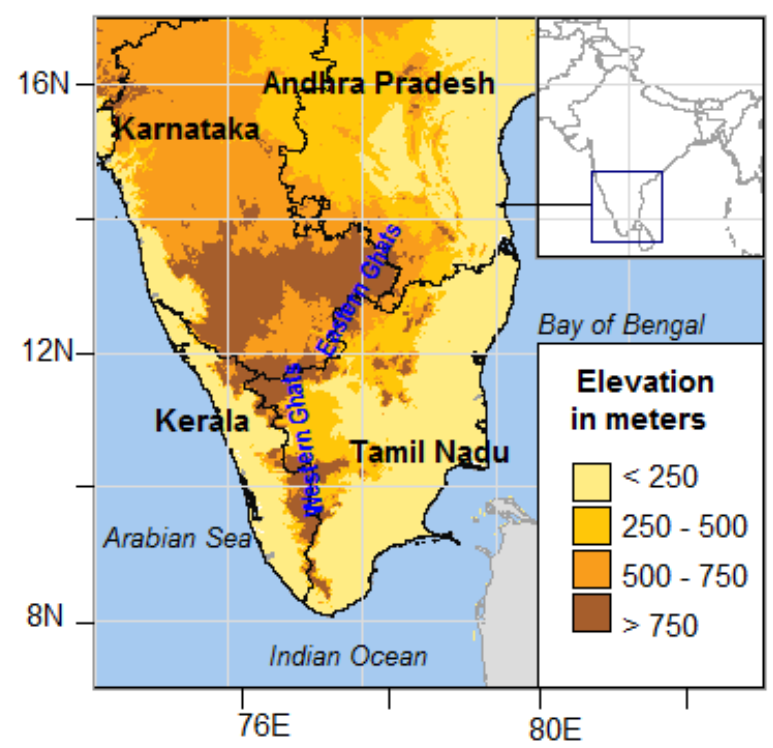

(b)

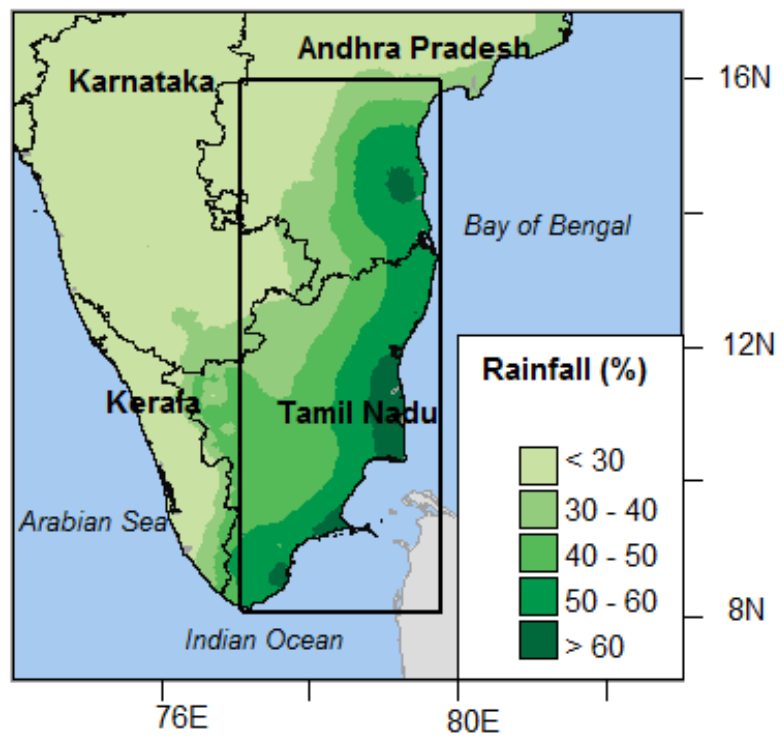

Figure 2.1 Map showing (a) geography and topography of peninsular India and (b) percentage of annual rainfall received during October to December months. The study region is outlined in the rectangle in (b).

The amount, intensity, and duration of NEIMR is highly variable both at the interannual and intra-seasonal time scales (Raj 2012, Rajeevan et al. 2012). Recent studies have revealed that the inter-annual variability of seasonal NEIMR exhibited random fluctuation and abnormal rainfall quantities (Kripalani and Kumar 2004, George et al. 2011, Sreekala et al. 2011, Yadav 2012). For instance, seasonal NEIMR was abovenormal $(>19 \%$ departure from the seasonal average as defined by the India Meteorological Department (IMD)) for 22 years and below-normal $(<19 \%$ departure from the seasonal average) for 25 years during 1901-2004. During the below- and abovenormal years, the seasonal rainfall departures can range from $-60 \%$ to $+60 \%$ (Balachandran et al. 2006). The previous studies of NEIMR indicated that the studies were heavily focused on the inter-annual variability of seasonal NEIMR rather than on the intra-seasonal NEIMR (Kumar et al. 2007, Rajeevan et al. 2012). As Charlotte et al. (2012) highlighted, it was not simple to correlate the identified prominent variations in seasonal NEIMR to intra-seasonal NEIMR. Therefore, extensive research is required to understand the intra-seasonal nature of NEIMR (Charlotte et al. 2012, Rajeevan et al. 2012). 
The characterization of spatial and temporal patterns in the rainfall variability can be heavily influenced by the spatial domain and the time step considered in the study. In the past, the variability of NEIMR has been studied based on the rainfall time series averaged over the entire southern peninsular of India (Sreekala et al. 2011, Kumar et al. 2007). The climate and its drivers of the western (Kerala and Karnataka) and eastern (Tamil Nadu and parts of Andhra Pradesh) sides of the southern peninsular are different due to the different orographic effects on precipitation between the Western Ghats and the Eastern Ghats (e.g., Gunnell 1997) and the different atmospheric circulation patterns associated with the surrounding oceans and their interactions with the atmosphere (e.g., Srinivasan and Ramamurthy 1974). In the past, the intra-seasonal variability of NEIMR was investigated using daily time-step data and the findings indicated that the rainfall variations at the daily time-step were chaotic (Charlotte et al. 2012). The pentad (five days period) rainfall averages could suppress the large daily variations (Figure 2.2) and might capture some key intra-seasonal rainfall characteristics that are associated with distinct synoptic patterns (Barradas and Nigam 2013). The pentad could be the approximate lifetime of a synoptic scale rain-bearing weather system, including cyclone and easterly waves, although fewer attempts were made to investigate the NEIMR variability at the pentad time scale. Examining the variability of NEIMR with pentad rainfall time series over the southeastern peninsular of India would help to address some of the issues concerning the spatial domain and the time-step considered in the previous studies. Further, this examination would benefit the requirements of the end users in agriculture and hydrological operations. 
(a)

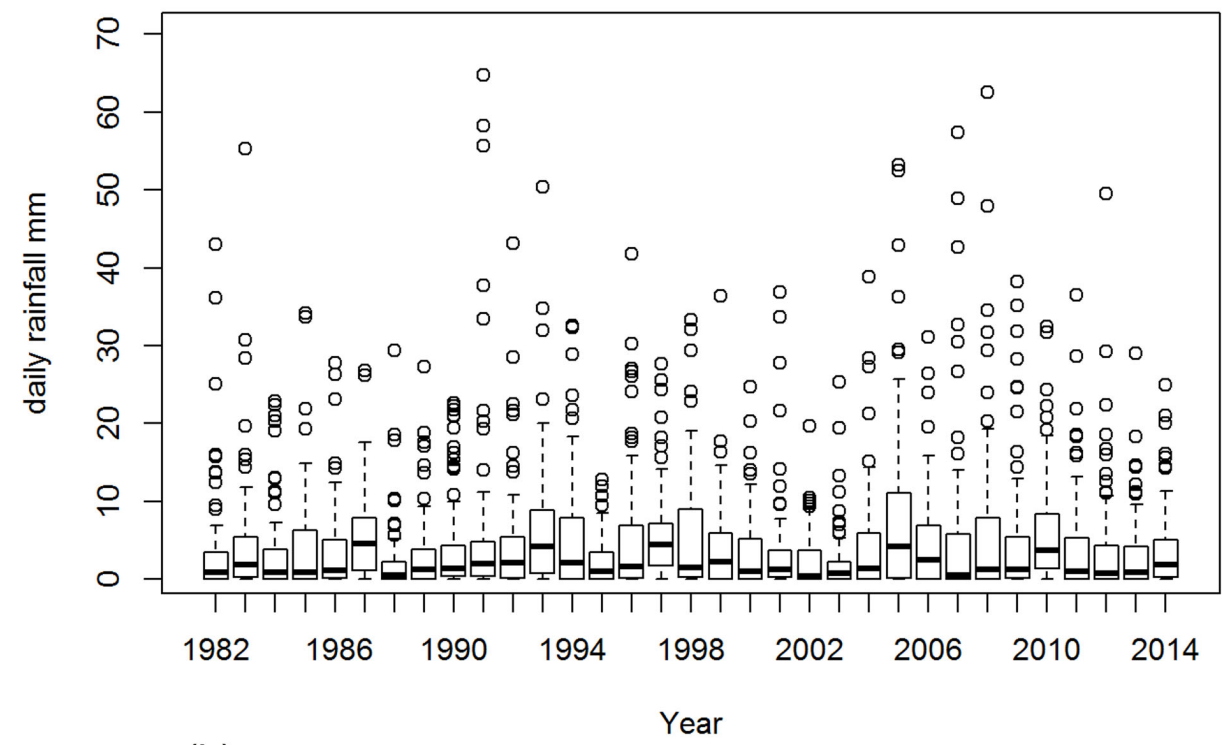

(b)

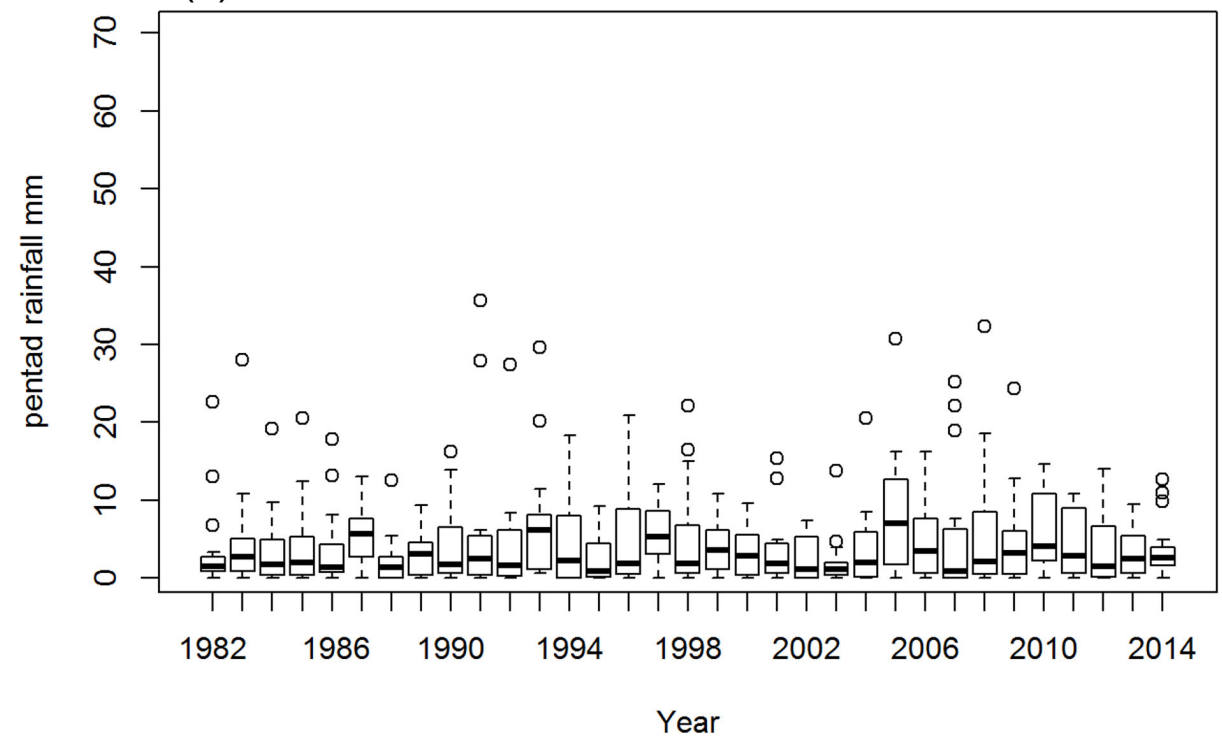

Figure 2.2 Rainfall variability over the NEIMR domain of $77.5-80.25^{\circ} \mathrm{E}$ and $8-16^{\circ} \mathrm{N}$ during the months of October to December for the years of 1982-2014. (a) daily rainfall variability, and (b) pentad rainfall variability

The atmospheric circulation and surface temperature conditions controlling the rainfall variability have been considered for both understanding and predicting rainfall variation. Past studies have identified that the year-to-year variability of seasonal NEIMR were modulated by the Bay of Bengal sea surface temperature, the Indian Ocean Dipole, El Niño and the Southern Oscillation, and the Equatorial Indian Ocean Oscillation (Singh 1995, Kripalani and Kumar 2004, George et al. 2011, Sreekala et al. 2011, Yadav 2012). All these above mentioned factors primarily caused warmer SST over the surrounding 
oceans of the southeastern peninsular of India and created more favorable conditions for cyclones to form and propagate in southeastern India (Kripalani and Kumar 2004, Yadav 2012). Yadav (2013) documented the importance of sea surface temperatures in the Indian Ocean in causing the inter-annual NEIMR variability through modulating the cyclonic activities. The atmospheric circulation and surface temperature conditions linked to the rainfall variability at intra-seasonal time scales are critical for predicting NEIMR, whereas this aspect has been seldom studied (Charlotte et al. 2012, Rajeevan et al. 2012). To address the above-mentioned research gaps and needs, this study investigated: (1) rainfall states that characterize the spatio-temporal variation of pentad-mean NEIMR over the southeastern peninsular of India and (2) the atmospheric circulation and surface temperature conditions linked to the identified rainfall states.

\subsection{Data and Methods}

\subsubsection{Study area}

The unique topography (Western Ghats and Eastern Ghats shown in Figure 2.1(a)) of the southeastern peninsular of India sets the boundary for the two monsoon seasons in the region, comprising the SWIMR season during June to September and the NEIMR season during October to December. The southwesterly seasonal winds from the Arabian Sea during the SWIMR season (Rao 1976) provides maximum benefits to the western side of the Western Ghats (the entire Kerala and parts of Karnataka). The rain shadow regions located on the leeward side of the Western Ghats (Tamil Nadu and parts of Andhra Pradesh) receives less benefit from the southwest monsoonal winds. The southeastern peninsular of India covering the entire Tamil Nadu and parts of Andhra Pradesh receives the majority of its annual rainfall during the NEIMR season (Figure 2.1(b)) (Raj 2012). Although the state of Kerala and parts of Karnataka receive rainfall during the NEIMR season, the climate drivers of the western and eastern sides of the peninsular are entirely different due to the effects of topography and neighboring oceans, as mentioned in introduction. In this study, the geographical extent of the southeastern

peninsular of India was selected $\left(77.5-80.25^{\circ} \mathrm{E}\right.$ and $8-16^{\circ} \mathrm{N}$, shown as a rectangle in 
Figure 2.1(b)) as the study region to investigate the NEIMR variations at the pentad timestep.

\subsubsection{Data}

The IMD gridded rainfall data at $0.25^{\circ}$ by $0.25^{\circ}$ spatial resolution over the southeastern India at a daily time scale for the period 1982-2014 was used in this study (Rajeevan et al. 2006). Pentad gridded rainfall data were constructed by taking the average of every five days from day 1 to 365 in a year. The pentad gridded rainfall data has 73 pentads/year and 2,409 pentads for the period 1982-2014. For the leap year, $29^{\text {th }}$ February rainfall value was counted as the $13^{\text {th }}$ pentad of that particular year $\left(13^{\text {th }}\right.$ pentad average was done for 6 days during leap years instead of 5 days). To examine the associations with atmospheric circulation and surface temperature, the land, ocean and atmospheric variables from the National Center for Environment Prediction (NCEP) Reanalysis-2 data of $2.5^{\circ} \times 2.5^{\circ}$ resolution were used at a daily time scale for the period 1982-2014 (Kanamitsu et al. 2002). The surface air temperature, mean sea level pressure, specific humidity at $850 \mathrm{hPa}$, and zonal ( $u$-wind) and meridional ( $v$-wind) winds at the surface, 850 and $200 \mathrm{hPa}$ levels were considered in this study. The vorticity was calculated using $u$ - and $v$-winds at $850 \mathrm{hPa}$ (Sikka and Gadgil 1978). The moisture convergence was calculated by multiplying the specific humidity and by the convergence (from $u$ - and $v$-winds) variables at $850 \mathrm{hPa}$ (Banacos and Schultz 2005). The gridded reanalysis data at a daily time-step was converted to a pentad time step for the period 1982-2014. Although the constructed gridded data has 73 pentads in a year, 18 pentads/year from 03 October to 31 December (three months of the NEIMR season) were examined for the rainfall and reanalysis data.

\subsubsection{Methods}

In order to understand the climatology (onset, peak, and withdrawal) of intraseasonal NEIMR, the rainfall variability was plotted for 1-73 pentads (averaged for the years 1982-2014). The Hovmöller diagram was used (Lau and Peng, 1987) to plot the 
longitudinal and latitudinal cross-sections of rainfall and winds to show the spatiotemporal variation of the key monsoon variables during the NEIMR season.

To investigate the spatio-temporal variations of rainfall over the southeastern peninsular India at pentad time step, the Hidden Markov Model (HMM) was used. The HMM has advantages over other spatio-temporal techniques on three aspects: 1) characterizing the rainfall variability into fewer discrete rainfall states at a finer temporal scale, 2) capturing the dominant spatio-temporal variability of rainfall over a smaller geographical extent such as the southeastern peninsular of India, and 3) obtaining the rainfall states potentially linked to the distinct patterns of the large-scale atmospheric and surface variables (Guttorp and Minin 1995, Wallace 2000, Dommenget and Latif 2002, Bracken et al. 2014). The average meteorological structure appeared to be reasonable within the HMM-derived weather state (Guttorp and Minin 1995). The HMM fits a model to observed rainfall records by introducing a small number of discrete rainfall states (not to be confused with political States of India). These rainfall states were basically a diagnostic interpretation of observed rainfall variability in terms of a few rainfall patterns. The rainfall quantity is only observable, and the rainfall states are 'hidden' from the observer, i.e., they are not directly observable (Robertson et al. 2006). The HMM uses Markov chain assumption, in which the probability of the occurrence of next state depends only on the current state and not on the rainfall state that preceded it in the state space (Zucchini and Guttorp 1991). In sum, the HMM accounts for spatial dependence in the data and captures the spatio-temporal pattern of rainfall intensity and its probability of occurrence over a network of stations or grid points (Robertson et al. 2006, Greene et al. 2008, Bracken et al. 2014, Pal et al. 2015).

The HMM Tool, developed by the International Research Institute (IRI), was employed in this study to identify rainfall states that could capture the spatio-temporal variability within the NEIMR season over the study region (IRI 2007). The pentad rainfall data consists of the inter-annual, annual, intra-seasonal and synoptic variations (e.g., Wang and Rui 1990, Wang and Xu 1997). The rainfall variability on a different time-scale could be ascribed to distinct physical mechanisms. In this study, the pentad time series of rainfall was studied for the months of October-December (India Meteorological Department's definition of NEIMR period for operational applications) 
for the period 1982-2014 over the southeastern peninsular of India (297 grid locations as shown in Figure 2.6(a)). The number of rainfall states to be modeled in the HMM is specified by the user. The number of rainfall states cannot exceed the maximum number of time-steps in a year. Therefore, the HMM was run for the one- to eighteen-state model, as there were eighteen pentads in a year during October-December. The statistical and synoptic analysis techniques were used to identify the meaningful rainfall states. The Bayesian Information Criterion (BIC) score and probability value of state transition were the statistical techniques utilized in this study (Schwarz 1978, Robertson et al. 2006). The Viterbi algorithm (Forney 1978), a dynamic programming scheme, was used to express the time evolution of the identified rainfall states within the season over the study period. The year-to-year (inter-annual) variability of the rainfall states within the NEIMR season was investigated using the time series of the frequency of identified rainfall states. Further, correlation analysis (von Storch 2001) was used to measure the strength of the associations between the frequency of rainfall states and seasonal total NEIMR.

In order to examine the atmospheric circulation and surface temperature conditions during the identified rainfall states, the composite analysis of surface air temperature, mean sea level pressure, winds, vorticity, and moisture convergence at the different atmospheric levels of surface and 850 and $200 \mathrm{hPa}$ for the pentad synoptic variables in each rainfall state were used. Composite differences of the atmospheric variables were calculated by subtracting the mean values of the pentads that fell into each rainfall state from the mean value of all the pentads. Student's $t$-test was used to quantify the statistical significance (95\%) of differences between the two composite means.

\subsection{Results}

\subsubsection{Climatology of intra-seasonal NEIMR}

The pentad variability of rainfall over the southeastern peninsular of India during the months of January to December (averaged for the period 1982-2014) indicated that daily rainfall amounts of more than $5 \mathrm{~mm}$ /day were received during October and November (Figure 2.3(a)). The pentad variability of rainfall for the months of September 
to December is shown in Figure 2.3(b). The onset of NEIMR occurred during the $59^{\text {th }}$ pentad (18-22 October), consistent with the mean NEIMR onset defined by the IMD (Raj 2012). Peak rainfall amounts (approximately $8 \mathrm{~mm} /$ day) during the NEIMR season were observed during the $61^{\text {st }}$ and $62^{\text {nd }}$ pentads ( 28 October to 6 November). The effective rainfall period ( $>5.9 \mathrm{~mm} /$ day - above $95^{\text {th }}$ percentile of pentad time series) lasted from 18 October to 11 November, after that, the rainfall quantity dropped gradually until the monsoon rainfall ceased at the end of December. The longitudinal (Figure 2.3(c)) and latitudinal (Figure 2.3(d)) cross-section plots of rainfall indicate the spatial heterogeneities of rainfall at pentad time-scale during the months of January to December, over the geographical extents of $77.5-80.25^{\circ} \mathrm{E}$ and $8-16^{\circ} \mathrm{N}$, respectively. Figure 2.3(e) also showed a distinct rainfall gradient in the east-west direction. NEIMR was confined to the longitudes of 78.5 to $80.25^{\circ} \mathrm{E}$, with intensified rainfall conditions (> $12 \mathrm{~mm} /$ day) along the coast (79.5-80.25 ${ }^{\circ} \mathrm{E}$, see Figure 2.3(e)). NEIMR was received over all the latitudes $\left(8-16^{\circ} \mathrm{N}\right)$ from mid-October to end of November $\left(57^{\text {th }}\right.$ to $66^{\text {th }}$ pentad), and rainfall was confined to the southern latitudes $\left(8-12^{\circ} \mathrm{N}\right)$ during December (from $66^{\text {th }}$ to $70^{\text {th }}$ pentad, see Figure 2.3(f)). The longitudinal (Figure 2.3(g)) and latitudinal (Figure 2.3(h)) cross-sections of $850 \mathrm{hPa}$ winds during the months of January to December indicated that northwesterlies changed to northeasterlies from the $57^{\text {th }}$ pentad $(8-12$ October) onwards. The advance of the northeast Indian monsoon from north to south was indicated by the northeasterly onset marked over $15^{\circ} \mathrm{N}$ during the $57^{\text {th }}$ pentad $(8-12$ October), $12.5^{\circ} \mathrm{N}$ during the $58^{\text {th }}$ pentad (13-17 October), and $10^{\circ} \mathrm{N}$ during the $59^{\text {th }}$ pentad (18-22 October) (Figure 2.3(h)). Although the northeasterlies prevail during January and February, these winds only bring the dry, cold winter air from the northeast that does not produce any significant rainfall. 
(a)

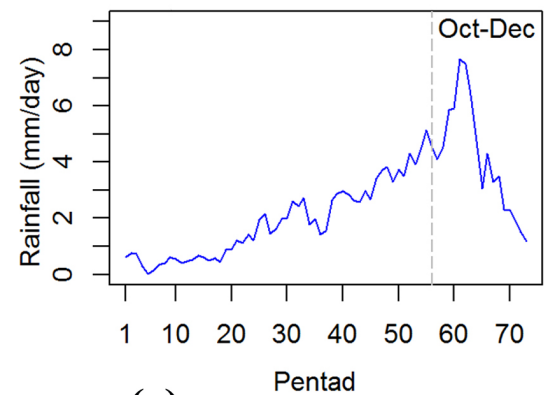

(c)

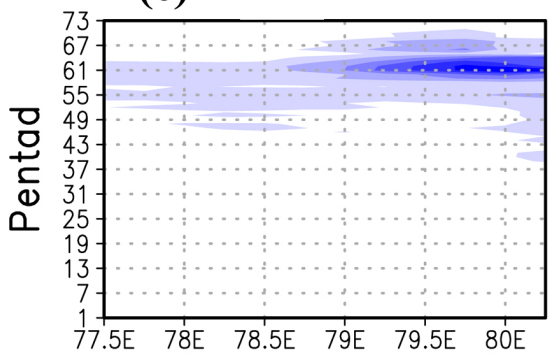

(e)

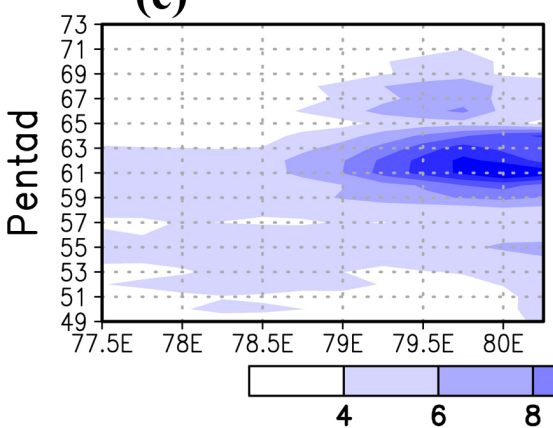

(g)

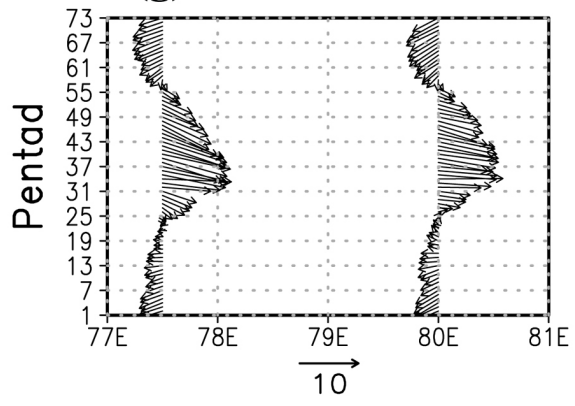

(b)

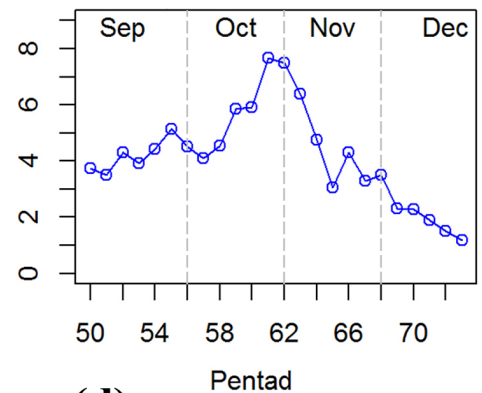

(d)

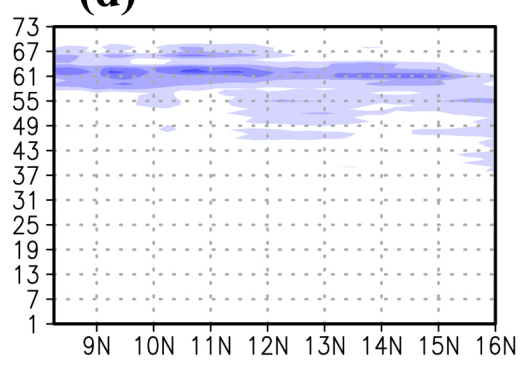

(f)

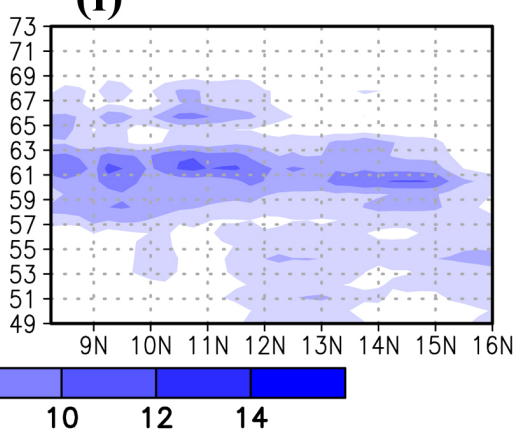

(h)

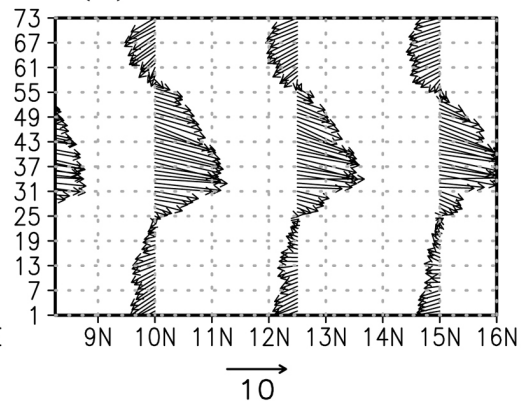

Figure 2.3 Rainfall ( $\mathrm{mm} /$ day) variation by pentad from Jan. to Dec., over the study domain $\left(77.5-80.25^{\circ} \mathrm{E}\right.$ and $\left.8-16^{\circ} \mathrm{N}\right)$, (b) Same as (a), but for Sept. to Dec., (c)

Longitudinal cross-section $\left(77-81^{\circ} \mathrm{E}\right)$ of wind vectors $(\mathrm{m} / \mathrm{s})$ area-averaged over $8-16^{\circ} \mathrm{N}$ during Jan. to Dec., (d) Latitudinal cross-section $\left(8-16^{\circ} \mathrm{N}\right)$ of wind vectors area-averaged over $77-81^{\circ} \mathrm{E}$ during Jan. to Dec., (e) Longitudinal cross-section (77-80.25 $5^{\circ}$ ) of pentad rainfall area-averaged over $8-16^{\circ} \mathrm{N}$ during Jan. to Dec., (f) Latitudinal cross-section (8$16^{\circ} \mathrm{N}$ ) of pentad rainfall area-averaged over 77.5-80.25 E during Jan. to Dec, (g) Same as (e), but for Sept. to Dec., and (h) Same as (f), but for Sept. to Dec. 


\subsubsection{Intra-seasonal states of NEIMR}

HMM evaluation. The BIC scores for the fitted 1-18 rainfall states in the HMMs of intra-seasonal NEIMR indicates that the 6-state model had the lowest BIC score and over fitting occurred from the 7-state model onwards (Figure 2.4). Therefore, the 6-state model was considered statistically meaningful. The synoptic associations of the six different rainfall states in the 6-state model were investigated by using the patterns of mean sea level pressure and $850 \mathrm{hPa}$ winds. The differences of synoptic associations between the rainfall states in the 3-, 4-, 5-, and 6-state models were also evaluated. The diagnostics, based on the synoptic associations, indicate that the 3-state model was optimal in terms of capturing meaningful sea level pressure and wind patterns at $850 \mathrm{hPa}$. The higher-numbered rainfall state models did not add value to the identified rainfall states in the 3-state model. For instance, the spatio-temporal characteristics of the rainfall states already presented in the 3-state model were either repeated or split into smaller regions in the higher-numbered state models (Figure 2.5). The higher-numbered rainfall states also did not show any clear synoptic associations beyond that shown by the 3rainfall state model. In addition, following the law of parsimony a model with lower dimension for greater reliability was chosen (Pal et al. 2015). Based on the synoptic reasoning and statistical criterion, the 3-state model was considered in this study to characterize the spatio-temporal variability of rainfall during the NEIMR season.

HMM rainfall states. The characteristics of rainfall for the three different rainfall states in the 3-state model were shown in Figures 4(b) to 4(d) and the corresponding probability of occurrence are shown in Figures 4(e) to 4(g). The State-1 was the wettest state, with intense rainfall over the coastal region (higher than $15 \mathrm{~mm} /$ day). The interior landmass of southeastern India received less rainfall (higher than 6-15 mm/day), compared to the coast. During the State-2 conditions, the rainfall was up to 6-12 $\mathrm{mm} /$ day along the south and southeastern coastal strip of the Tamil Nadu. The State-3 condition was the driest state with scanty rainfall (lesser than $6 \mathrm{~mm} /$ day) over the coastal Tamil Nadu. The probabilities of occurrence of State-1 and State-2 over the study region during the NEIMR season were higher than $80 \%$, whereas the probability of State-3 for the same region was lower than $70 \%$. The rainfall amount anomalies of the three states from the climatology are shown in Figure 2.6 (h), (i), (j). The rainfall anomalies are much higher 
for State-1 (between 3-12 mm over the southeastern India, Figure 2.6(h)) than the other two rainfall states which exhibited negative rainfall departures (Figure 2.6(i), (j)) from the climatology.

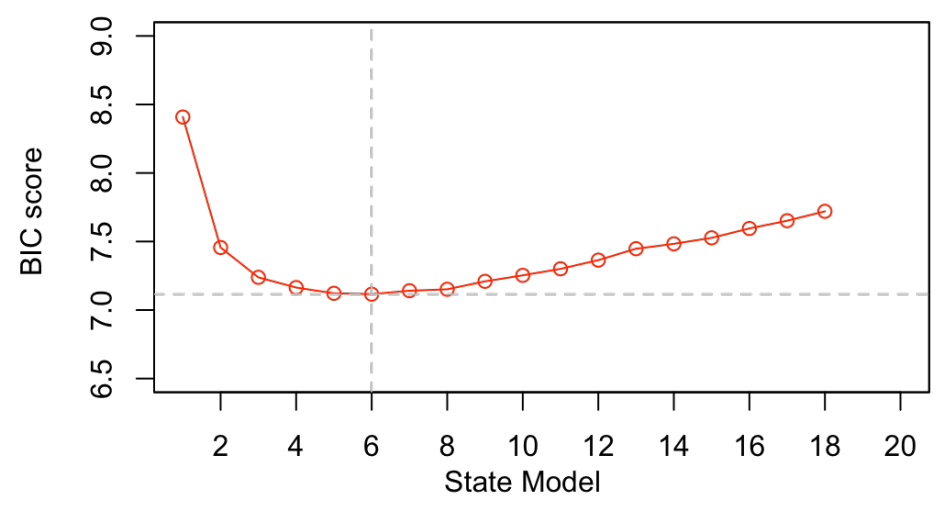

Figure 2.4 Bayesian Information Criterion (BIC) scores for 1-18 NEIMR state models classified by the Hidden Markov Model (HMM). Horizontal dotted line indicates the lowest BIC score and vertical line indicates its corresponding state model.

(a) State-1

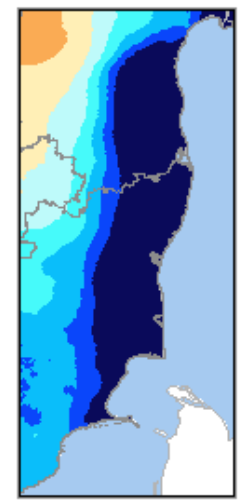

(d) State-4

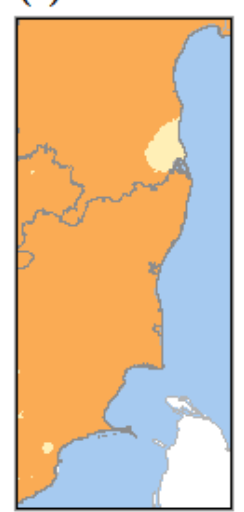

(b) State-2

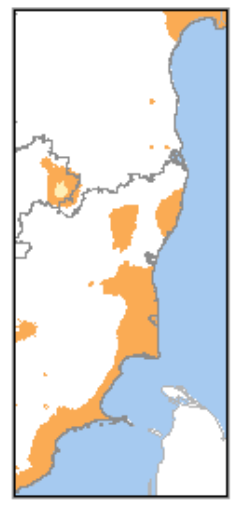

(e) State-5

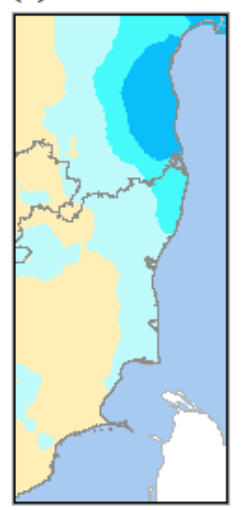

(c) State-3

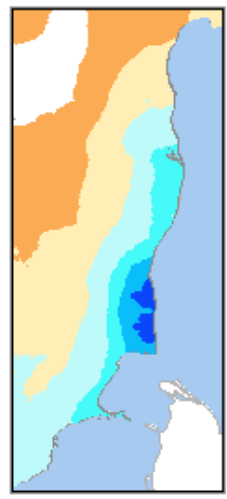

(f) State-6

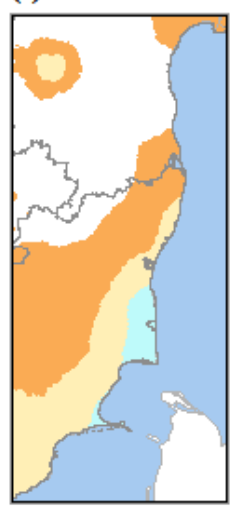

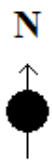

Rainfall
mm/day

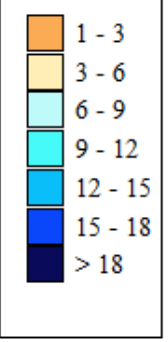

Figure 2.5 Mean pentad NEIMR (mm/day) for the six rainfall states. 
(a) Grid locations

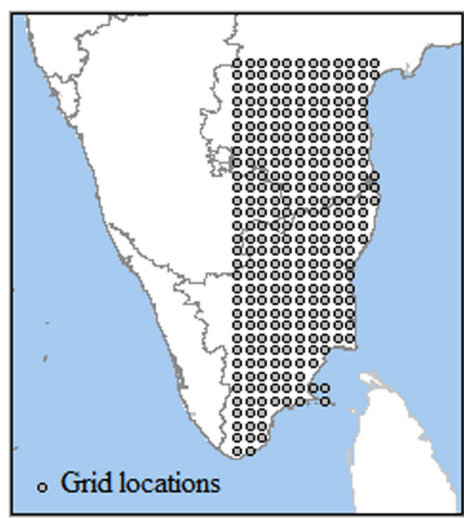

(e) State-1

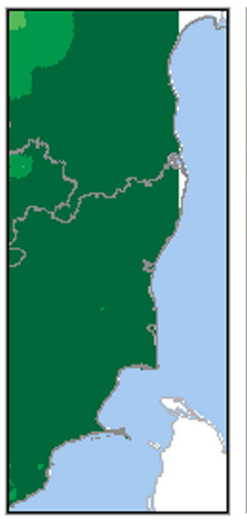

(h) State-1

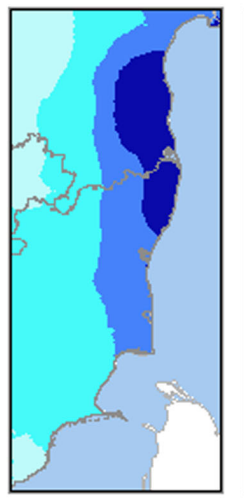

(b) State-1

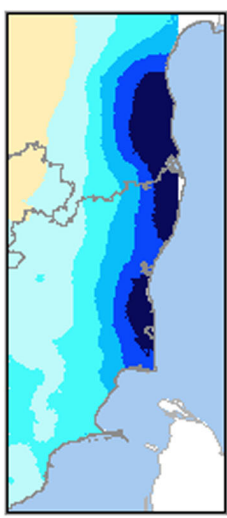

(g) State-3

(f) State-2

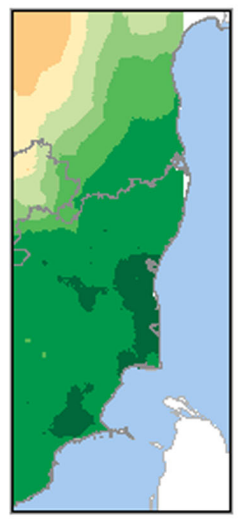

(i) State-2

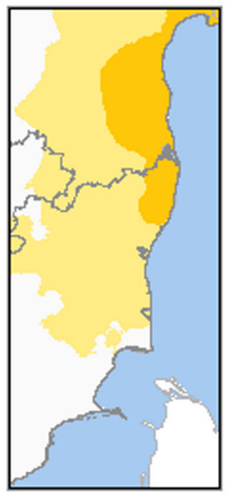

(j) State-3

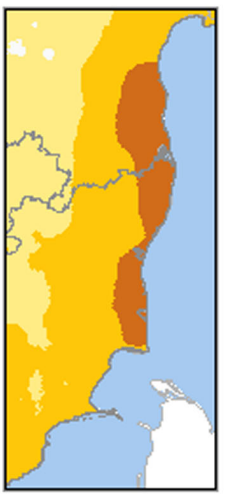

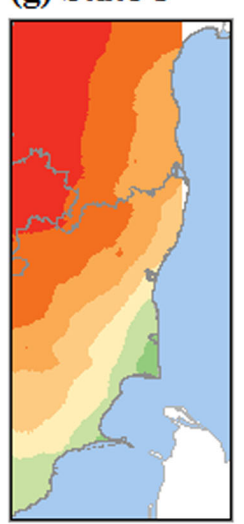

(c) State-2

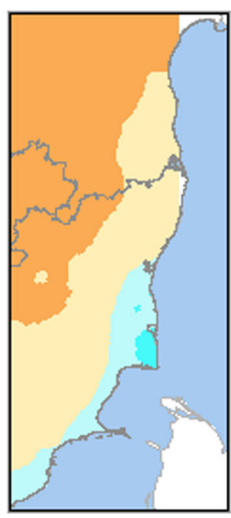

(d) State-3
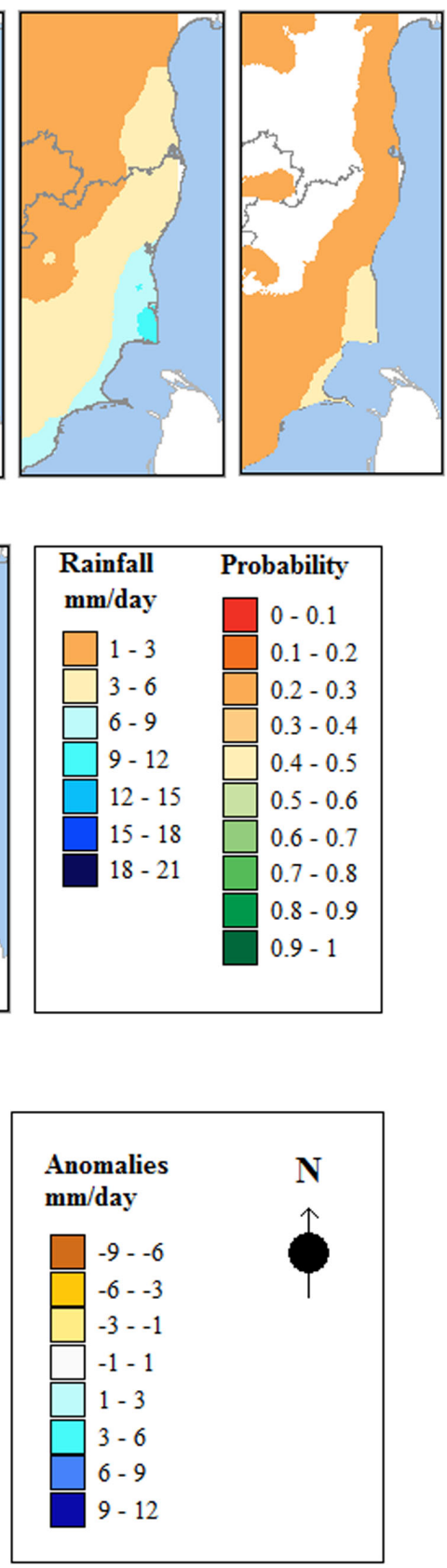

Figure 2.6 (a) Grid locations considered for the HMM modelling, (b) mean pentad NEIMR (mm/day) and (e) occurrence probabilities from the 3-state model, for the State1, ( $c$ and $f$ ) and ( $d$ and $g$ ) are as (b and e), but for the State-2 and State-3, respectively. Anomalies of rainfall amounts during (h) State-1, (i) State-2, and (j) State-3 from the seasonal mean climatology. 
Figure 2.7 shows the spatial patterns of the seasonal rainfall and anomalies from the seasonal climatology for the highest four years (top 10\% in 33 years) of each state (a) State-1: 1987, 1997, 2005 and 2010, (b) State-2: 1982, 1989, 2001 and 2014, and (c) State-3: 1988, 1992, 1995 and 2002. Overall, the study region received favorable seasonal rainfall $\left(>6 \mathrm{~mm} /\right.$ day over $78.5-80.25^{\circ} \mathrm{E}$ and $8-15.5^{\circ} \mathrm{N}$, and $>10 \mathrm{~mm} /$ day over the coastal Tamil Nadu region) during the highest years of State-1 (Figure 2.7(a)). The seasonal rainfall was confined to $79.5-80^{\circ} \mathrm{E}$ and $10-12^{\circ} \mathrm{N}(>6 \mathrm{~mm} /$ day) during the highest years of State-2 (Figure 2.7(b)). The study region received no rainfall, except for scanty rainfall ( $<6 \mathrm{~mm}$ /day) over the coastal stretch, during the highest years of State-3 (Figure 2.7(c)). The anomalies from the seasonal climatology indicate that State-2 resembled with the seasonal climatology (Figure 2.7(e)), the State-3 had negative departure of $<-3 \mathrm{~mm}$ /day (Figure 2.7(f)), and State-1 had positive departure of $>3$ $\mathrm{mm} /$ day over the southeastern India (Figure 2.7(d)). 

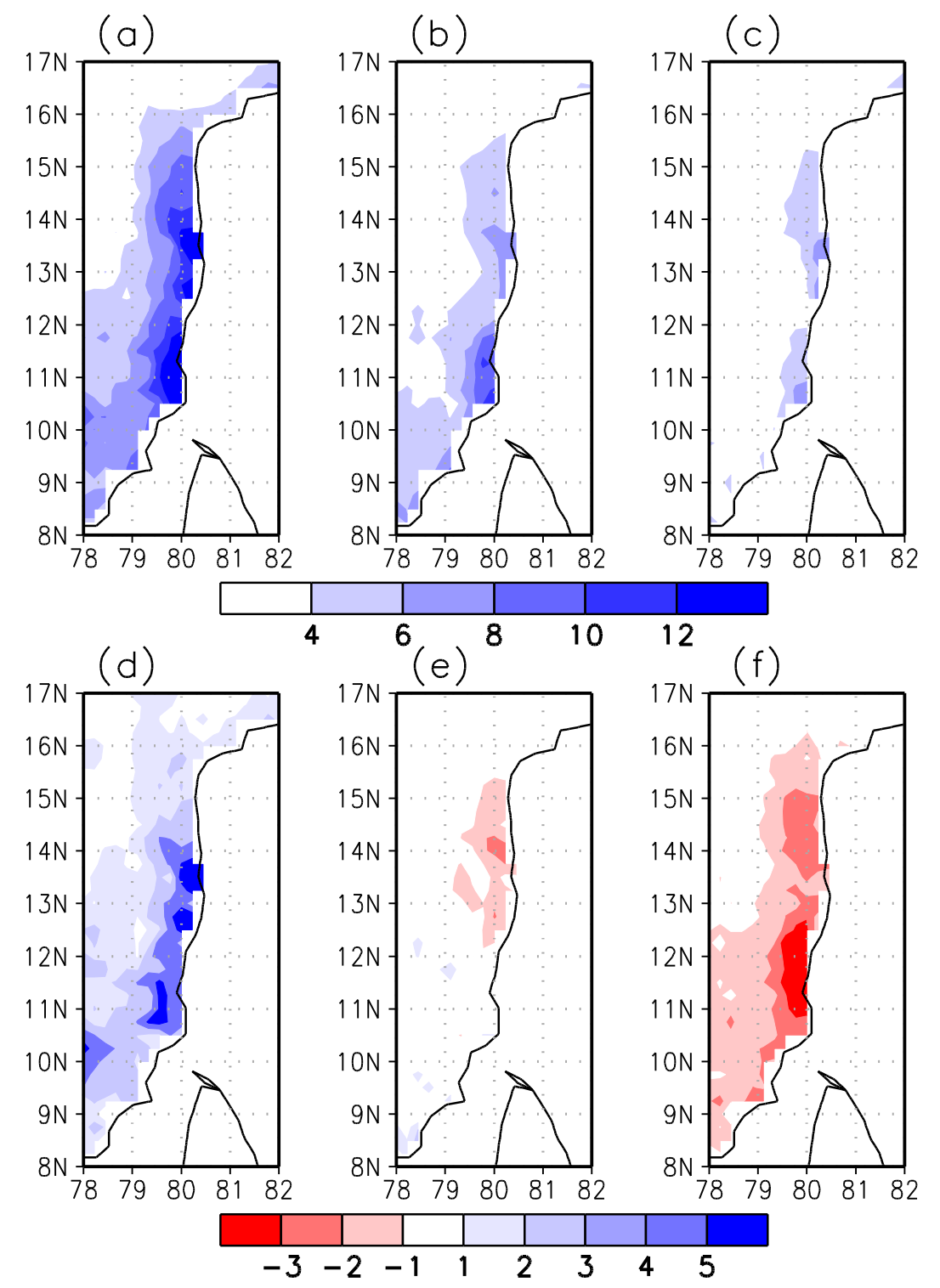

Figure 2.7 Seasonal OND rainfall $(\mathrm{mm} /$ day) for the years with enhanced frequencies of (a) State-1 (1987, 1997, 2005 and 2010), (b) State-2 (1982, 1989, 2001, ad 2014), and (c)

State-3 (1988, 1992, 1995, and 2002). (d, e, f) are same as $(a, b, c)$ but show the anomalies from the seasonal mean climatology.

The transition probability of the rainfall states is presented in Table 2.1. The probability of transition from the State-1 (wet) to the State-2 (coastal wet) (34\%) was higher than the State-1 (wet) to the State-3 (dry) (12\%). The transition from the State-2 (coastal wet) was more likely to the dry rainfall state (State-3) (37\%), compared to the wet state (State-1) (27\%). The probable chances for transition from the State-3 (dry) to the State-2 (coastal wet) (27\%) was higher than the transition to State-1 (wet) (11\%). The 
transition probability between the rainfall states indicates that the State-2 (coastal wet) acted as a transition between the State-1 (wet) and the State-3 (dry). The probabilities of persistence in the consecutive pentad for the State- 3 and the State- 1 were $61 \%$ and $53 \%$, respectively.

Table 2.1 Probability of transitions between the rainfall states from the 3-state HMM.

\begin{tabular}{|c|c|c|c|}
\hline & State-1 & State-2 & State-3 \\
\hline State-1 & 0.53 & 0.34 & 0.12 \\
\hline State-2 & 0.27 & 0.36 & 0.37 \\
\hline State-3 & 0.11 & 0.27 & 0.61 \\
\hline
\end{tabular}

The year-to-year variations in occurrences of the three rainfall states during the NEIMR season $\left(56^{\text {th }}\right.$ to $73^{\text {rd }}$ pentad) from 1982-2014 are shown in Figure 2.8. The patterns of occurrence of rainfall states indicates that State- 1 occurred dominantly from the $56^{\text {th }}$ pentad (03-08 Oct.) to the $64^{\text {th }}$ pentad (11-16 Nov.). The occurrence of State-3 was more often from the $66^{\text {th }}$ pentad (22-27 Nov.) until the end of the NEIMR season. State-2 occurred randomly in between the State-1 and the State-3 throughout the monsoon season, while the State-1 and the State-3 occurred during consecutive time-steps. 


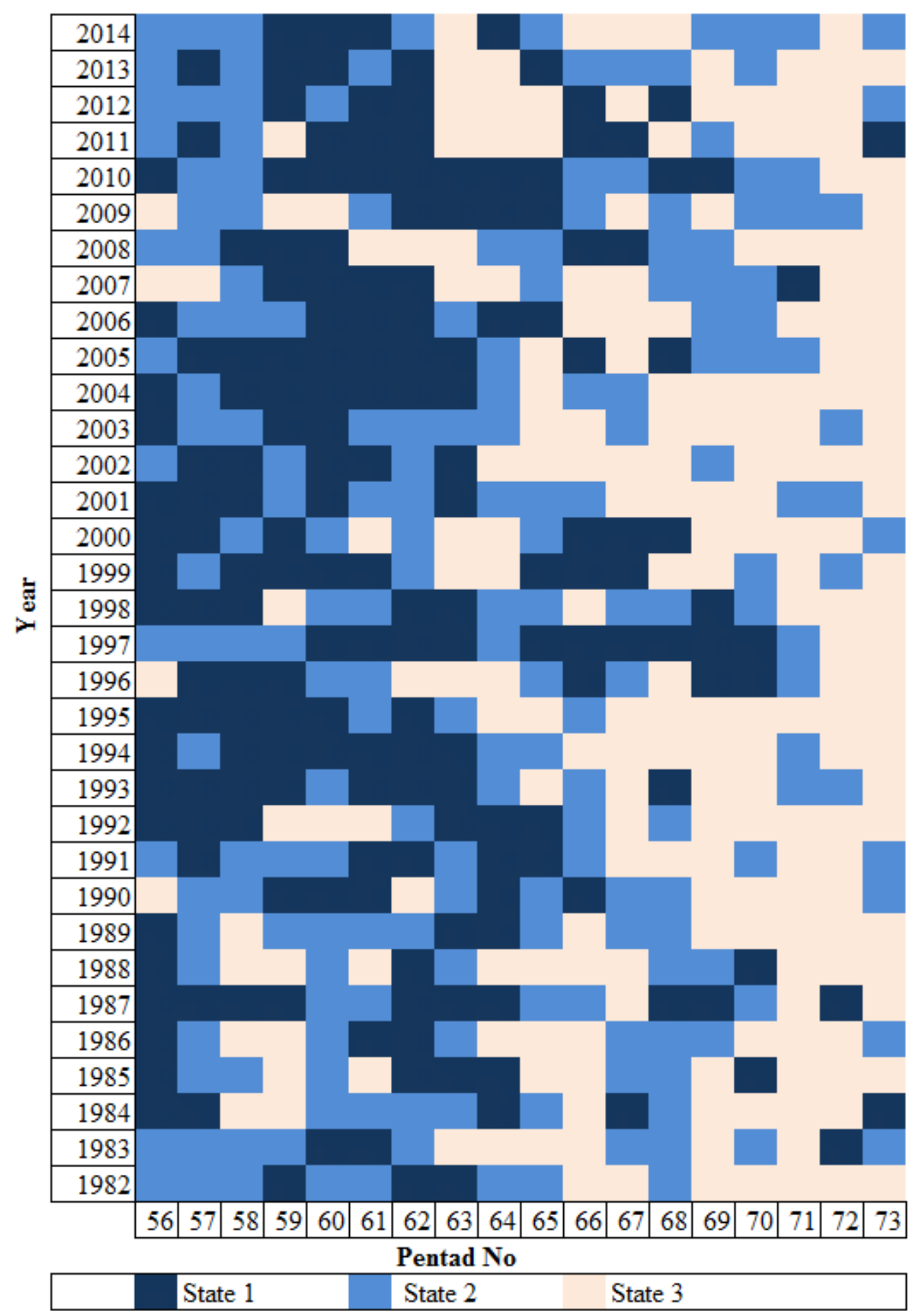

Figure 2.8 Year-to-year variations in occurrences of the three rainfall states based on the Viterbi algorithm during 1982-2014. X-axis is pentad number from 56 (03-08 Oct.) to 73 (27-31 Dec.) and Y-axis is years from 1982 to 2014. 
The inter-annual variations of the frequencies of rainfall states are shown in Figure 2.9(a). State-1 frequencies increased, and State-3 decreased during the strong NEIMR years (top 5 years out of 33 years - 1987, 1993, 1997, 2005 and 2010) (Figure 2.9(b)). In general, the frequencies of State-3 and State-1 were opposed to each other during the extreme (flood and drought) years. The associations between the time series of the frequency of three rainfall states and seasonal NEIMR were evaluated by the Pearson correlation coefficient. The correlation (positive) was stronger between the State-1 frequency and seasonal NEIMR $(r=0.64, p$-value $<0.01)$. Similarly, the correlation (negative) between the State-3 frequency and seasonal NEIMR was also stronger $(r=$ $0.63, p$-value $<0.01)$. The relationship between the State-2 and seasonal NEIMR was weaker and insignificant $(r=-0.07)$.

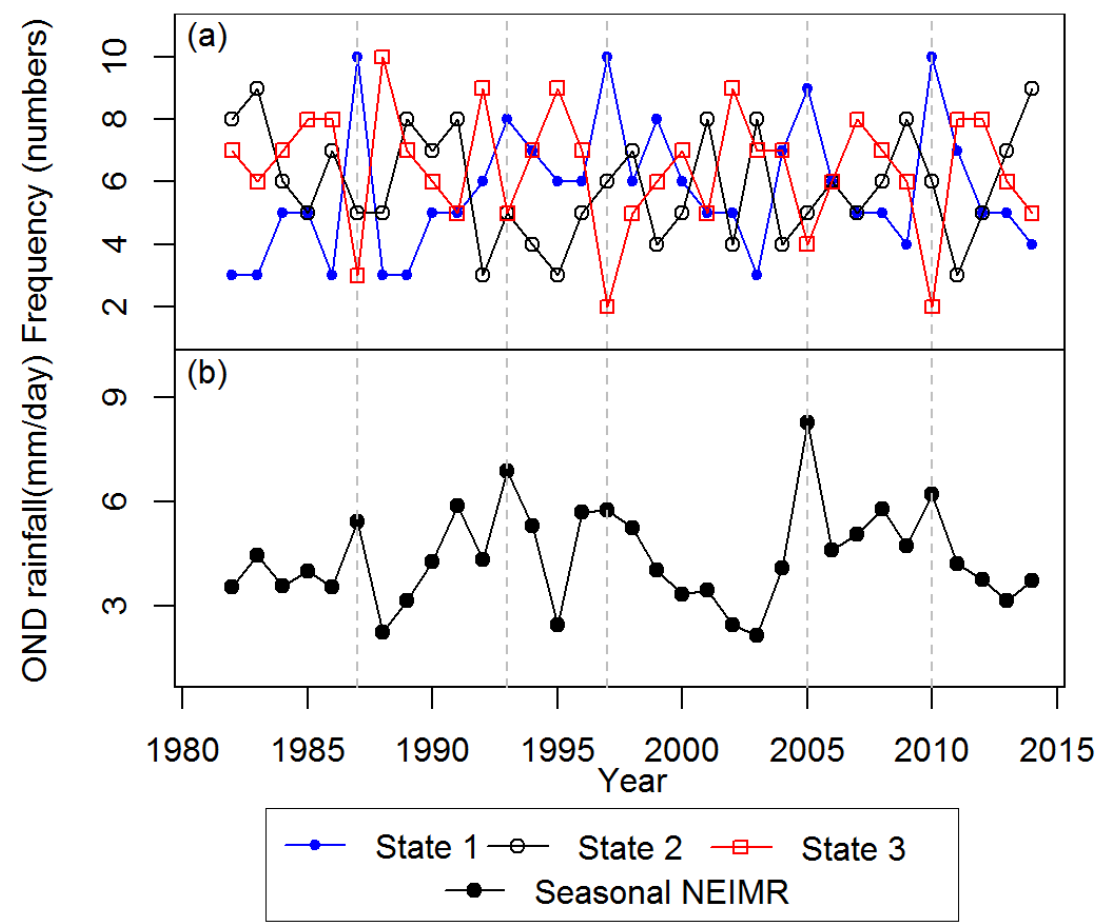

Figure 2.9 Inter-annual variations of (a) frequency of rainfall states (numbers), and (b) seasonal mean rainfall during $O N D(\mathrm{~mm} /$ day). Vertical dotted lines indicate the highest 5 years of NEIMR during 1982-2014. 


\subsubsection{Atmospheric circulation and surface temperature conditions for the rainfall states}

The seasonal climatology of the synoptic parameters (surface air temperature, mean sea level pressure, winds, vorticity, and moisture convergence) during the NEIMR season are presented in Figures 2.10(a) to (d). During the NEIMR season, the surface air temperatures were higher than $27^{\circ} \mathrm{C}$ over the Bay of Bengal and the Arabian Sea (Figure 2.10(a)). The large warm oceanic region in the Bay of Bengal adjacent to the east coast of the southern peninsular of India could be one of the necessary conditions for tropical cyclones to develop (Evans 1993, Yadav 2013). There was a strong temperature contrast over the northern Indian sub-continent with the neighboring oceans of the southern peninsular being the warmest with surface mean temperatures of up to $8^{\circ} \mathrm{C}$ warmer than in the north. The sea level pressure was characterized by relatively lower pressure (< $1011 \mathrm{hPa}$ ) over the Arabian Sea, the Bay of Bengal and the southern peninsular regions below $15^{\circ} \mathrm{N}$, compared to the continental regions above $15^{\circ} \mathrm{N}$ (Figure $2.10(\mathrm{~b})$ ). The northeasterly surface winds over the peninsular and the associated cyclonic circulation over the southern Bay of Bengal and North Indian Ocean regions can be discerned (Figure 2.10(b)). The vorticity (positive) and winds at $850 \mathrm{hPa}$ indicate strong cyclonic circulation over the Bay of Bengal and the Indian Ocean, while central India was dominated by anticyclonic circulation and negative vorticity (Figure 2.10(c)). The moisture convergence at the lower troposphere showed positive moisture convergence over $77-100^{\circ} \mathrm{E}$ and $0-8^{\circ} \mathrm{N}$ in the Indian Ocean region and a mildly negative patch over the southeastern peninsular India (Figure 2.10(d)). The seasonal climatology of moisture convergence did not show increased moisture convergence over the southeastern peninsular of India, because the number of wet states (188 pentads during 1982-2014) were less, compared to the coastal and dry states (406 pentads during 1982-2014). Overall, the atmospheric circulation and surface temperature conditions evident over the Bay of Bengal and Indian Ocean during the NEIMR season comprised warmer surface air temperature, lower mean sea level pressure, lower-level cyclonic circulations, and enhanced moisture convergence at $850 \mathrm{hPa}$. The atmospheric circulation and surface 
temperature conditions over the surrounding oceans might be favorable for NEIMR by providing the moisture sources to the southeastern peninsular.
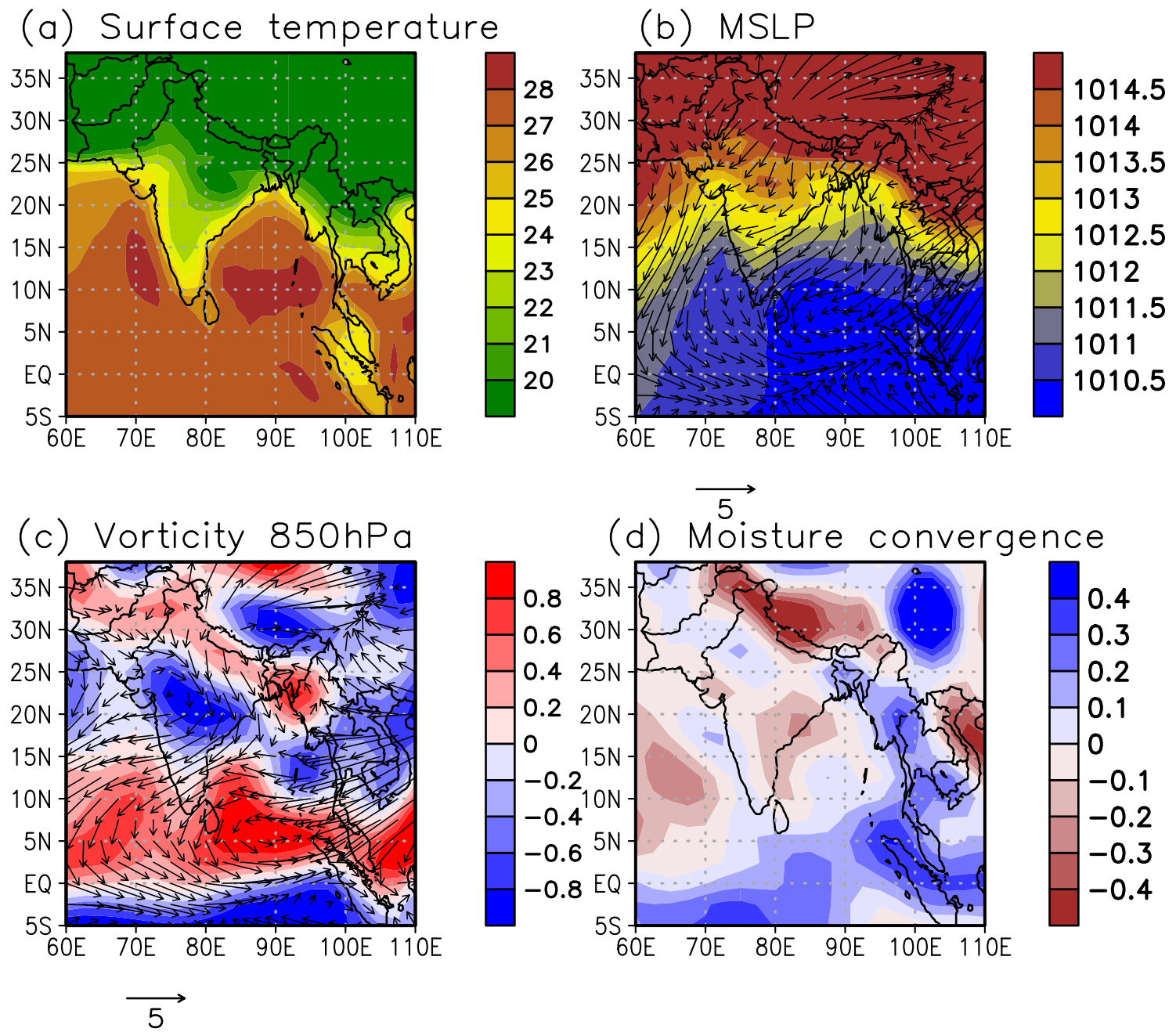

Figure 2.10 Seasonal climatology during OND for (a) surface air temperature $\left({ }^{\circ} \mathrm{C}\right)$, (b) mean sea level pressure ( $\mathrm{hPa}$ ) and surface winds (vectors, $\mathrm{m} / \mathrm{s})$, (c) vorticity (10-5 s-1) and winds $(\mathrm{m} / \mathrm{s})$ at $850 \mathrm{hPa}$, and (d) moisture convergence at $850 \mathrm{hPa}\left(\mathrm{gkg}^{-1} \mathrm{~s}^{-1}\right)$

The atmospheric circulation and temperature associated with each rainfall state and its deviation (anomaly) from the seasonal climatology of NEIMR are shown in Figures 9 to 12. The surface air temperature exhibited a large warm area $\left(>28^{\circ} \mathrm{C}\right)$ in the Arabian Sea, the Bay of Bengal and the Indian Ocean during the rainfall State-1 (Figure 2.11(a)). The temperature deviation from the seasonal climatology indicates a warm temperature 
anomaly gradient (up to $2^{\circ} \mathrm{C}$ ) from north to south (Figure 2.11(d)). The State-2 also showed similar warm areas over the Arabian Sea and the Bay of Bengal, but with much smaller temperature anomalies $\left(<0.5^{\circ} \mathrm{C}\right)$ (Figure $2.11(\mathrm{e})$ ). The temperature anomaly during State-3 was opposite to that of State-1, which showed the anomalous negative temperature gradient from north to south (Figure 2.11(f)). The significant anomalies of temperature during the State-1 and State- 3 were observed in the entire study domain, except for the tropical Indian Ocean region (below Equator) at the $95 \%$ level. The surface air temperature anomalies for State-2 were insignificant and reflected the similar condition of seasonal climatology. 

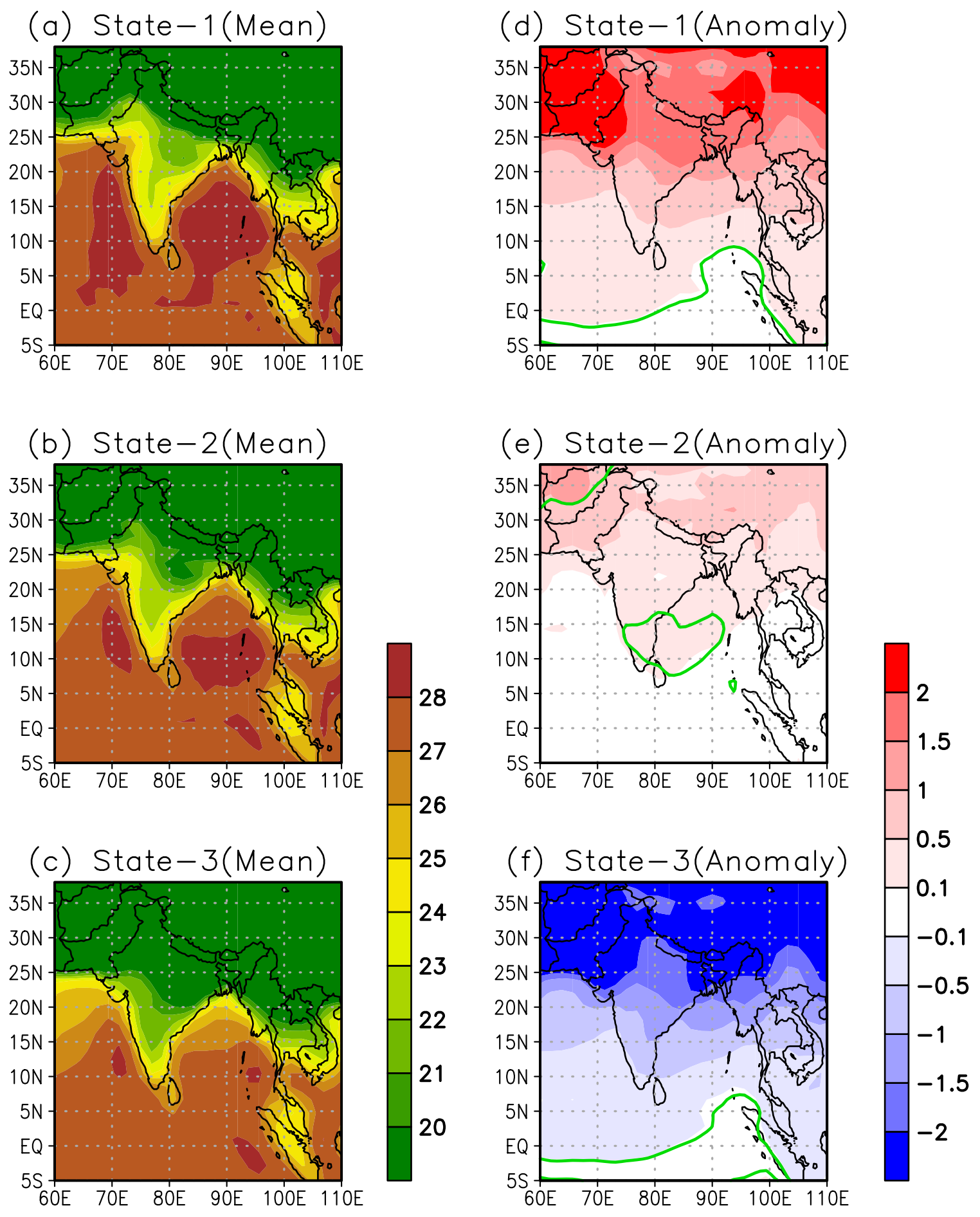

Figure 2.11 Surface air temperature $\left({ }^{\circ} \mathrm{C}\right)$ - Mean climatology of (a) State-1, (b) State-2, (c) State-3, and the anomaly from the NEIMR seasonal climatology of (d) State-1, (e) State-2, and (f) State-3. The green lines in $(d),(e)$, and (f) indicate the region significant at $95 \%$ level. 
The mean sea level pressure over the neighboring ocean regions of the southern peninsular region was less than that for the surrounding regions $(<1010.5 \mathrm{hPa})$ during the periods of State-1 (Figure 2.12(a)). Over the low-pressure regions, the surface winds showed a cyclonic circulation pattern. For the State-2, mean sea level pressure was between $1010.5-1011 \mathrm{hPa}$ over the region of $70-100^{\circ} \mathrm{E}$ and $0-12^{\circ} \mathrm{N}$, showing a cyclonic circulation over the lower pressure regions (Figure 2.12(b)). The mean sea level pressure over the oceanic regions closer to the Indian peninsular during the State-3 was around 1011-1012 hPa, which was higher pressure, compared to that of State-1 and the State-2 (Figure 2.12(c)). The related cyclonic circulation patterns were less distinct during State3. The deviation of mean sea level pressure during State-1 from the seasonal climatology indicates that the pressure was lower (up to $1.2 \mathrm{hPa}$ ) over the Indian subcontinent and the surrounding oceans. The anomalous strong southwesterly winds are observed over the Indian Ocean and the Bay of Bengal during the State-1 (Figure 2.12(d)). The deviation of mean sea level pressure during State-2 was statistically insignificant, with little change in the wind pattern (Figure 2.12(e)). During State-3, the mean sea level pressure was greater (up to $1.2 \mathrm{hPa}$ ), compared to seasonal climatology. The anomalous winds over the Bay of Bengal and the Indian Ocean were northeasterlies during State-3 (Figure 2.12(f)). The deviations of winds during State-1 and State- 3 conditions from the seasonal climatology indicate that they were opposite to each other in terms of pressure patterns (lower pressure anomalies during State-1 and higher anomalies during State-3) and wind patterns (strong southwesterlies during State-1 and strong northeasterlies during State-3) in the southern peninsular of India and neighboring oceans. The potential reasons for the wind patterns during State-1 and State-3 are discussed in a following section. The significant anomalies of mean sea level pressure during State-1 and State-3 were mostly confined to the Indian landmass and the adjoining Arabian Sea and Bay of Bengal areas. 

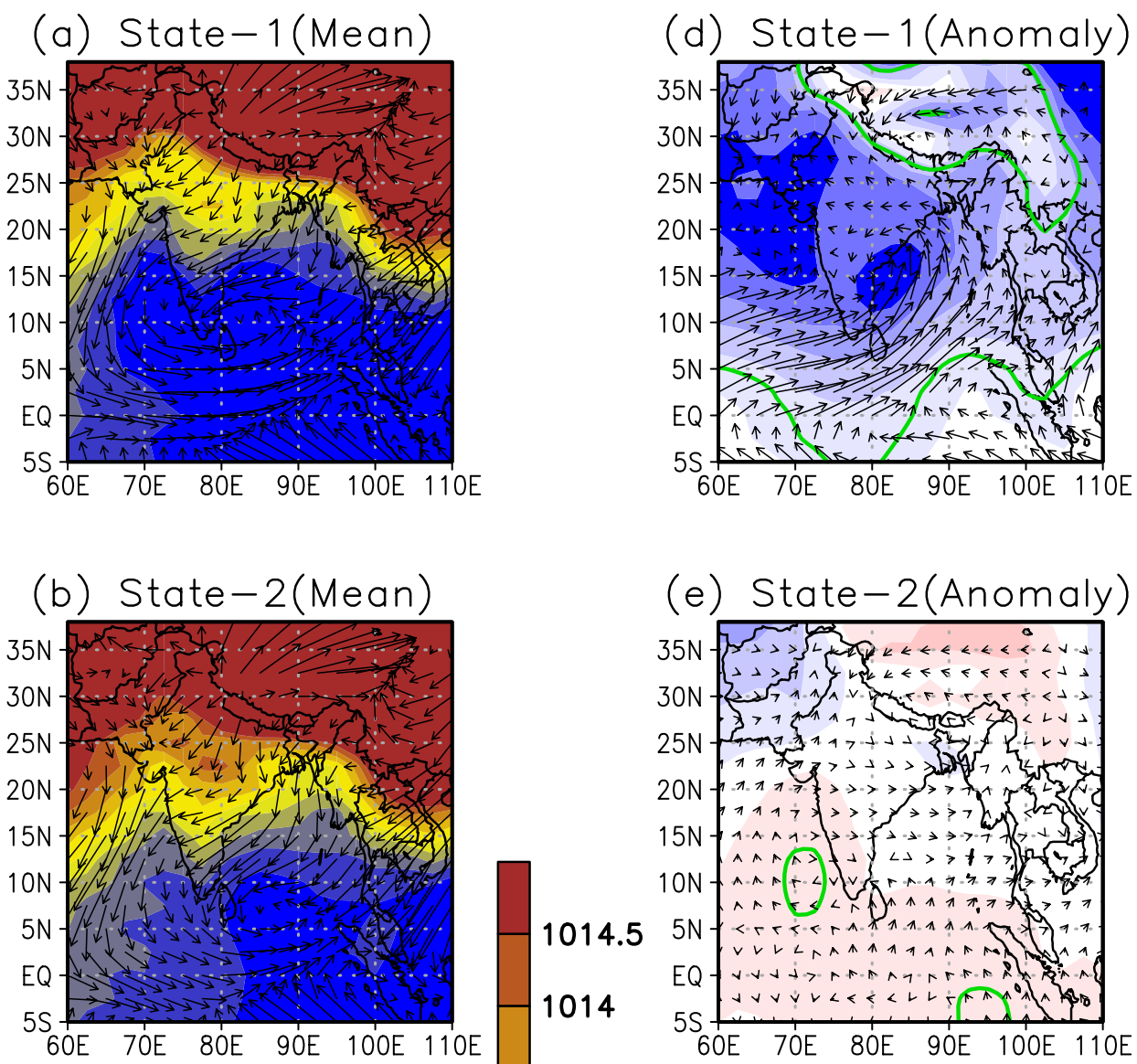

(e) State-2(Anomaly)
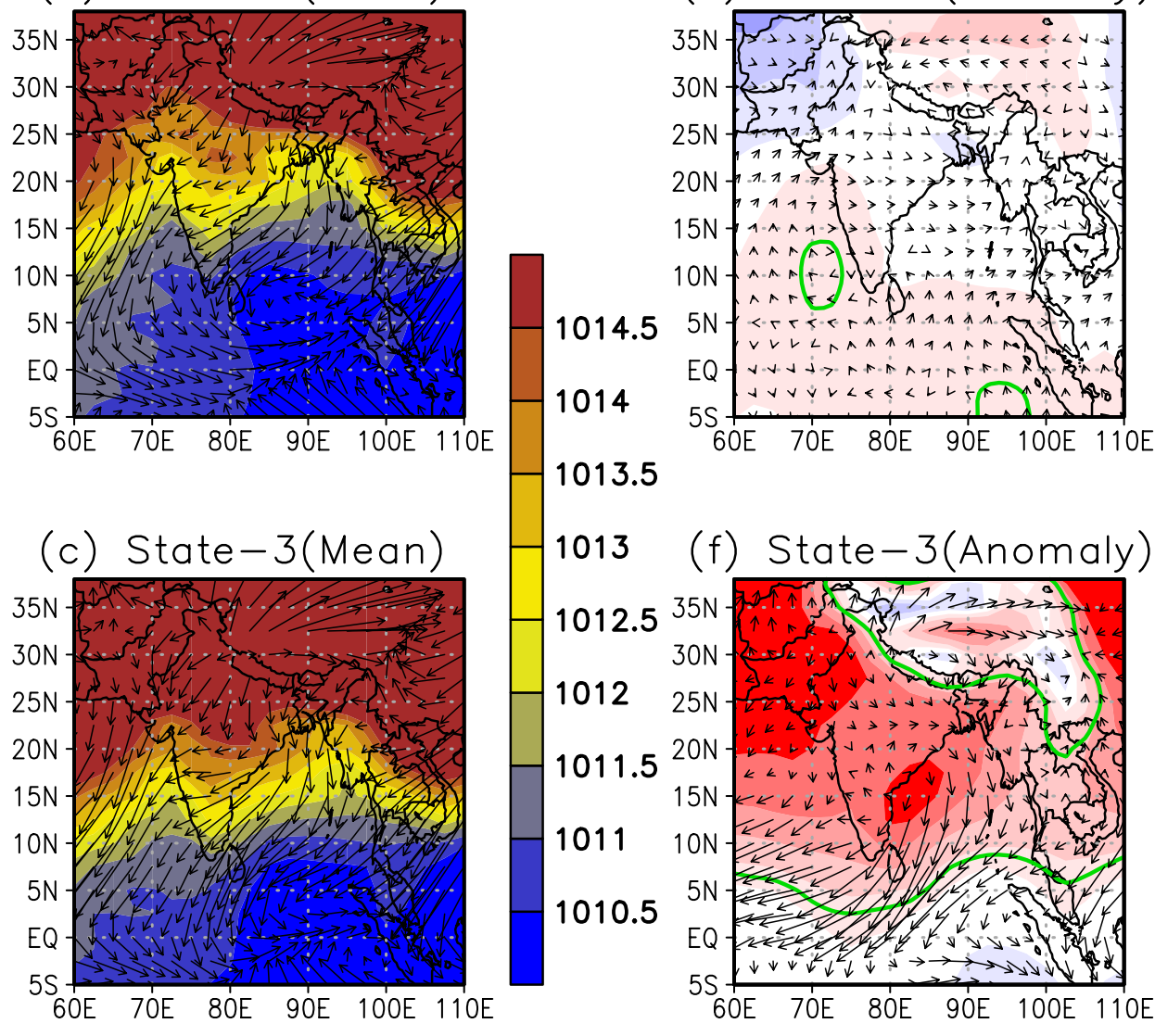

(f) State-3(Anomaly)
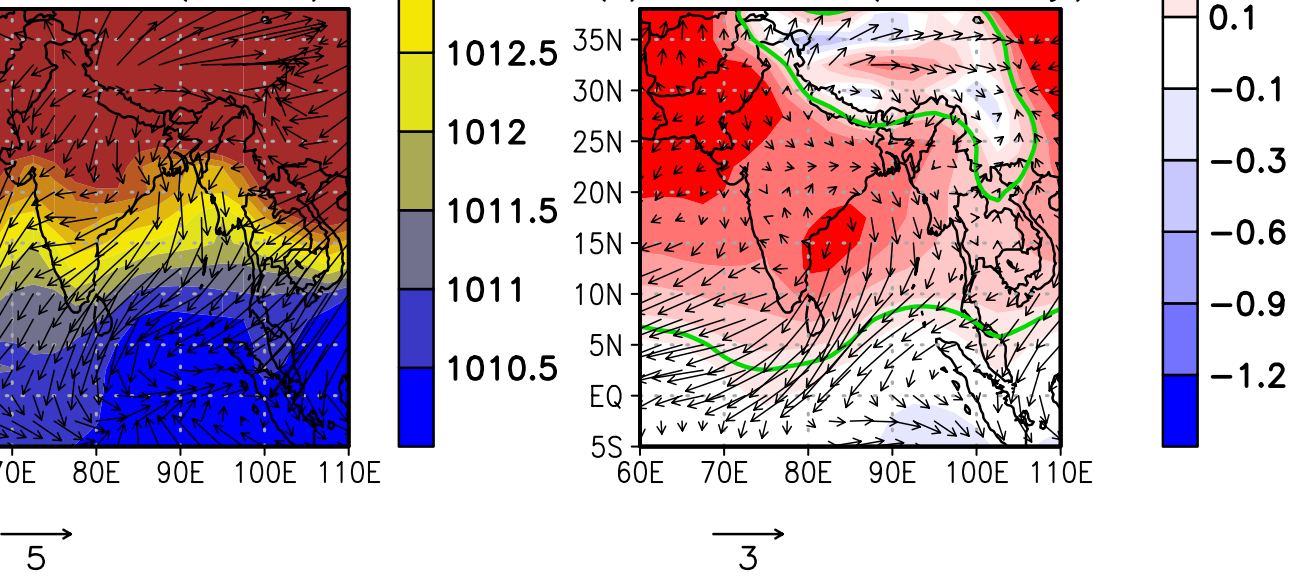

Figure 2.12 Mean sea level pressure $(\mathrm{hPa})$ and surface winds $(\mathrm{m} / \mathrm{s})$ - Mean climatology of (a) State-1, (b) State-2, (c) State-3, and the anomaly from the NEIMR seasonal climatology of (d) State-1, (e) State-2, and (f) State-3. The green lines in (d), (e), and ( $f)$ indicate the region significant at $95 \%$ level. 
The mean vorticity and winds at $850 \mathrm{hPa}$ for the three different rainfall states and how these conditions deviated from the seasonal climatology are shown in Figure 2.13. During the State-1, a strong cyclonic circulation was observed across the Arabian Sea, the Bay of Bengal, and the Indian Ocean regions, which was consistent with the positive vorticity values $\left(>0.8 \times 10^{-5} \mathrm{~s}^{-1}\right)$ over the ocean regions (Figure 2.13(a)). In central India, a negative vorticity and associated anticyclonic circulations were seen above $18^{\circ} \mathrm{N}$. The cyclonic and anticyclonic circulation regions observed in State-1 shifted to southern latitudes during State-2 (Figure 2.13(b)), and the positive vorticity pattern shifted away from the southern peninsular of India during State-3 (Figure 2.13(c)). The deviations of the mean conditions during the three different rainfall states from the seasonal climatology indicate that, over the southern peninsular of India, anomalous positive vorticity values (enhanced cyclonic activities) were observed during State-1 (Figure 2.13(d)) and negative vorticity anomalies (reduced cyclonic or enhanced anticyclonic activities) were seen during State-3 (Figure 2.13(f)). The vorticity anomalies during the State-1 and the State-3 conditions were significantly different from their seasonal climatology over the central and southern peninsular of India and the surrounding oceans at the $95 \%$ significance level.

The moisture convergence at the lower tropospheric level $(850 \mathrm{hPa})$ during the three rainfall states and its deviation from the seasonal climatology are shown in Figure 2.14. During the State-1, the moisture convergence was enhanced $\left(>0.10 \mathrm{gkg}^{-1} \mathrm{~s}^{-1}\right.$, Figure 2.14(a)) over the Bay of Bengal and the Indian Ocean region $\left(80-100^{\circ} \mathrm{E}\right.$ and $\left.0-13^{\circ} \mathrm{N}\right)$. The moisture convergence zones were slightly weakened and shifted far from the southern peninsular during State-2 and State-3 conditions. Based on the deviations from the seasonal climatology, the moisture convergence values are significantly enhanced during State-1 (Figure 2.14(d)) and were significantly decreased during State-3 (Figure 2.14(f)) over the southern peninsular of India and the Bay of Bengal. 

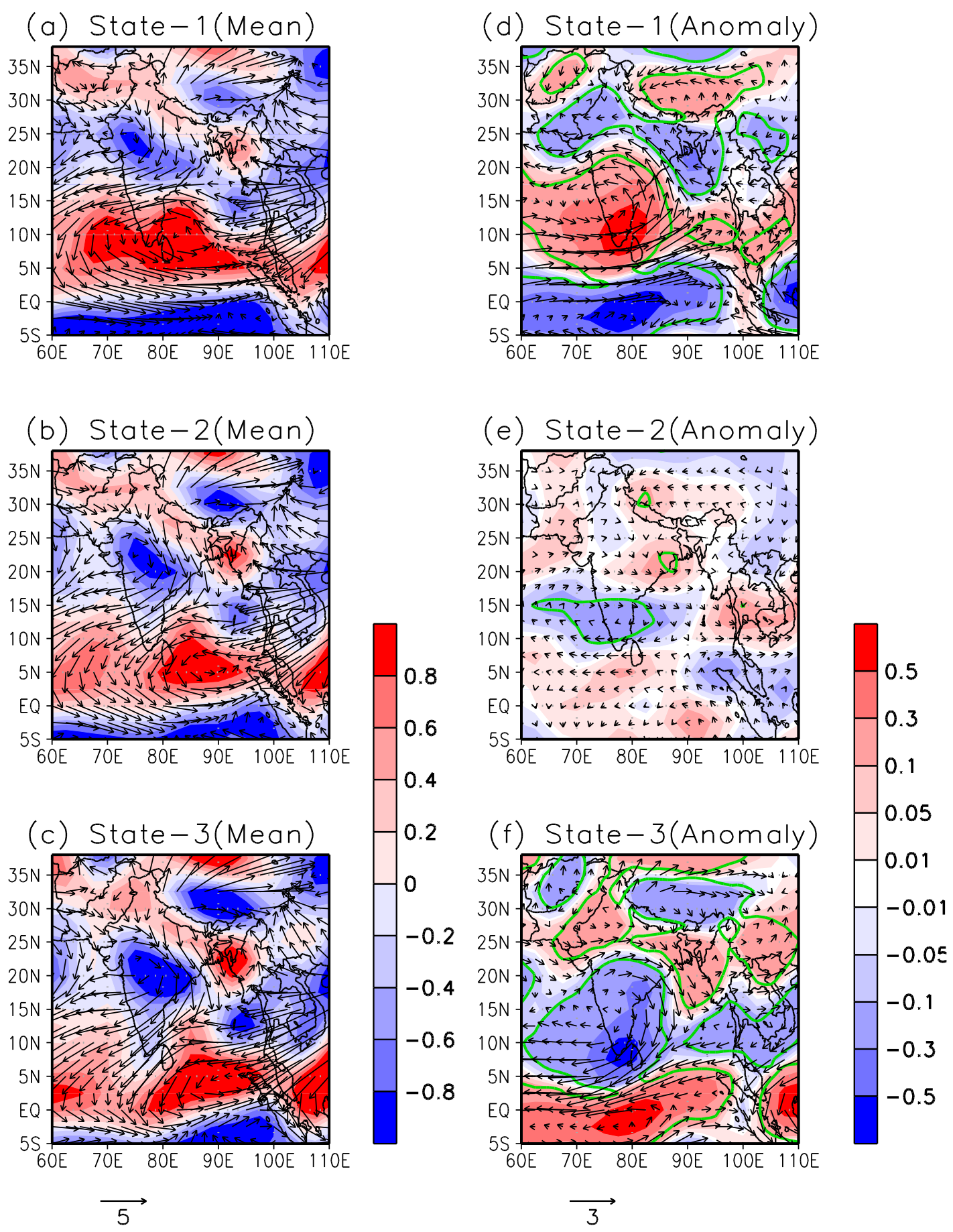

Figure 2.13 Vorticity $\left(10-5 \mathrm{~s}^{-1}\right.$; shaded) and winds $(\mathrm{m} / \mathrm{s})$ at $850 \mathrm{hPa}$ - Mean climatology of (a) State-1, (b) State-2, (c) State-3, and the anomaly from the NEIMR seasonal climatology of (d) State-1, (e) State-2, and (f) State-3. The green lines in (d), (e), and (f) indicate the region significant at $95 \%$ level 

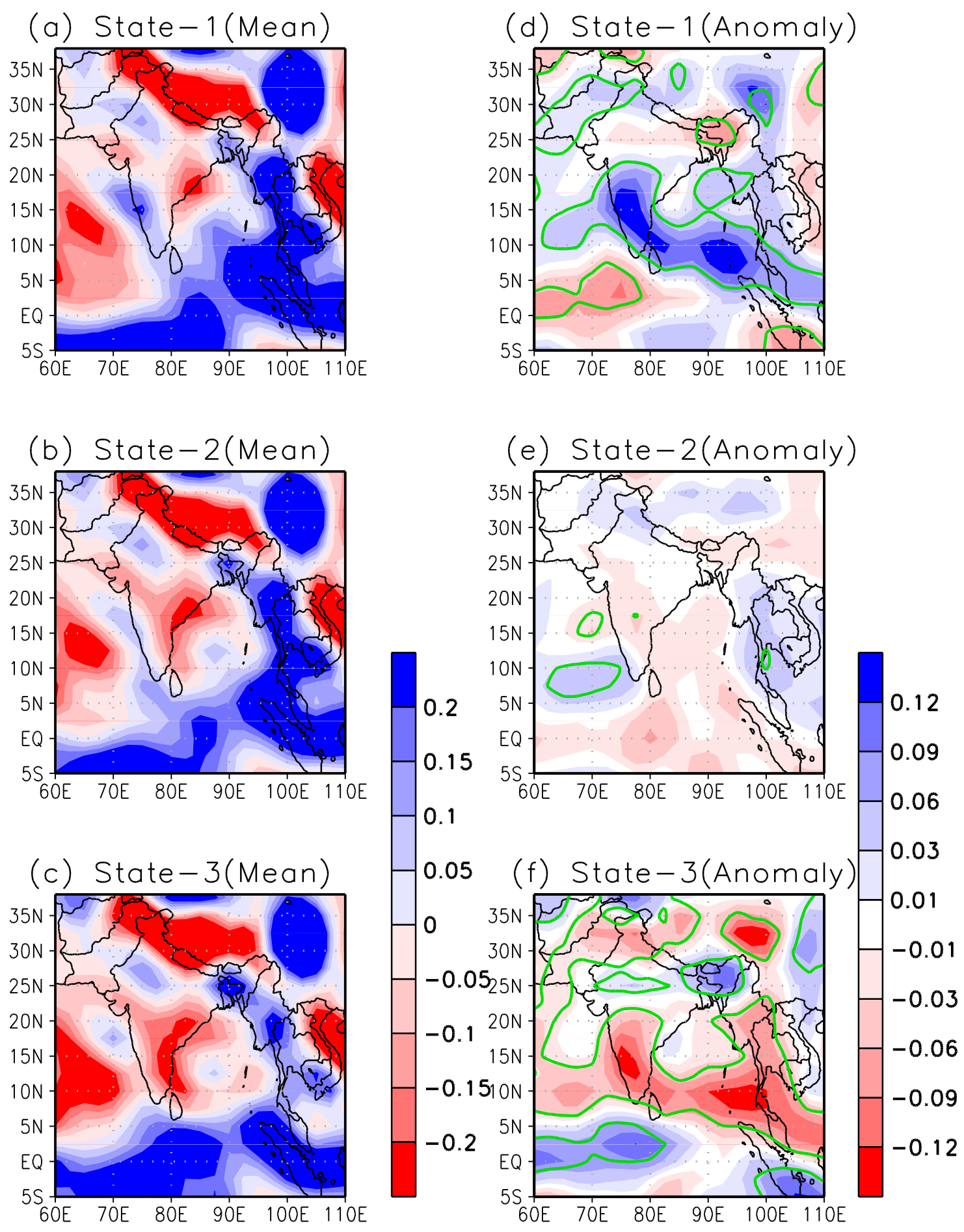

Figure 2.14 Moisture convergence $\left(\mathrm{gkg}^{-1} \mathrm{~s}^{-1}\right)$ at $850 \mathrm{hPa}$ level - Mean climatology of (a) State-1, (b) State-2, (c) State-3, and the anomaly from the NEIMR seasonal climatology of (d) State-1, (e) State-2, and (f) State-3. The green lines in (d), (e), and (f) indicate the region significant at $95 \%$ level. 


\subsection{Discussion}

During State-1 conditions, the rainfall intensity was higher ( $>9 \mathrm{~mm} /$ day) and the rainfall-received region $\left(79-80.25^{\circ} \mathrm{E}\right.$ and $\left.10-15.5^{\circ} \mathrm{N}\right)$ was comparatively larger than that for State-2. As State-1 rainfall was distributed throughout the southeastern peninsular of India, the water harvesting structures would have plenty of rainwater during State-1. State-2 conditions reflected rainfall confined to the thin coastal stretch of Tamil Nadu, which would not have helped the water harvesting structures distributed over the southeastern peninsular of India. The State-3, dry condition, was observed throughout the southeastern peninsular, and this rainfall condition would have caused significant negative impacts due to drought-like conditions. The seasonal NEIMR total was heavily influenced by the frequency of both State-1 and State-3. Considering the characteristics of the rainfall states, State-1 was observed to be critical for water requirements over the southeastern peninsular of India. In the past, poor water resources management had negative consequences on drinking water availability, agriculture (irrigation) operations, industrial outputs, and the socio-economy of the region (Prasanna 2014, UNDP 2013). Thus, planning agencies should pay greater attention to the behaviour of both State-1 and State-3 to manage the consequences of NEIMR conditions.

A distinct pattern of anomalous surface air temperature gradient was observed during wet (State-1) and dry conditions (State-3). During State-1, the temperature deviation over the land regions above $20^{\circ} \mathrm{N}$ was warmer by $>1.5^{\circ} \mathrm{C}$ from the seasonal normal (see Figure 2.11(d)). The surface air temperature deviation over the ocean below $20^{\circ} \mathrm{N}$ was less than $0.5^{\circ} \mathrm{C}$. The increased temperature anomaly over the land regions could have caused the lower pressure over the Indian land mass and its surrounding oceans (see Figure 2.12(d)). The combination of temperature and pressure patterns could drive the anomalous southwesterly winds from the Indian Ocean to the southeastern peninsular India during State-1 (see Figure 2.12(d)-winds). The anomalous winds were distinctly in the lower-right rim of lower pressure anomalies. As the ocean was already warm, these southwesterly anomalous wind patterns from the Indian Ocean could have carried a lot of moisture to the southeastern peninsular of India. The roles of land and ocean in NEIMR were consistent with the physical mechanisms proposed on the land-sea temperature contrast in regulating the monsoonal wind patterns over the South-West 
Indian monsoon (Webster 1987, Lee et al. 2009), East Asian monsoon (Lee et al., 2011), and West African monsoon (He and Lee, 2016). In contrast, the cooler anomaly in surface air temperature over the land areas above $20^{\circ} \mathrm{N}$ (dry State-3) could induce higher pressure over the land mass and its adjacent ocean areas. The cooler temperature anomaly and increased mean sea level pressure conditions could cause the anomalous northeasterly winds over the southeastern peninsular of India and adjoining oceanic areas. These anomalous winds from the cooler and drier land areas could drive the drier conditions over the southeastern peninsular of India (Kumar et al. 1999). The latitudinal oscillations of temperature-pressure-winds between land and ocean could modulate the NEIMR (Clemens et al. 1991).

The upper-level jet streams were found to be one of the major drivers for the intraseasonal variability of Asian monsoon (Koteswaram 1958, Ramaswamy 1962, Joseph and Sijikumar 2004). The magnitude and direction of $200 \mathrm{hPa}$ winds during the NEIMR season indicates that the State-3 featured stronger westerly jet stream in the upper atmosphere over the peninsular of India, characterizing a winter regime with strong upper-level westerlies (Figure 2.15(c)). State-1 exhibited the opposite pattern to State-3, which reflected a weaker westerly jet stream due to an easterly anomaly (Figure 2.15 (b)). The changes in the upper-level westerly jet streams could be associated with the northsouth temperature gradient (see Figures 2.15(d) and (f)) and it might induce changes in rainfall conditions during the NEIMR season. For example, the study of Krishnamurthy et al. (2002) reported that the intense wet rainfall episodes during the 2001 NEIMR season were associated with a blocking situation between $60^{\circ} \mathrm{E}$ and $80^{\circ} \mathrm{E}$ in $200 \mathrm{hPa}$ westerly jet streams. It is also important to note that State-1 could represent a warmer climate regime under the influence of the retreating monsoon trough or the Inter-Tropical Convergence Zone (ITCZ) that had a major contribution to NEIMR (Gadgil 2003, Rajeevan et al. 2012). The State-3 occurred more towards the second half of the season and could represent a winter regime with cooler temperatures, stronger surface northeasterly winds, and drier atmospheric conditions dominated by high-pressure areas over the southern peninsular India (Balachandran et al. 2006). 

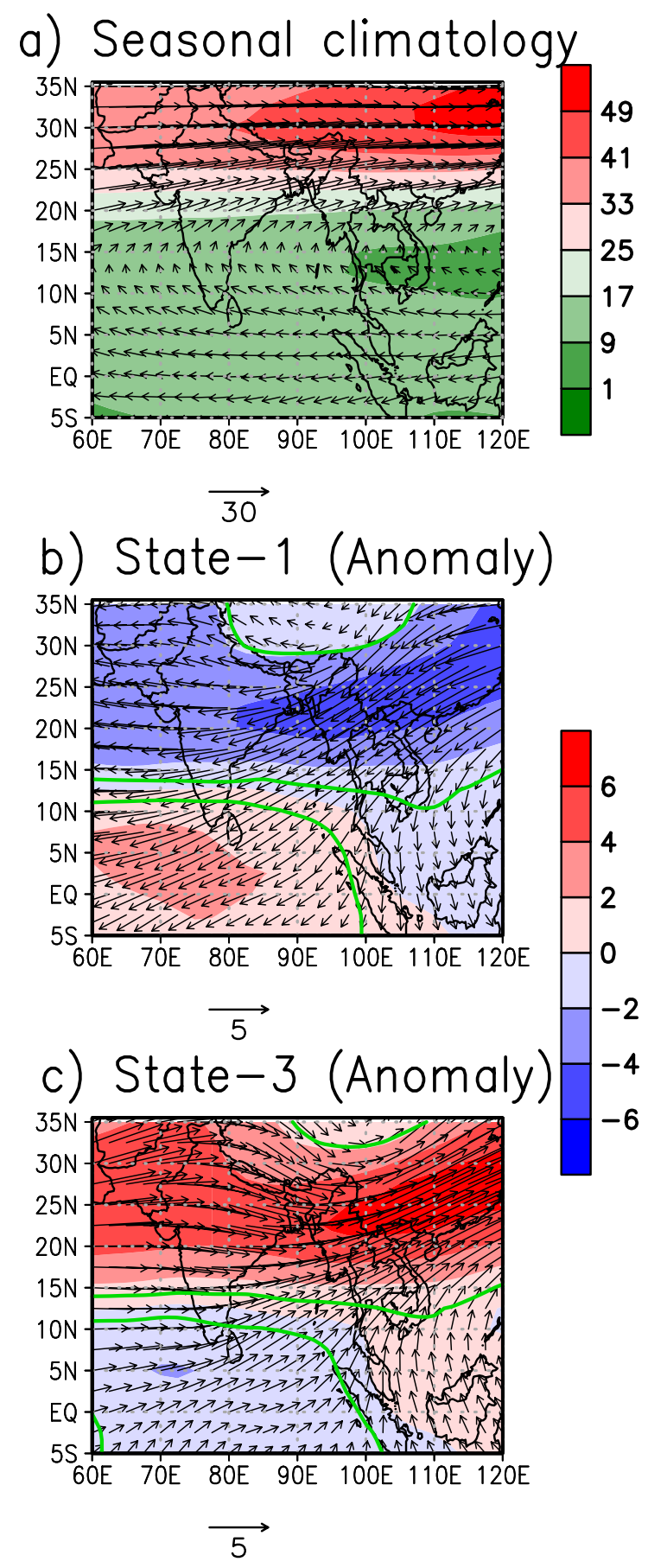

Figure 2.15 Wind velocity (shaded; $\mathrm{m} / \mathrm{s}$ ) and direction (vector; $\mathrm{m} / \mathrm{s}$ ) at the $200 \mathrm{hPa}$ level - (a) Seasonal climatology, and anomaly from the seasonal climatology of (b) State-1, (c) State-3. The green lines in (b) and (c) indicate the region significant at 95\% level. 
During the wet conditions (State-1), the southwesterly surface winds and lowerlevel cyclonic anomalies, consistent with positive vorticity anomalies, over the NEIMR region could bring moisture from the enhanced convergence regions over the Bay of Bengal and northern Indian Ocean. The positive vorticity during these wet conditions shifted northward from the seasonal climatology and the center of positive anomaly located over the southeastern peninsular India (see Figure 2.13(a) and (d)). The northward movement of cyclonic circulation during State-1 was consistent with the northward propagation of rainfall episodes during the NEIMR period (Rajeevan et al. 2012). These physical processes could result in the wet NEIMR condition observed over the southeastern peninsular of India. During dry conditions (State-3), the anomalies in surface winds were mostly northeasterly, flowing from land to the ocean. The lower level wind anomalies were mostly anticyclonic, which was confirmed by the negative vorticity values over the southern peninsular of India. These anticyclonic wind anomalies could drive the moisture away from the southern peninsular India to the oceanic regions. Also, the moisture convergence was suppressed over the Bay of Bengal and northern Indian Ocean (See Figure 2.14(f)). The explained physical processes could lie behind the drier NEIMR conditions over the Indian southeastern peninsular.

\subsection{Summary}

In this study, three distinct rainfall states during the NEIMR season were identified over the southeastern peninsular of India for the period 1982-2014. The State-1 and State3 conditions were the wet and dry conditions of NEIMR, respectively, over the entire southeastern peninsular. State-1 and State-3 were critical for the water requirements during the NEIMR season, as the seasonal rainfall quantity and distribution were predominantly determined by these two rainfall states. The increased frequency of State-1 significantly increased total seasonal NEIMR and the increased frequency of State-3 decreased NEIMR. State-2 led to the increased rain conditions confined to the thin coastal stretch of Tamil Nadu.

The atmospheric circulation and surface temperature variables observed during State-1 (wet) and State-3 (dry) conditions exhibited significantly opposite patterns. The 
atmospheric circulation and temperature conditions during State-2 did not show any significant patterns, nor deviated much from the seasonal climatology. From the observed atmospheric and surface conditions, a potential physical mechanism is proposed as contributing to the wet and drier conditions over southeastern India. The anomalous warmer (cooler) land temperature above $20^{\circ} \mathrm{N}$ could induce lower (higher) sea level pressure anomalies and thereby driving anomalous southwesterly (northeasterly) surface winds over the NEIMR region. These anomalous surface winds and the associated lowerlevel cyclonic (anticyclonic) circulations could enhance (suppress) moisture transport from the convergence regions over the Bay of Bengal and northern Indian Ocean into the southern peninsular of India. The proposed physical processes could result in the wet (dry) NEIMR condition over the southeastern peninsular India.

The rainfall states identified in this study might be useful for understanding the extreme NEIMR conditions (wet and dry rainfall states) over the southeastern peninsular of India. The identified atmospheric and surface conditions associated with the distinct rainfall states could be useful for understanding the physical drivers behind the intraseasonal characteristics of NEIMR. However, the physical mechanisms driving the atmospheric circulation and temperature conditions with respect to oceanic heat and moisture fluxes and atmospheric moisture transport processes were not investigated in this study, but will be carried out in future research. The knowledge derived from this study could lead the forecasting community to improve the northeast Indian monsoon forecasting at shorter time scales, by fine-tuning the driving synoptic variables. Further efforts on finding the relationships between rainfall states and the drivers at lagged time scales could improve the lead-time forecast of NEIMR. 


\section{Ocean and atmospheric conditions associated with NEIMR}

\subsection{Background}

NEIMR of the southeastern peninsular India during October to December is highly variable at inter-annual as well as intra-seasonal time scales (Rajeevan et al. 2009, Charlotte et al. 2013). Past studies highlighted the roles of surrounding oceans on modulating the inter-annual variations of NEIMR over the southeastern peninsular of India, which are significantly associated with the sea surface temperature (SST) over the Bay of Bengal region (e.g., Singh 1995, Kripalani and Kumar 2004, George et al. 2011, Charlotte et al. 2013) and the Indian Ocean region (e.g., Yadav 2013). For example, warmer SSTs in the western Bay of Bengal are associated with normal or above normal seasonal NEIMR over the southern peninsular, and the reversal of the above-mentioned conditions reduced the seasonal NEIMR (Singh 1995, George et al. 2011, Raj 2012). Previous studies on NEIMR were heavily focused on the role of the Bay of Bengal forcing the inter-annual variation of NEIMR, while the intra-seasonal rainfall conditions, considering both of the Indian Ocean as well as the Bay of Bengal, have been seldom studied.

The ocean and atmosphere interactions observed in the low-latitude regions could be related to either oceanic forcing of the atmosphere or the atmospheric forcing of the ocean (Wu et al. 2005). The positive anomalies of latent heat flux (LHF) followed by the positive anomalies of SSTs during the active Southwest Indian monsoon season of June through September over the Indian Ocean could be an example of the ocean forcing of the atmosphere (Wu and Kirtman 2006). On the other hand, the positive SST anomalies negatively correlated with LHF anomalies would be the dominant role of atmospheric forcing on the ocean (Wu et al. 2005). The rate of evaporation over the ocean is highly dependent on the atmospheric moisture demand and also the lower-level winds (Wu and Kirtman et al. 2007, Novick et al. 2016). The atmospheric demand can control evaporation from the ocean surface where the increased demand of atmospheric moisture enhances the evaporation and the lower moisture demand suppresses the evaporation (Novick et al. 2016). The winds over the ocean surface could also play a role in altering the association between SST and LHF during the active monsoon period (Zhou et al. 
2015). The positive feedback between winds and evaporation was observed in the eastern equatorial Indian Ocean (Wang et al. 2003, Wu and Kirtman 2007). The oceanic and atmospheric conditions over the surrounding oceans of the southern peninsular of India with respect to the intra-seasonal NEIMR have been relatively less studied, although investigating these aspects would help identify the ocean-atmospheric processes driving the moisture sources of NEIMR.

The atmospheric moisture transport processes are important for convective activities over the landmasses in the monsoon regions (Mo et al. 2005, Lele et al. 2015). The vertically integrated atmospheric moisture flux convergence and moisture transport vectors were investigated to examine the moisture transport mechanisms associated with the heavier rainfall episodes over the Southwest Indian (Li et al., 2015), Southwest United States (Wei et al. 2015) and West African (Lele et al. 2015) monsoon regions. Similarly, Li et al. (2007) and Fujinami et al. (2014) used atmospheric moisture convergence to investigate the relationship between atmospheric moisture transport and rainfall over Northeast China and Southeast Asia, respectively. The storms and depressions over the Bay of Bengal can induce heavy rains that substantially contribute to the seasonal total NEIMR (Srinivasan and Ramamurthy 1974, Raj 2012). On average, two to three cyclonic storms made landfall annually over the eastern coast of peninsular India during the NEIMR season between 1960 to 2010 (Raj 2012). During El Nino years, the greater number of cyclones that developed in the North Indian Ocean progressed over the Bay of Bengal to make landfall over the southeastern peninsular of India (Kumar 2007, Yadav 2013). The easterly wave over the southern peninsular and the Bay of Bengal might also contribute favorable conditions for NEIMR (Raj 2012, Prakash and Goirala 2013). Some studies indicate that the cyclonic activities and the easterly waves from the Bay of Bengal and the Indian Ocean could be the potential "moisture transport medium" for the inter-annual NEIMR variations (Prasanna and Yasunari 2008, Raj 2012, Lekshmy et al. 2015). It is necessary to explore the atmospheric processes in transporting moisture from the neighboring oceans to the land, associated with the intra-seasonal variations of NEIMR, over the monsoon dominated region (Prasanna and Yasunari 2008. To overcome the research gap, this study investigated oceanic and atmospheric conditions over the Bay of Bengal and the Indian Ocean regions, associated with wet 
NEIMR conditions over the southeastern peninsular of India, and identified the potential moisture transport processes.

\subsection{Data and Methods}

The daily time series of rainfall data were calculated by taking an average over the southeastern peninsular India of $77.5-80.25^{\circ} \mathrm{E}$ and $8-16^{\circ} \mathrm{N}$ (Figure 3.3) from the India Meteorological Department's gridded rainfall data with a spatial resolution of $0.25^{\circ}$ by $0.25^{\circ}$ (Rajeevan et al. 2006). The daily time series were converted into pentad time series, 73 pentads/year and 2,190 pentads for the thirty-year period of 1985-2014. The oceanic and atmospheric variables were obtained from two different reanalysis data sets at daily time scale for the study period: Woods Hole Oceanographic Institution (WHOI) OAFlux project data of $1^{\circ}$ by $1^{\circ}$ resolution ( $\mathrm{Yu}$ et al. 2008) and National Center for Environment Protection (NCEP) Reanalysis-1 data of $2.5^{\circ}$ by $2.5^{\circ}$ resolution (Kanamitsu et al. 2002). The SST and LHF variables from WHOI OA Flux data were also utilized. The specific humidity, and zonal ( $u$-wind) and meridional ( $v$-wind) winds from surface to $300 \mathrm{hPa}$ levels were used from the NCEP Reanalysis-1. The gridded WHOI OA Flux and NCEP Reanalysis-1 data sets at daily time steps were converted to pentad time steps for the period 1985-2014. The vorticity was calculated using $u$ - and $v$-winds at each atmospheric pressure level from 1000 to $300 \mathrm{hPa}$ (Sikka and Gadgil 1978).

As the NEIMR time series data exhibited non-uniform distributions ( $p$ value of Kolmogorov-Smirnov test was less than 0.01 , which rejected the null hypothesis that the NEIMR variables are normally distributed), the non-parametric Spearman correlation analysis was used (Von and Zweirs 2001, Wilks 2011) to identify the relationships of NEIMR over the southeastern peninsular with SST and LHF over the surrounding oceans. The pentad rainfall time series consisted of 18 pentads for every year, averaged for every 5 days during $3^{\text {rd }}$ October to $31^{\text {st }}$ December, making a total of 540 pentads for the 30 years 1985-2014. The time series of oceanic and atmospheric variables consisted of 22 pentads for every year, averaged for every five days from $13^{\text {th }}$ September to $31^{\text {st }}$ December, including lags up to four pentads, and thus 660 pentads for 30 years. Lags up 
to four lags were considered as further lags exhibited weaker correlations between oceanic and atmospheric variables with NEIMR (not shown here). The correlation analysis between the time series of the NEIMR averaged over the southeastern peninsular India with the gridded SST and LHF (one variable at a time) was performed for the same time step. To examine the lagged associations, the correlation analysis was repeated for time step $t$ of NEIMR and the lagged time step $t-1, t-2, t-3$, and $t-4$ of SST and LHF. The pentad time series of SST and LHF averaged over the identified oceanic regions where the heat and moisture variables significantly correlated with NEIMR were examined and the simultaneous and lagged correlations between the two time series of NEIMR (time step $t$ ) and SST or LHF (time step $t, t-1, t-2, t-3$, and $t-4$ ) were generated.

To confirm the associations shown in the results of correlation analysis, a composite analysis was used by calculating the deviations in the SST and LHF during the wet NEIMR pentads, which were defined with rainfall amount that exceeds $90^{\text {th }}$ percentile, from the average of all the pentads during the months of October to December (i.e., seasonal climatology) for the period 1985-2014 (Von and Zweirs 2001). The composite differences were calculated for the oceanic and atmospheric variables between the wet NEIMR pentads and the seasonal climatology at the same time $(t)$ and lagged time steps $(t-1, t-2, t-3$, and $t-4)$. A student's $t$-test was performed on the results of the composite analyses to identify the significantly different regions at the $95 \%$ level.

Over the significant oceanic regions for NEIMR, identified from the correlation and composite analysis, the atmospheric moisture demand and winds were examined to explore their roles in controlling evaporation over the ocean during the same and lagged time steps of wet NEIMR pentads. The zonal and meridional moisture fluxes were calculated by multiplying the specific humidity by $u$ - and $v$-winds at each pressure level from surface to $300 \mathrm{hPa}$ (Banacos and Schultz 2005). The moisture convergence and moisture transport vectors at each atmospheric level from surface to $300 \mathrm{hPa}$ during the same or lagged time steps of wet NEIMR pentads were investigated to identify the level that has strong convergence and divergence and also the moisture transporting wind patterns. Based on the composite differences of moisture convergence and moisture 
transport vectors, appropriate atmospheric pressure levels were identified for calculating the vertically integrated moisture flux (VIMF). The VIMF was derived from surface to the identified atmospheric pressure level for each grid location over the significant oceanic regions for NEIMR (Lele et al. 2015, Wei et al. 2015). The zonal and meridional fluxes of water vapor were calculated by vertical integration, using the following equations (1) and (2) (Lele et al. 2015):

$$
\begin{aligned}
& \overline{Q_{\lambda}}=\frac{1}{g} \int_{P_{u}}^{P_{s}} \overline{q u} d p \\
& \overline{Q_{\varnothing}}=\frac{1}{g} \int_{P_{v}}^{P_{s}} \overline{q v} d p
\end{aligned}
$$

Where $u$ is zonal wind, $v$ is meridional wind, $q$ is specific humidity, $P s$ is surface air pressure, $Q_{\lambda}$ is the zonal component and $Q_{\varnothing}$ is the meridional component of the vertically integrated total mean moisture flux (i.e., VIMF). The variable $g$ is the gravitational acceleration. The value of $g$ is $9.81 \mathrm{~ms}^{-2}$, so the units for $Q_{\lambda}$ and $Q_{\varnothing}$ are $\mathrm{kg}$ $\mathrm{m}^{-1} \mathrm{~s}^{-1}$.I plotted moisture transport vector using the zonal and meridional components of $Q_{\lambda}$ and $Q_{\varnothing}$ for visual investigation. The composite analysis of vorticity, VIMF convergence, and VIMF transport vectors were used to explain the moisture transport processes, associated with wet NEIMR conditions. 


\subsection{Results}

\subsubsection{Oceanic conditions for NEIMR}

The spatial patterns of the non-parametric correlation coefficient of the simultaneous and lagged pentads of SSTs (averaged over the surrounding oceans) with the time series of NEIMR (averaged over the southeastern peninsular India) are shown in Figure 3.1. The significant positive correlations are seen in the SST over the Bay of Bengal during the same and all the lag-1 to -4 pentads. The significant positive correlations were also observed in the equatorial western Indian Ocean during the lag-2, -3 , and -4 pentads (Figure 3.1(c), (d), (e)). The LHF over the Bay of Bengal region was significantly and negatively correlated with the NEIMR time series during the same and all the lag pentads (Figure 3.2). Over the equatorial western Indian Ocean, the LHF was positively correlated with NEIMR and the significant correlations were observed during the same and lag-1 and -2 pentads (Figure 3.2(a), (b), (c)). The correlation values between the time series of averaged NEIMR and the time series of SST and LHF, averaged over the significantly correlated regions of the Bay of Bengal $\left(80-95^{\circ} \mathrm{E}\right.$ and $\left.8-19^{\circ} \mathrm{N}\right)$ and the equatorial western Indian Ocean $\left(56-76^{\circ} \mathrm{E}\right.$ and $\left.3^{\circ} \mathrm{S}-5^{\circ} \mathrm{N}\right)$ regions (Figure 3.3), are shown in Table-3.1. The SST correlations with NEIMR were statistically significant over the Bay of Bengal region $(+0.35$ to +0.48 , all $p$-values $<0.01)$ and the equatorial western Indian Ocean region $(+0.15$ to +0.26 , all $p$-values $<0.01)$ during the same and all the lagged pentads. The negative correlations of NEIMR with LHF over the Bay of Bengal region $(-0.36$ to -0.39 , all $p$-values $<0.01)$ were significant during all the time steps. The positive correlations of LHF and NEIMR were statistically significant over the equatorial western Indian Ocean during all the time steps $(+0.13$ to +0.35 , all $p$-values $<0.01)$, except during the lag-4 pentad. 
(a) Same pentad

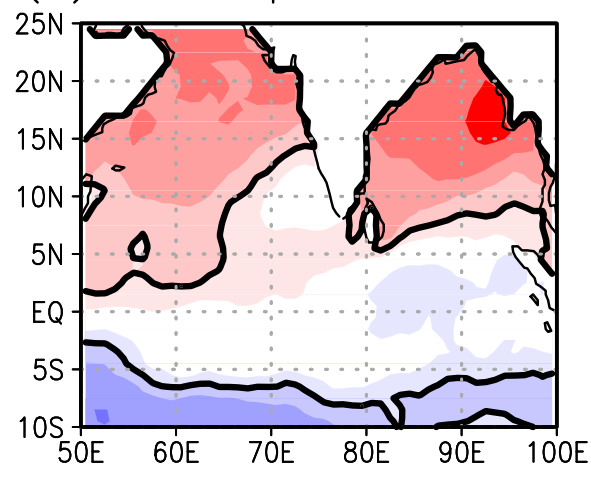

(b) Lag 1 pentad

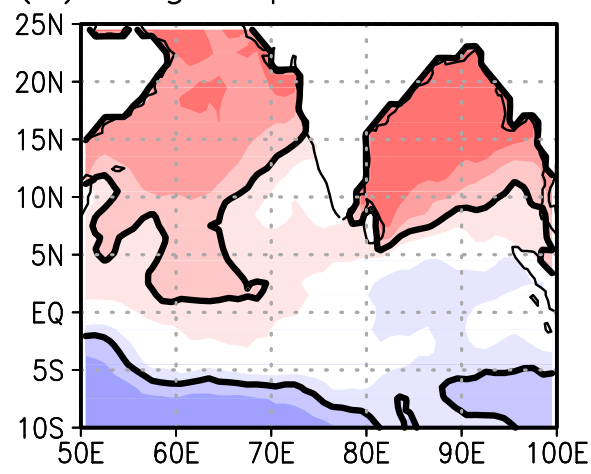

(c) Lag 2 pentad

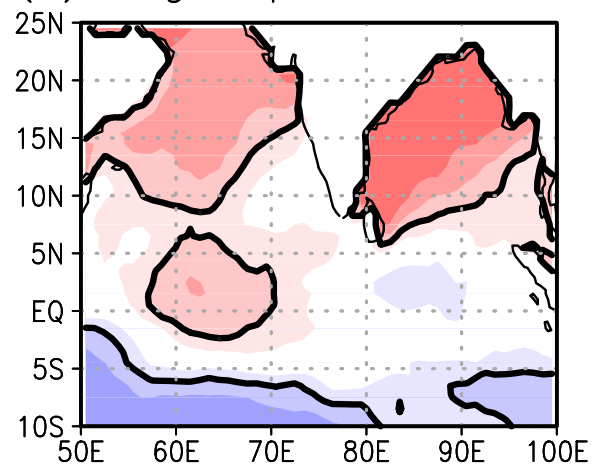

(d) Lag 3 pentad

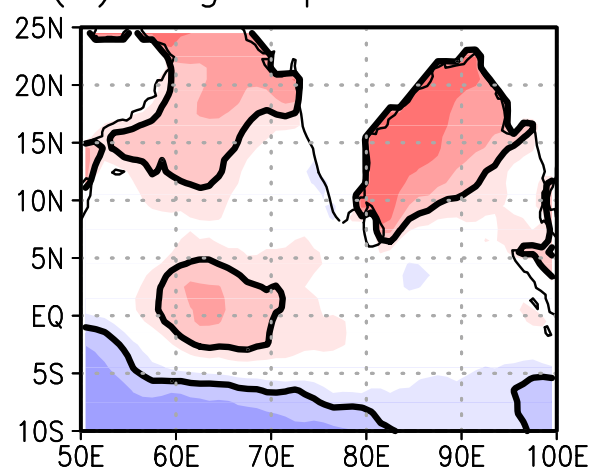

(e) Lag 4 pentad

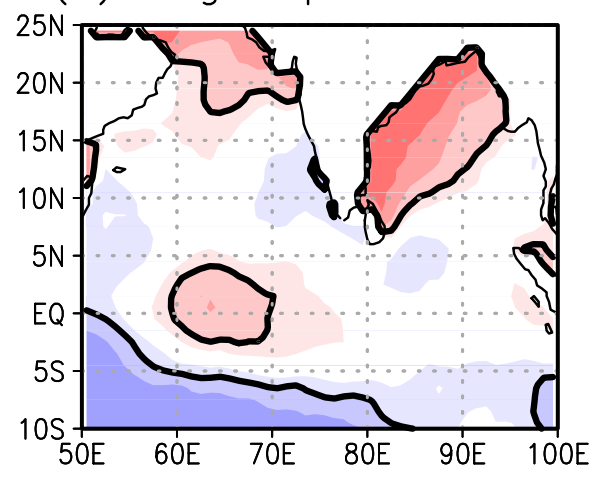

0.5

0.4

0.3

0.2

0.1

$-0.1$

$-0.2$

$-0.3$

$-0.4$

Figure 3.1 The spearman correlation coefficients between NEIMR (t) and SSTs of the simultaneous (t) and the lagged pentads at the (b) lag-1 (t-1), (c) lag-2 (t-2), (d) lag-3 (t3), and (e) lag-4 (t-4) pentads during the months of Oct-Dec for the period 1985 to 2014.

The thick black lines indicate the significant regions at the 95\% confidence level. 
(a) Same pentad

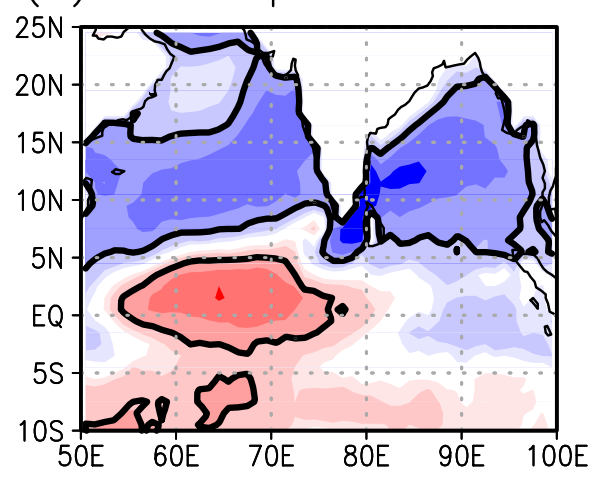

(b) Lag 1 pentad

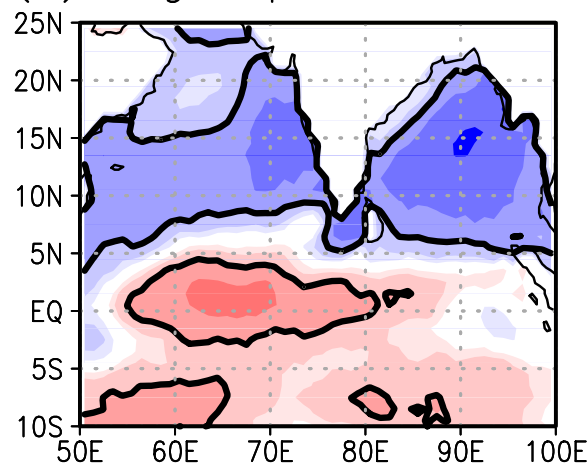

(c) Lag 2 pentad

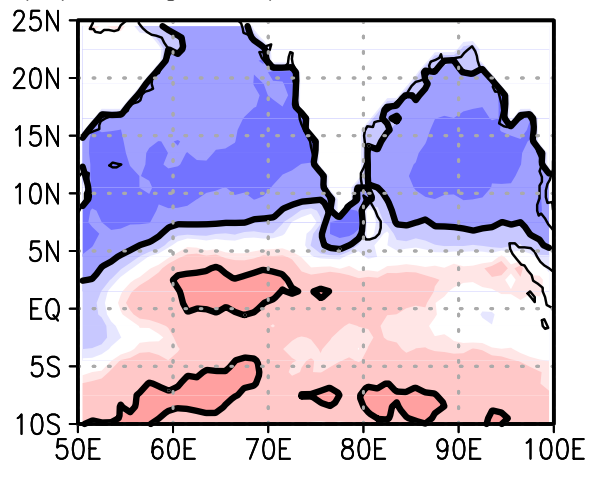

(d) Lag 3 pentad

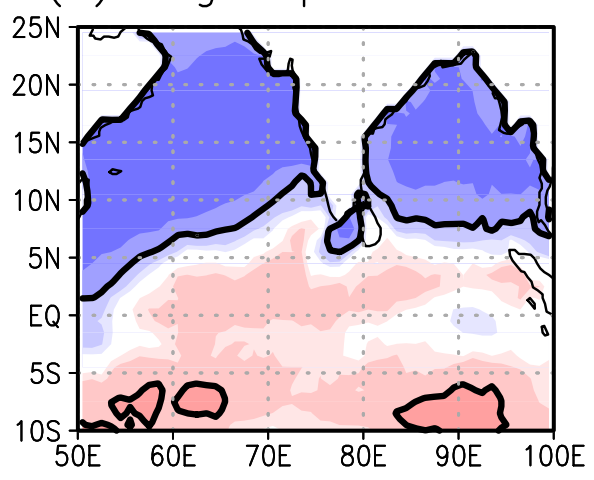

(e) Lag 4 pentad

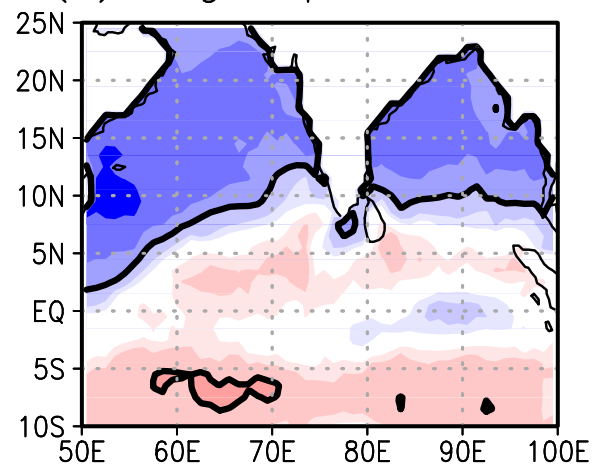

0.4

0.3

0.2

0.1

$-0.05$

$-0.05$

$-0.1$

$-0.2$

$-0.3$

$-0.4$

Figure 3.2 The spearman correlation coefficients between NEIMR (t) and latent heat flux of the simultaneous ( $\mathrm{t}$ ) and the lagged pentads at the (b) lag-1 (t-1), (c) lag-2 ( $\mathrm{t}-2),(\mathrm{d})$ lag-3 (t-3), and (e) lag-4 (t-4) pentads during the months of Oct-Dec for the period 1985 to 2014. The thick black lines indicate the significant regions at the 95\% confidence level. 


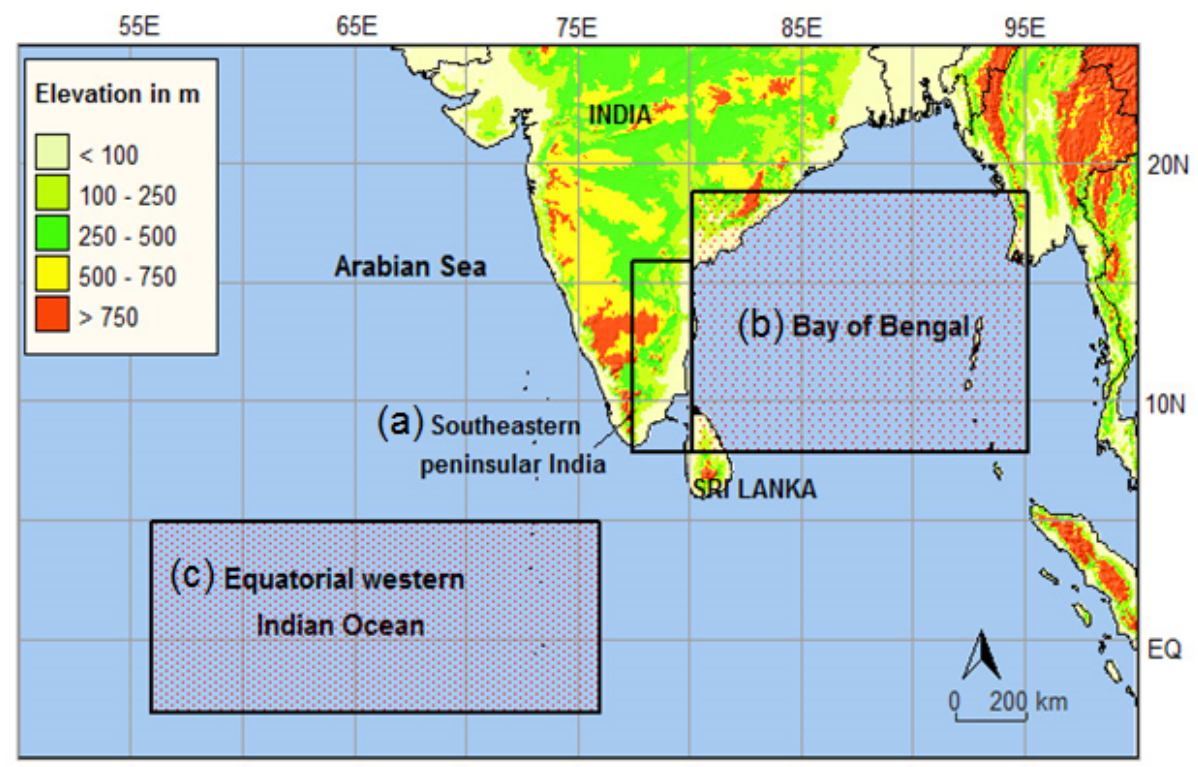

Figure 3.3 Geographical extent of the (a) southeastern peninsular India, (b) Bay of Bengal, and (c) equatorial western Indian Ocean.

Table 3.1 Spearman correlation coefficient of NEIMR, averaged over the southeastern India $\left(77.5^{\circ}\right.$ to $80.25^{\circ} \mathrm{E}, 8^{\circ}$ to $16^{\circ} \mathrm{N}$ ), with SST and LHF (simultaneous and lagged time steps), averaged over the Bay of Bengal $\left(80^{\circ}\right.$ to $95^{\circ} \mathrm{E}, 8^{\circ}$ to $\left.19^{\circ} \mathrm{N}\right)$ and equatorial western Indian Ocean $\left(56^{\circ}\right.$ to $76^{\circ} \mathrm{E}, 3^{\circ} \mathrm{S}$ to $\left.5^{\circ} \mathrm{N}\right)$ regions during the months of Oct-Dec for the period 1985 to 2014. All the correlation coefficient values are significant at the $99 \%$ level ( $p$ value $<0.01)$, except the value of lag-4 LHF over the equatorial western Indian Ocean ( $p$ value $<0.1)$.

\begin{tabular}{|r|r|r|}
\hline & SST & \multicolumn{2}{|c|}{ LHF } \\
\hline Bay of Bengal region & & -0.37 \\
\hline Same pentad & 0.47 & -0.38 \\
\hline Lag-1 & 0.48 & -0.36 \\
\hline Lag-2 & 0.47 & -0.39 \\
\hline Lag-3 & 0.43 & -0.39 \\
\hline Lag-4 & 0.35 & \\
\hline & & \\
\hline $\begin{array}{l}\text { Equatorial western Indian } \\
\text { Ocean region }\end{array}$ & & 0.35 \\
\hline Same pentad & 0.21 & 0.30 \\
\hline Lag-1 & 0.25 & 0.20 \\
\hline Lag-2 & 0.26 & 0.13 \\
\hline Lag-3 & 0.21 & 0.08 \\
\hline Lag-4 & & \\
\hline
\end{tabular}


The deviation (anomaly) of SST and LHF during the wet NEIMR pentads from the seasonal climatology are shown in Figures 3.4 and 3.5. The increased SST anomaly ( $>$ $0.3{ }^{\circ} \mathrm{C}$ ) is seen over the Bay of Bengal during the same and lagged time steps (1 to 4) of wet NEIMR pentads (Figure 3.4). Over the equatorial western Indian Ocean, the increased SST anomaly (up to $0.3{ }^{\circ} \mathrm{C}$ ) is prominent during the lag-3 and -4 pentads (Figure 3.4(d), (e)) and moderate $\left(0\right.$ to $0.2{ }^{\circ} \mathrm{C}$ ) during the lag-2 pentad (Figure 3.4(c)) . The deviation in the LHF significantly decreased over the Bay of Bengal during the same and all the lagged pentads (by lower than $-20 \mathrm{Wm}^{-2}$ during lag-2, -3 and -4 pentads) (Figure 3.5(c), (d), (e)). Over the equatorial western Indian Ocean, the LHF anomaly was significantly increased up to $20 \mathrm{Wm}^{-2}$ and above during the same pentad, and it also increased by $12 \mathrm{Wm}^{-2}$ and above during the lag-1 and -2 pentads (Figure 3.5(a), (b), (c)).

The role of the Arabian Sea in affecting monsoon rainfall in the southeastern peninsular India is considered as relatively less significant, compared to the Bay of Bengal and the Indian Ocean, because the Western Ghats act as a physical barrier to the moisture from the Arabian Sea entering into the southeastern peninsular of India (Gunnell 1997, see Figure 3.3). Considering the geographical locations of southeastern India, the oceanic and atmospheric conditions over the Bay of Bengal and the equatorial western Indian Ocean, which were significantly associated with NEIMR were examined. 

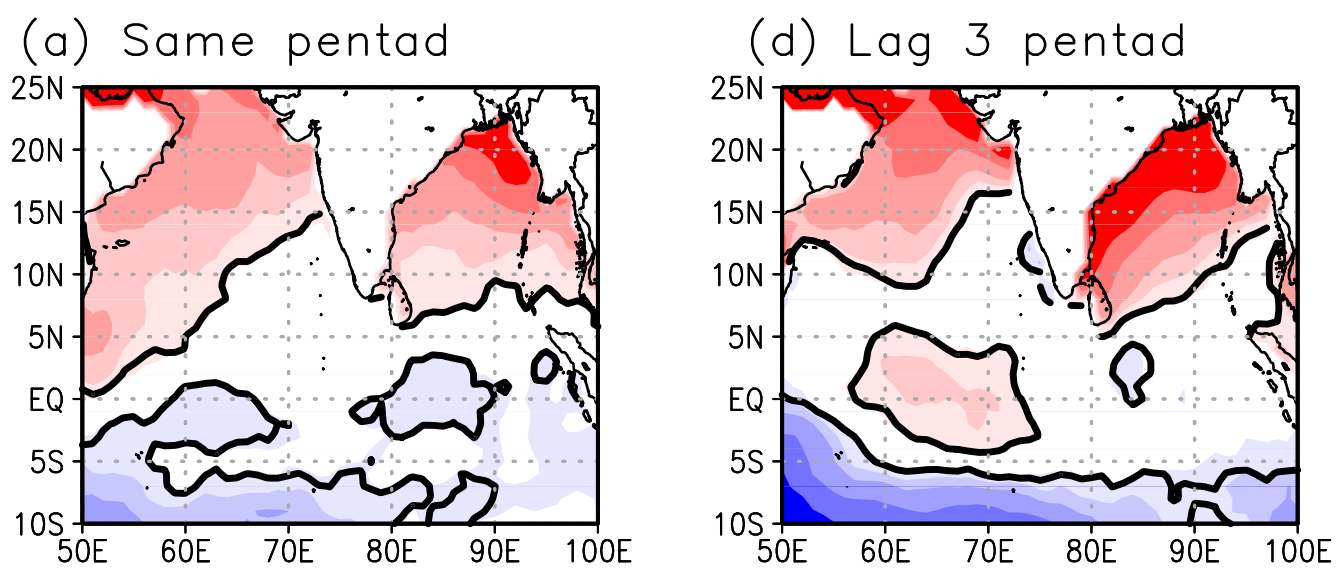

(b) Lag 1 pentad
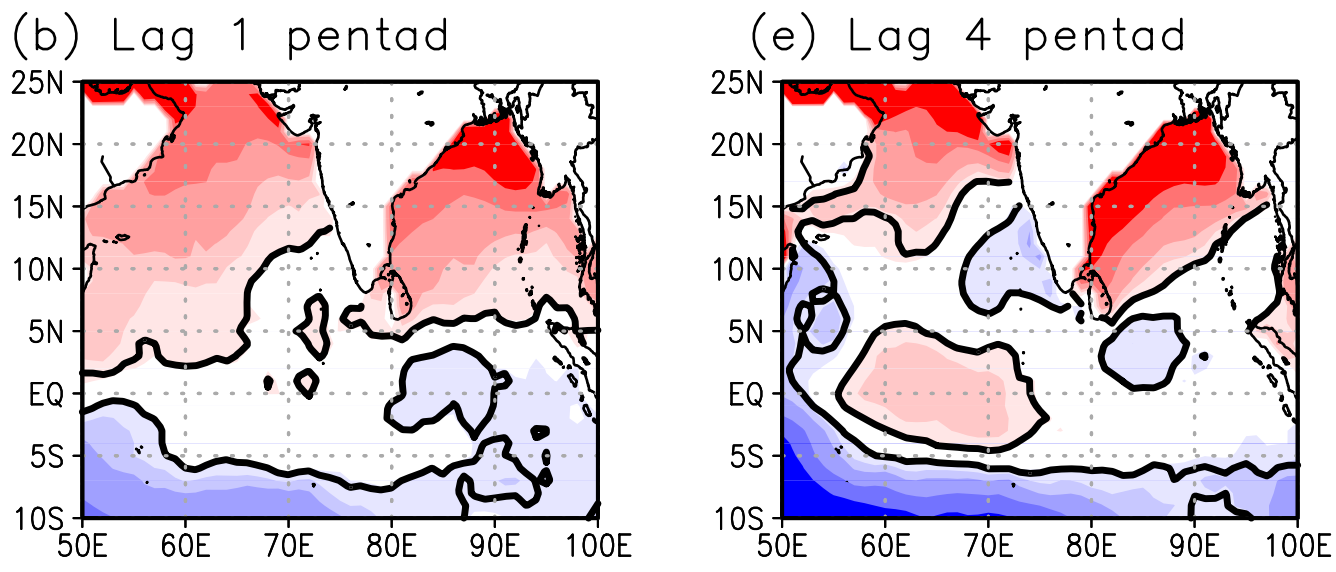

(c) Lag 2 pentad

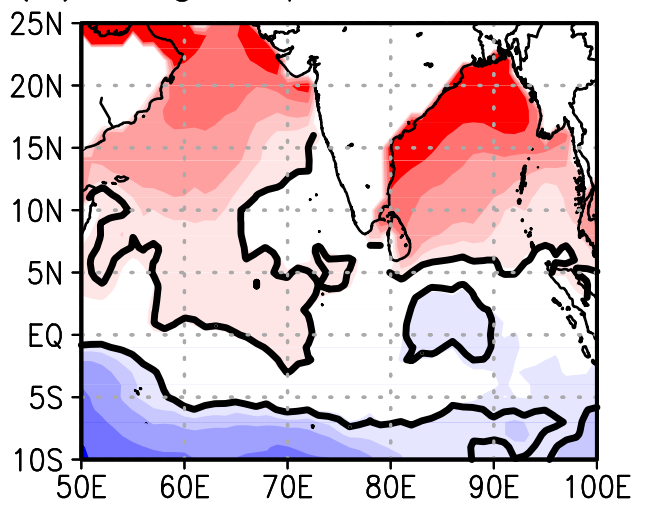

0.3

0.2

0.1

$-0.1$

$-0.2$

$-0.3$

$-0.5$

$-0.7$

Figure 3.4 Composite differences of SSTs $\left({ }^{\circ} \mathrm{C}\right)$ at (a) the simultaneous pentad and the lagged pentads of (b) lag-1, (c) lag-2, (d) lag-3, and (e) lag-4 between the wet NEIMR conditions (pentads exceeding $90^{\text {th }}$ percentile) and the seasonal climatology during the months of Oct-Dec for the period 1985-2014. The thick black lines indicate the significant regions at the $95 \%$ level. 
(a) Same pentad

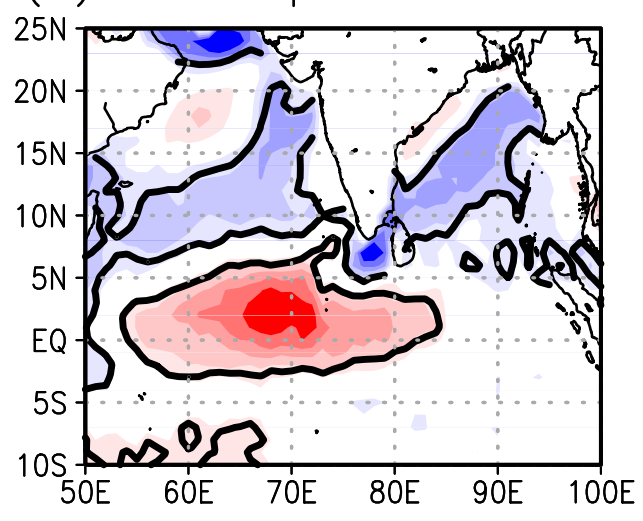

(b) Lag 1 pentad

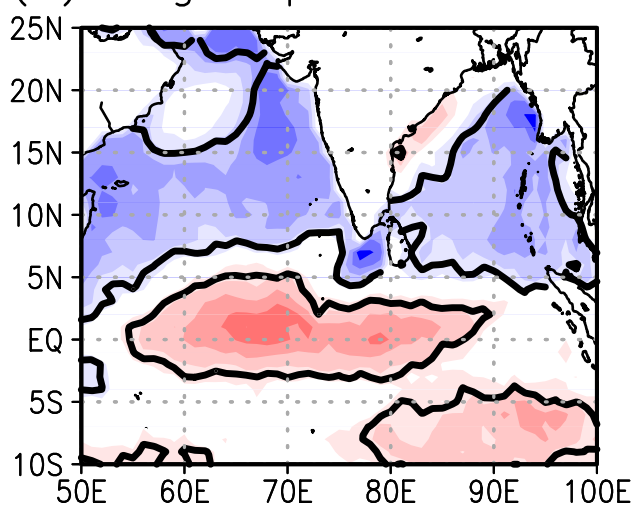

(c) Lag 2 pentad

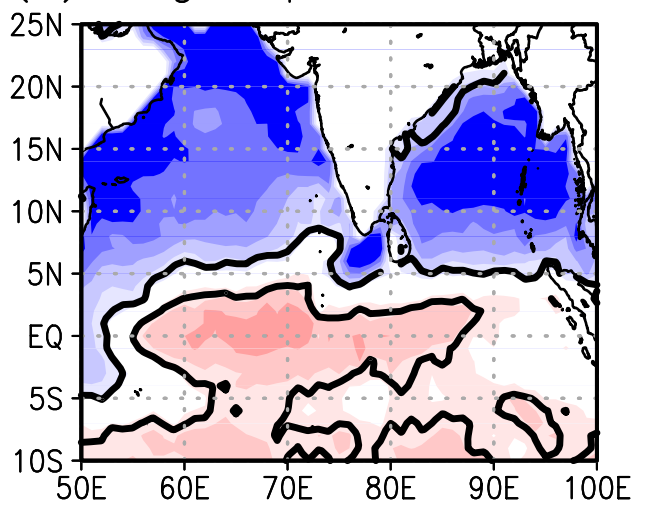

(d) Lag 3 pentad

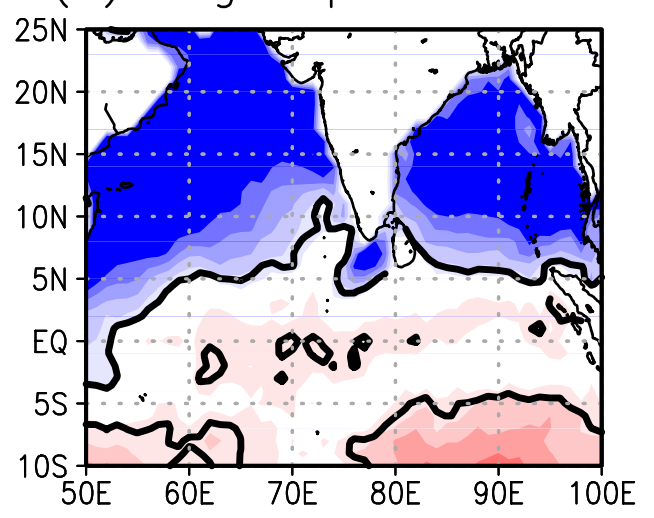

(e) Lag 4 pentad
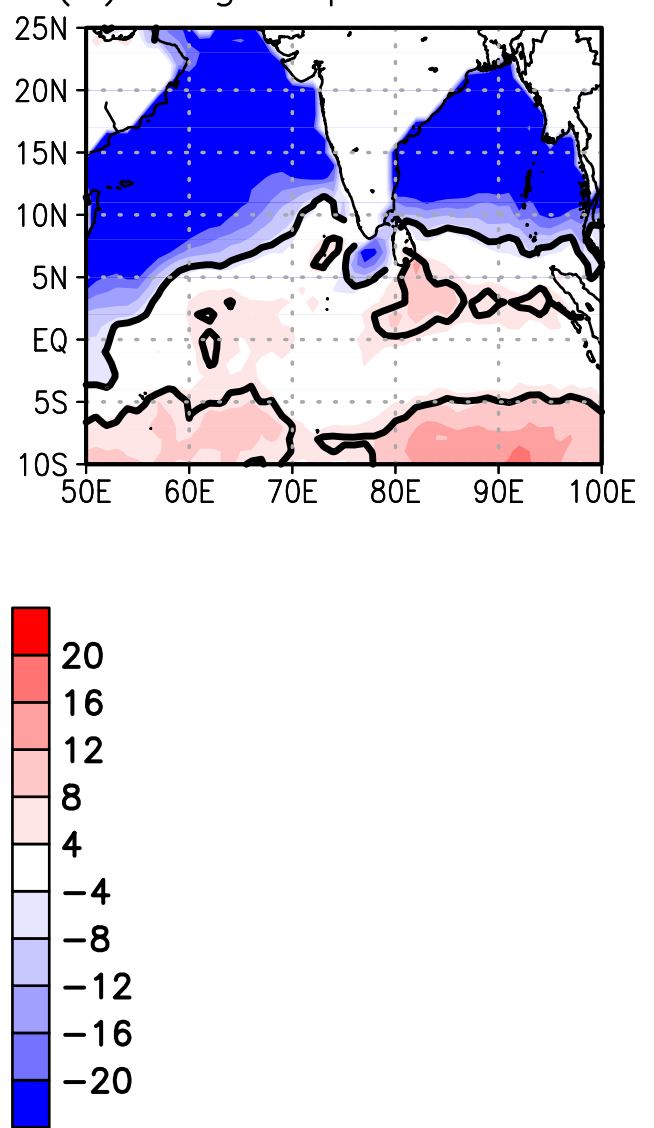

Figure 3.5 Composite differences of latent heat flux $\left(\mathrm{Wm}^{-2}\right)$ at (a) the simultaneous pentad and the lagged pentads of (b) lag-1, (c) lag-2, (d) lag-3, and (e) lag-4 between the wet NEIMR conditions (pentads exceeding $90^{\text {th }}$ percentile) and the seasonal climatology during the months of Oct-Dec for the period 1985-2014. The thick black lines indicate the significant regions at the $95 \%$ level. 


\subsubsection{Atmospheric conditions for NEIMR}

The vertical cross-section of the specific humidity anomaly over the equatorial western Indian Ocean, associated with the wet NEIMR pentads, showed significantly decreased specific humidity in the lower atmosphere up to $850 \mathrm{hPa}$ during the lag-2, -3 and -4 pentads (Figure 3.6(b)). In contrast, the specific humidity over the Bay of Bengal was significantly increased in the entire troposphere during all the time steps (Figure 3.6(a)). The spatial patterns of specific humidity anomalies, averaged over the lower levels at 1000, 900, and $850 \mathrm{hPa}$, indicate that the averaged specific humidity anomaly of the wet NEIMR pentads from the seasonal climatology was significantly lower $(<-3 \mathrm{x}$ $10^{4} \mathrm{~kg} / \mathrm{kg}$ ) over the equatorial western Indian Ocean during the lag-2, -3 and -4 pentads (Figure 3.7(c), (d), (e)). On the other hand, the specific humidity anomaly over the Bay of Bengal and southern India was significantly higher $\left(>3 \times 10^{4} \mathrm{~kg} / \mathrm{kg}\right)$ during the same and all the lagged pentads (Figure 3.7). The lower level wind anomaly, averaged over 1000, 900, and $850 \mathrm{hPa}$ levels, of the wet NEIMR conditions was significantly stronger over the equatorial western Indian Ocean during the same pentad (Figure 3.8(a)), which was the period when the largest LHF increase was observed over the Indian Ocean (see Figure 3.5(a)). The averaged lower-level winds also showed increased anomaly during the lag-1 pentad over the equatorial western Indian Ocean (Figure 3.8(b)), but this was not as strong as the same pentad. However, the magnitude of winds over the southern Bay of Bengal showed a significantly decreased anomaly during the lag-1, -2 , and -3 pentads. 


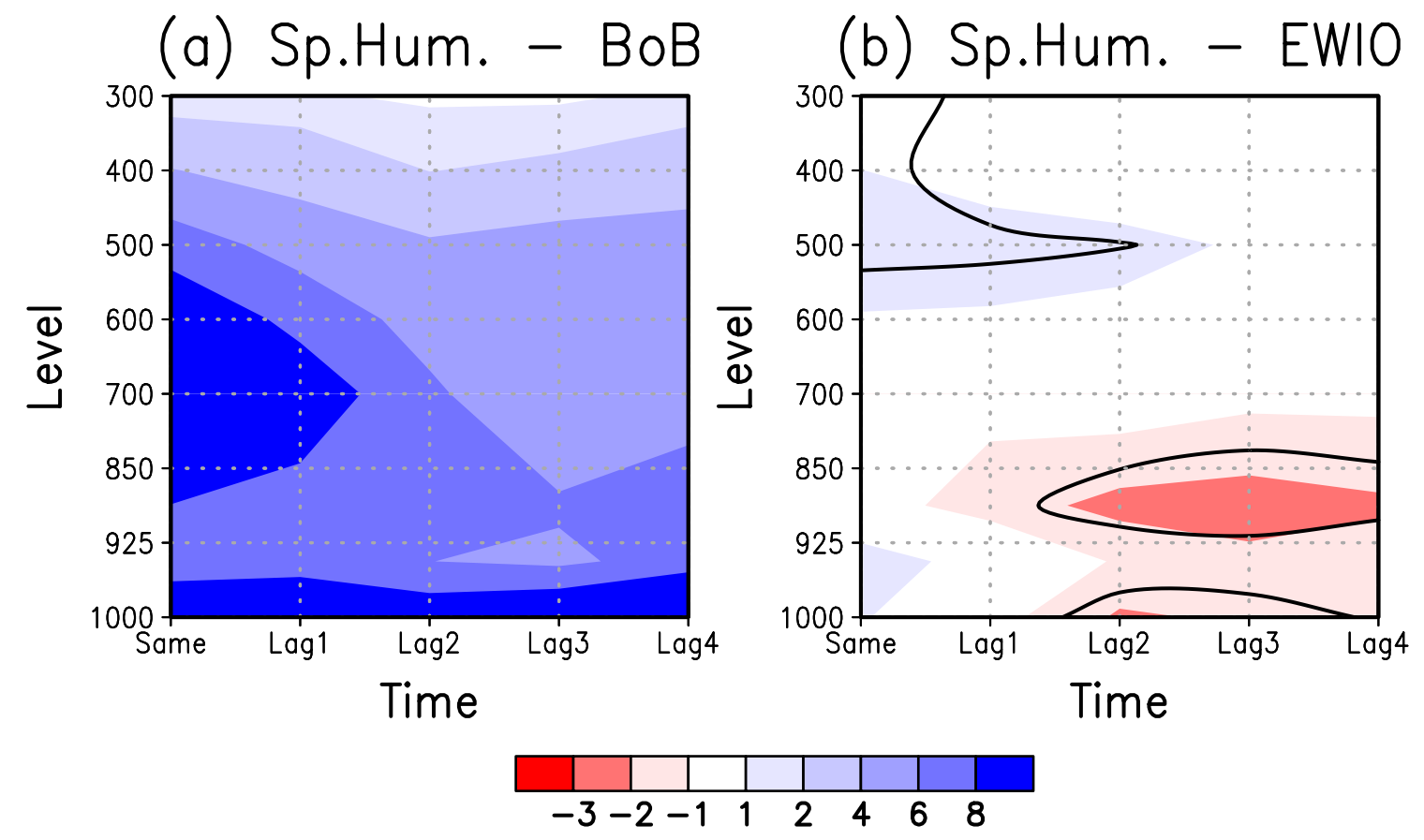

Figure 3.6 Vertical cross sections of composite differences of specific humidity $\left(10^{4}\right.$ $\mathrm{kg} / \mathrm{kg}$ ) at the simultaneous and lagged pentads between the wet NEIMR conditions and the seasonal climatology during the months of Oct-Dec for the period 1985 to 2014 over the (a) Bay of Bengal $\left(80^{\circ}\right.$ to $95^{\circ} \mathrm{E}, 8^{\circ}$ to $\left.19^{\circ} \mathrm{N}\right)$ and (b) equatorial western Indian Ocean $\left(56^{\circ}\right.$ to $76^{\circ} \mathrm{E}, 3^{\circ} \mathrm{S}$ to $\left.5^{\circ} \mathrm{N}\right)$ regions. The thick lines in (b) indicate the significant regions at the $95 \%$ level. The entire region in (a) is significant at the 95\% level. 
(a) Same pentad

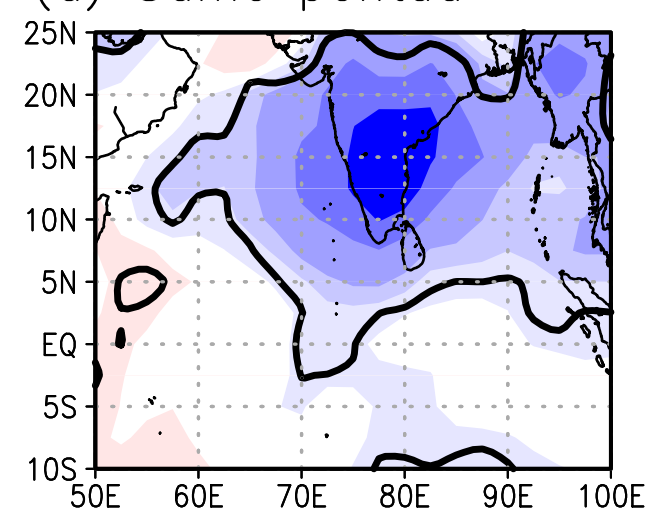

(b) Lag 1 pentad

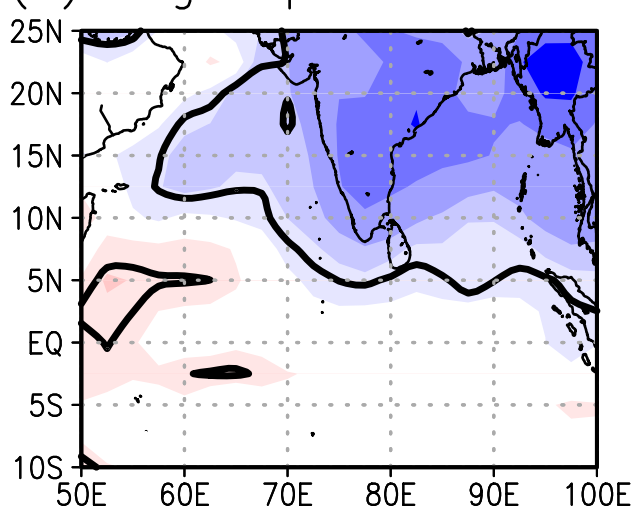

(c) Lag 2 pentad

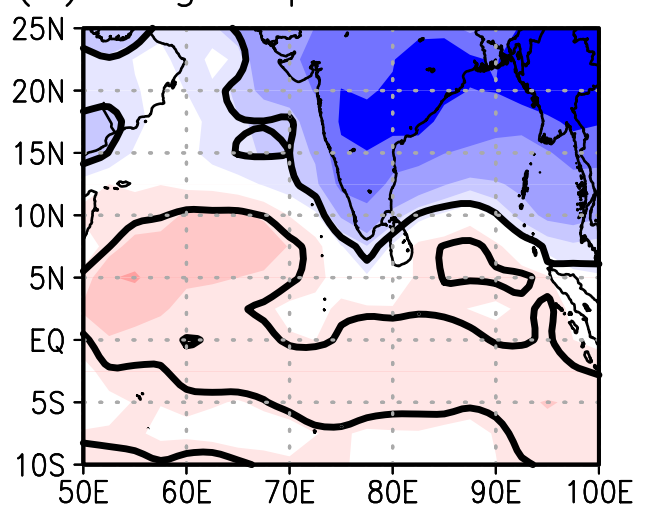

(d) Lag 3 pentad

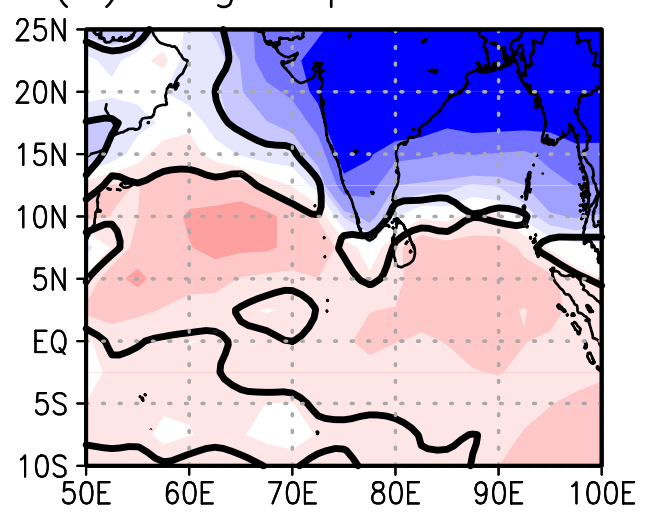

(e) Lag 4 pentad

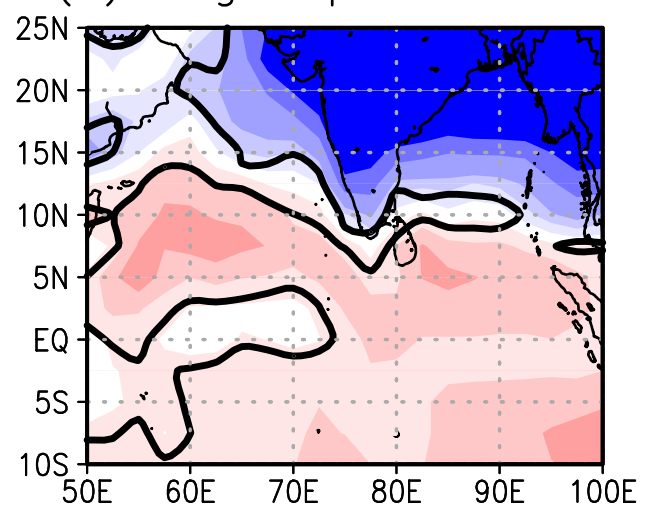

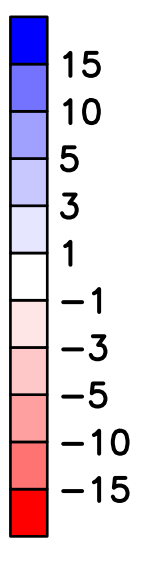

Figure 3.7 Composite differences of specific humidity $\left(10^{4} \mathrm{~kg} / \mathrm{kg}\right)$ averaged over 1000, 925, and $850 \mathrm{hPa}$. at (a) the simultaneous pentad and the lagged pentads of (b) lag-1, (c) lag-2, (d) lag-3, and (e) lag-4 between the wet NEIMR conditions (pentads exceeding $90^{\text {th }}$ percentile) and the seasonal climatology during the months of Oct-Dec for the period 1985-2014. The thick black lines indicate the significant regions at the 95\% level. 
(a) Same pentad

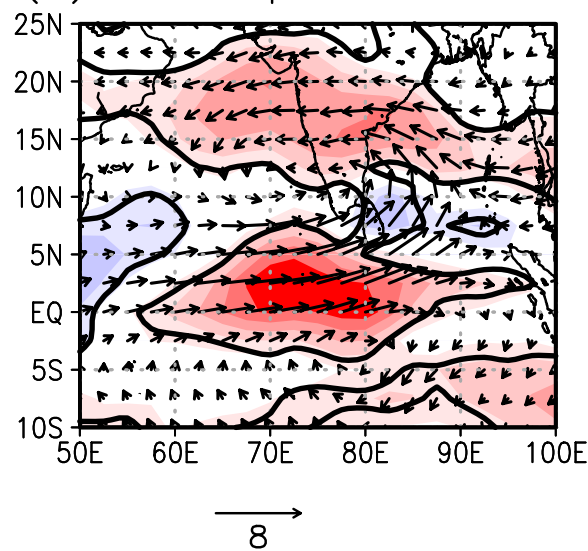

(b) Lag 1 pentad

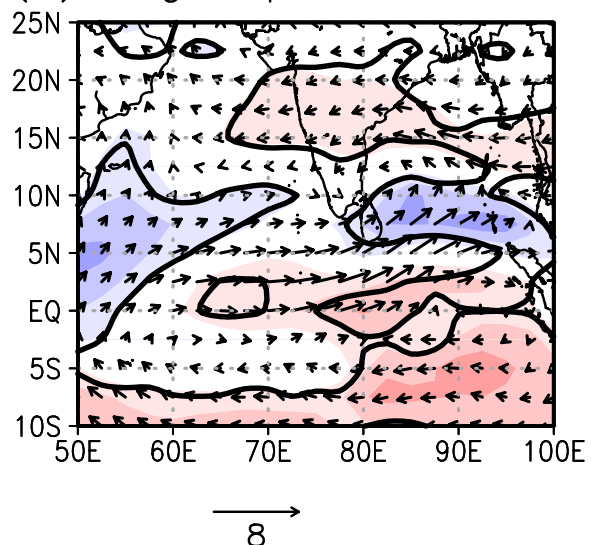

(c) Lag 2 pentad

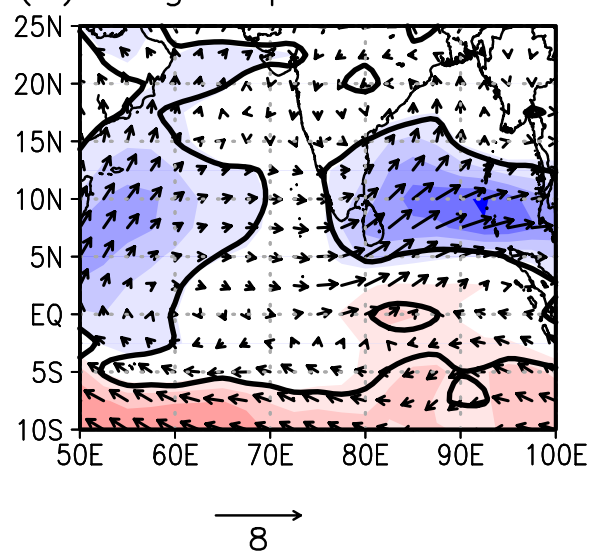

(d) Lag 3 pentad

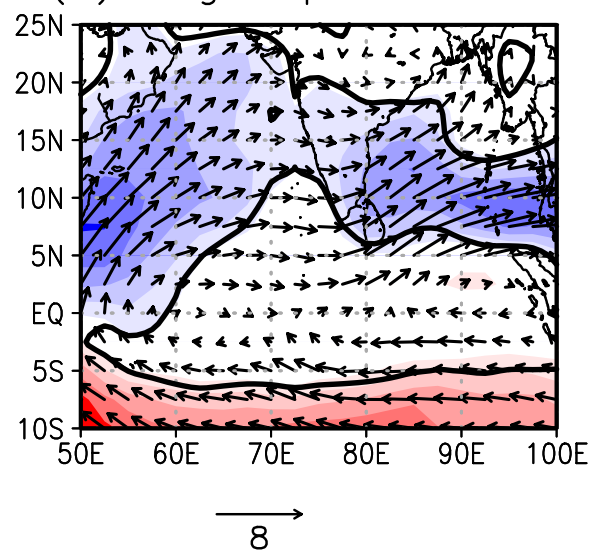

(e) Lag 4 pentad

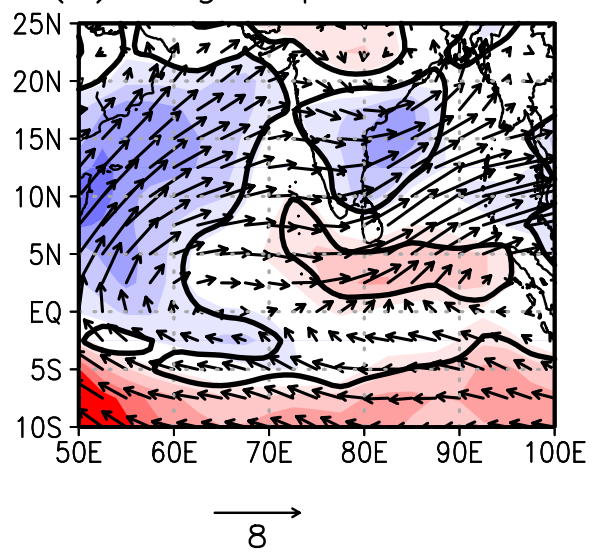

2
-1.6
-1.2
0.8
0.4
-0.4
-0.8
-1.2
-1.6
-2

Figure 3.8 Composite differences of wind magnitude $(\mathrm{m} / \mathrm{s}$; shaded) and direction $(\mathrm{m} / \mathrm{s}$; vectors) averaged over 1000, 925, and $850 \mathrm{hPa}$, at (a) the simultaneous pentad and the lagged pentads of (b) lag-1, (c) lag-2, (d) lag-3, and (e) lag-4 between the wet NEIMR conditions (pentads exceeding $90^{\text {th }}$ percentile) and the seasonal climatology during the months of Oct-Dec for the period 1985-2014. The thick black lines indicate the significant regions at the $95 \%$ level. 


\subsubsection{Moisture transport processes}

The anomaly of moisture flux convergence and moisture transport vectors at each atmospheric level from 1000 to $300 \mathrm{hPa}$ indicate that the moisture convergence and moisture transport over the southeastern India and its adjacent Bay of Bengal regions were dominant at the lower atmosphere up to $850 \mathrm{hPa}$ (Figure 3.9). Therefore, the anomaly of VIMF convergence, integrated from 1000 to $850 \mathrm{hPa}$, was examined for the same and lagged time steps of wet NEIMR pentads from the seasonal climatology (Figure 3.10(a), (b), (c)). Over the equatorial western Indian Ocean region, the westerly wind anomalies, linked to the anomalous cross-equatorial moisture transport winds, during the same, lag-1, and lag-2 pentads were carrying the moisture to the Bay of Bengal. The results indicate that the abundant increase in VIMF convergence anomaly (greater than $20 \times 10^{-3} \mathrm{~kg} \mathrm{~m}^{-2} \mathrm{~s}^{-1}$ ) was seen over the domain that covers parts of the Bay of Bengal and southern peninsular of India in the lower atmosphere during the same, lag-1, and lag-2 pentads. The moisture transport vectors also exhibited an anomalous cyclonic circulation in the above mentioned moisture converged regions during the same, lag-1, and lag-2 time steps of wet NEIMR pentads. The anomalous positive vorticity and wind vector, averaged over the lower level atmosphere, were consistent with the stronger cyclonic circulations over the southeastern India and its adjacent Bay of Bengal regions during the same and lag-1 pentads (Figure 3.10(d), (e)). Another anomalous cyclonic circulation over the tropical southern Indian Ocean, shown as negative vorticity anomalies, could support the moisture transport from the equatorial western Indian Ocean to the Bay of Bengal. 
(a) $700 \mathrm{hPa}-$ Same

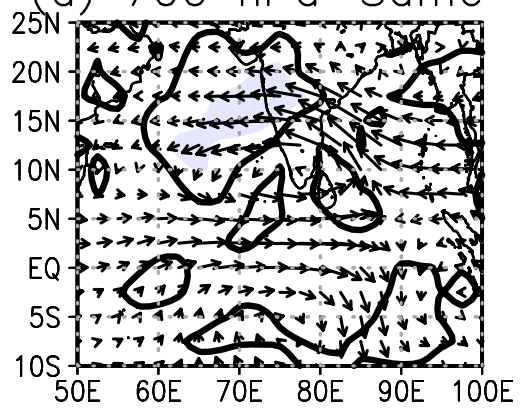

$\overrightarrow{0.05}$
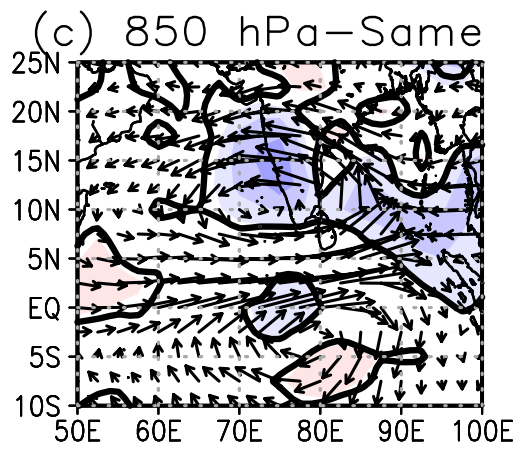

$\overrightarrow{0.05}$

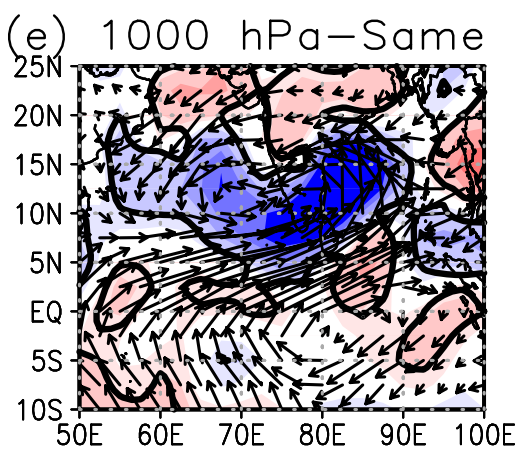

$\overrightarrow{0.05}$

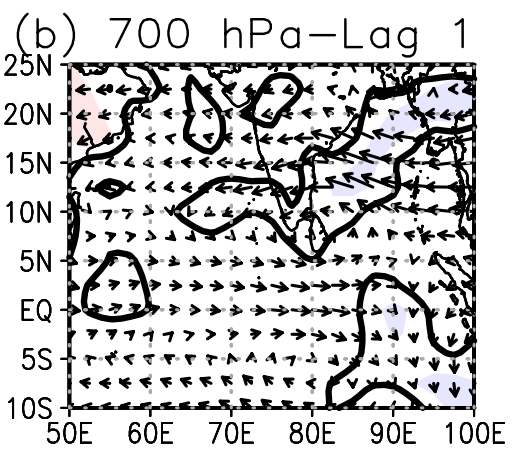

$\overrightarrow{0.05}$
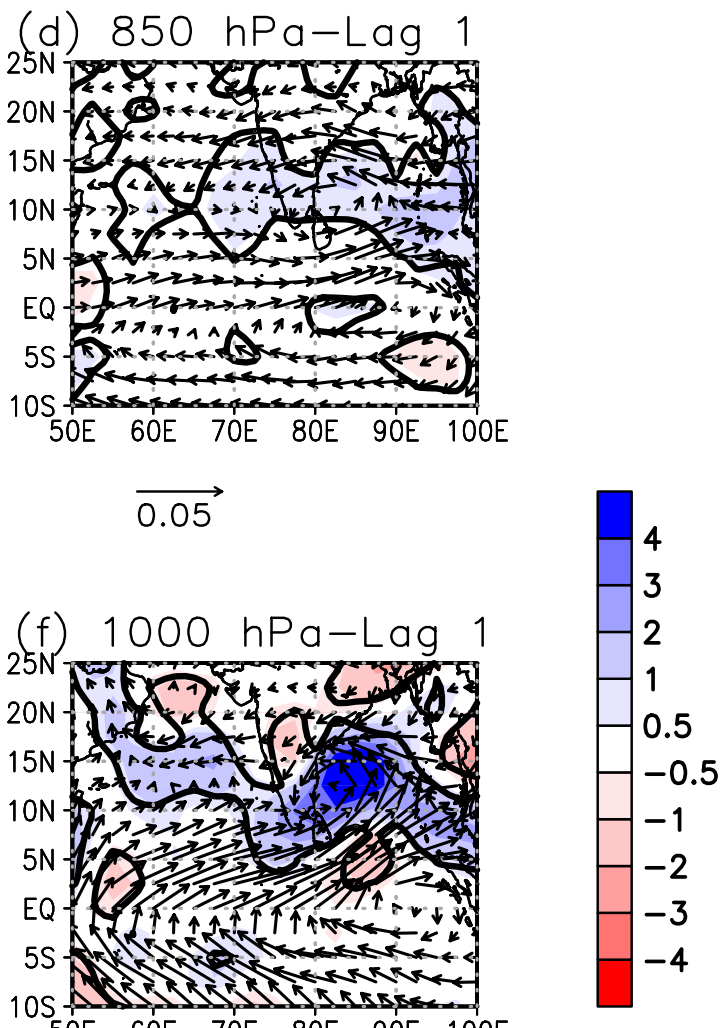

$\overrightarrow{0.05}$

Figure 3.9 Composite differences of moisture convergence $\left(10^{-4} \mathrm{~kg} \mathrm{~m}^{-1} \mathrm{~s}^{-1}\right.$; shaded) and moisture transport vectors $\left(\mathrm{kg} \mathrm{m}^{-1} \mathrm{~s}^{-1}\right)$ for the same pentad at (a) 1000, (c) 850 and (e) $700 \mathrm{hPa}$, and for the lag-1 pentad at (b) 1000, (d) 850 and (f) $700 \mathrm{hPa}$, between the wet NEIMR conditions and the seasonal climatology during the months of Oct-Dec for the period 1985-2014. The thick black lines indicate the significant regions at the 95\% level for moisture convergence. 
(a)VIMF-Same pentad

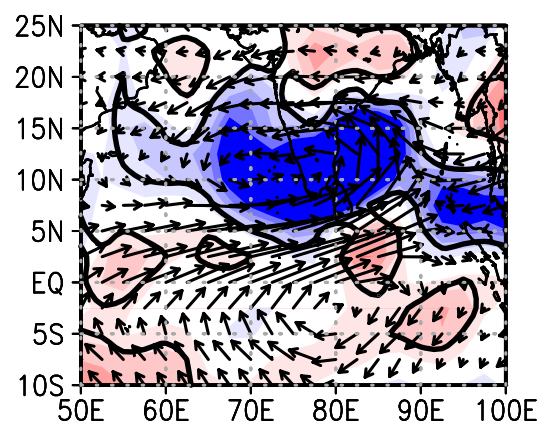

$\longrightarrow$

(b)VIMF-Lag 1 pentad

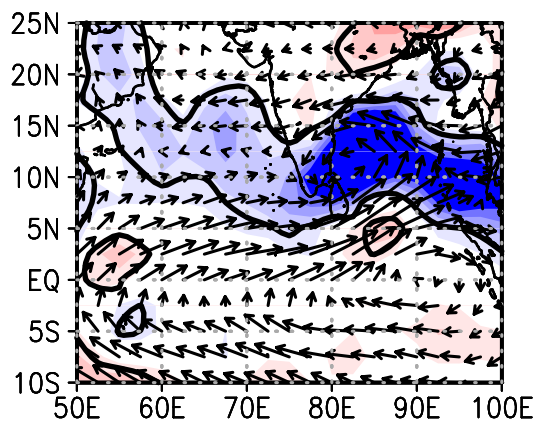

10

(c)VIMF-Lag 2 pentad

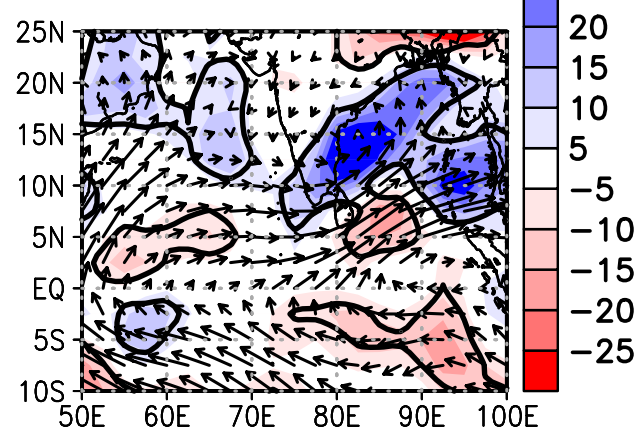

10
(d)Vort-Same pentad

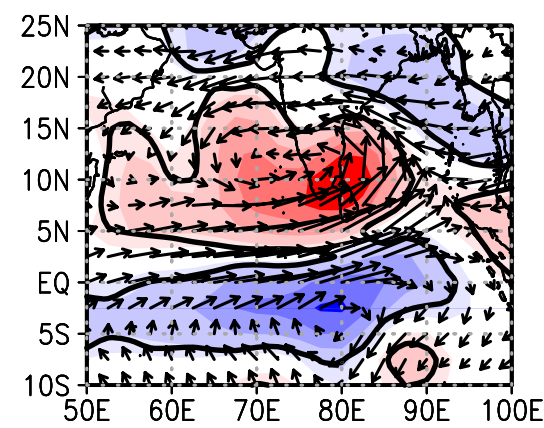

$\overrightarrow{4}$

(e) Vort-Lag 1 pentad

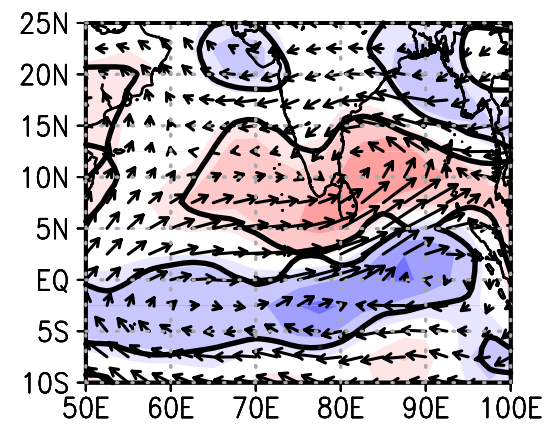

$\longrightarrow$

(f) Vort-Lag 2 pentad
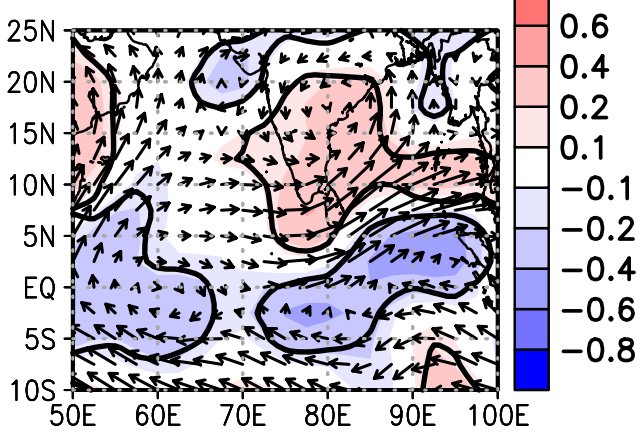

4

Figure 3.10 Composite differences of Vertical Integrated Moisture flux (VIMF) convergence $\left(10^{-3} \mathrm{~kg} \mathrm{~m}^{-2} \mathrm{~s}^{-1}\right.$; shaded) and moisture transport vectors $\left(\mathrm{kg} \mathrm{m}^{-1} \mathrm{~s}^{-1}\right)$, integrated from 1000 to $850 \mathrm{hPa}$, during (a) same, (b) lag-1, and (c) lag-2 pentads, between the wet NEIMR conditions and the seasonal climatology during the months of Oct-Dec for the period 1985-2014. (d), (e), and (f) are same as in (a), (b), and (c), but for vorticity $\left(10^{-5} \mathrm{~s}^{-1}\right)$ and wind vectors $(\mathrm{m} / \mathrm{s})$ averaged over the three pressure levels of 1000 , 925 , and $850 \mathrm{hPa}$. The thick black lines indicate the significant regions at the 95\% level for ( $a, b$, and c) VIMF and (d, e, and f) vorticity. 


\subsection{Discussion}

Over the equatorial western Indian Ocean, significantly increased SST anomalies during the lag-2, -3 and -4 time steps were observed before wet NEIMR conditions over the southeastern peninsular of India (see Figures 3.1 and 3.4). The anomalous warmer SSTs lead to the enhanced LHF anomalies over the Indian Ocean during the same and lag-1 and -2 pentads (see Figures 3.2 and 3.5). The increased LHF anomaly was possibly related to the increased atmospheric moisture demand due to less specific humidity in the lower atmosphere over the equatorial western Indian Ocean during the lag-2, -3 and -4 pentads (see Figures 3.6 and 3.7). In addition, the anomalous stronger winds during the same and lag-1 pentads over the equatorial Indian Ocean could contribute to enhance evaporation processes over the ocean (see Figure 3.8). The Bay of Bengal region showed different oceanic and atmosphere interaction, compared to the equatorial western Indian Ocean region. Anomalous increased SST and decreased LHF were observed over the Bay of Bengal during the same and all the lagged pentads. The decreased LHF could be related to the decreased atmospheric moisture demand, as the atmospheric moisture over the Bay of Bengal was abundant with more specific humidity (see Figures 3.6 and 3.7).

The anomalous winds over the equatorial western Indian Ocean were mostly westerlies during the same and lag-1 time steps of wet NEIMR pentads. These strong westerly anomalous winds could transport the oceanic moisture to the Bay of Bengal (see Figure 3.10). Stronger VIMF convergence was observed over the Bay of Bengal during the same and lag-1 and -2 time steps. Anomalous cyclonic circulations were observed over the Bay of Bengal and southeastern peninsular of India. The deviations of the winds and moisture transport vectors were mostly easterlies in the Bay of Bengal and the transported moisture can flow towards the southeastern peninsular. The above explained ocean and atmospheric processes associated with the wet NEIMR conditions over the southeastern peninsular India are illustrated in Figure 3.11. 
(a)

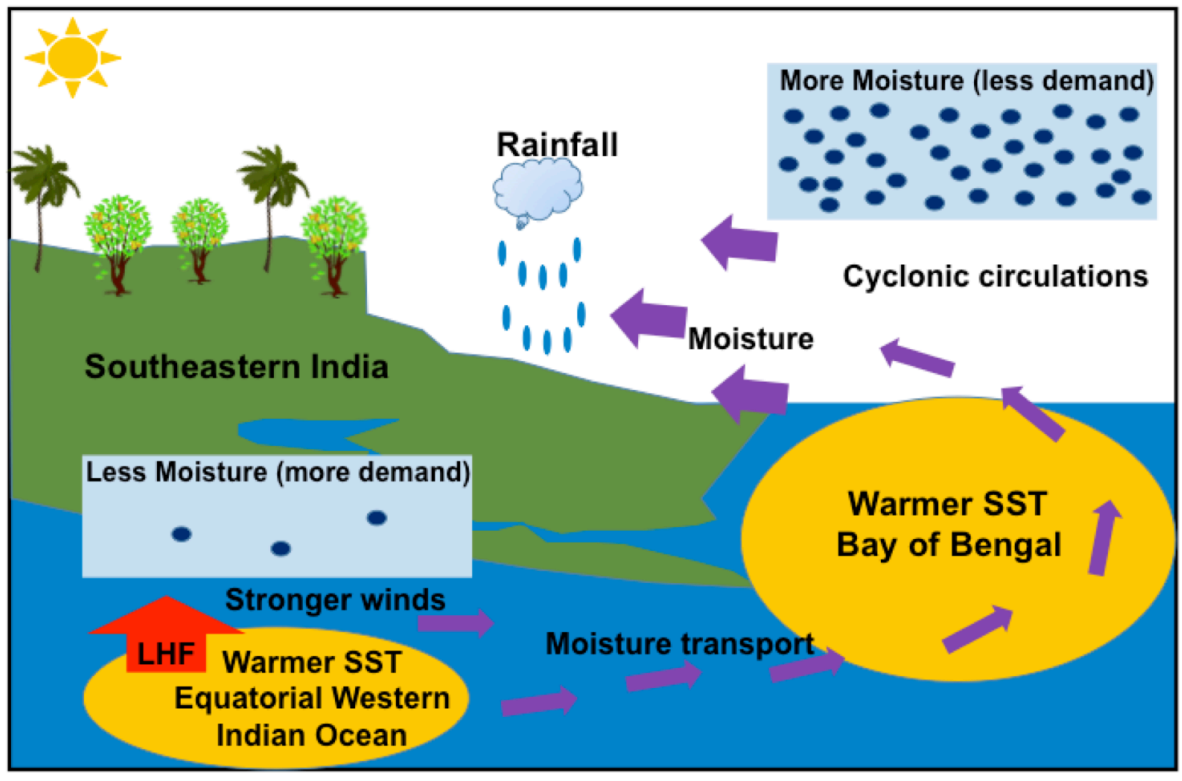

(b)

Increased NEIMR fed by moisture transported through cyclonic circulations

\section{SOUTHEASTERN INDIA}

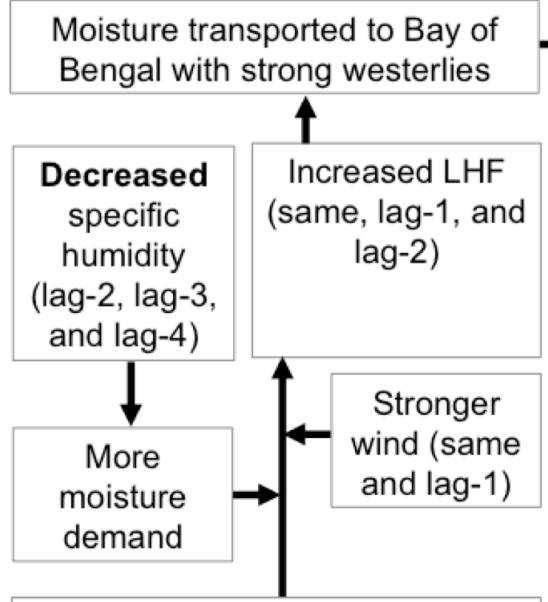

Increased SST (lag-2, lag-3, and lag-4)
Enhanced moisture convergence

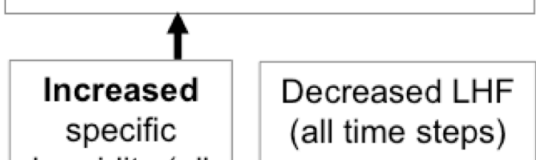

humidity (all

time steps)

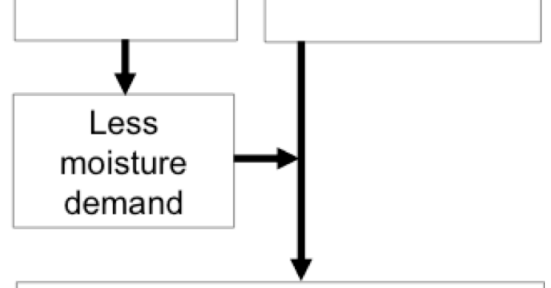

Increased SST (all time steps)

EQUATORIAL WESTERN INDIAN OCEAN

Figure 3.11 Schematic diagrams, (a) illustration and (b) flowchart, of the ocean and atmosphere processes over the equatorial western Indian Ocean and the Bay of Bengal, driving wet NEIMR conditions over the southeastern India. 


\subsection{Summary}

In this research question, distinct ocean and atmosphere conditions over the Bay of Bengal and the Indian Ocean regions were identified that were associated with the wet NEIMR pentads over the southeastern peninsular during October-December for the period 1985-2014. Two significant oceanic regions of moisture sources for NEIMR were identified in the Bay of Bengal $\left(80-95^{\circ} \mathrm{E}\right.$ and $\left.8-19^{\circ} \mathrm{N}\right)$ and the equatorial western Indian Ocean $\left(56-76^{\circ} \mathrm{E}\right.$ and $\left.3^{\circ} \mathrm{S}-5^{\circ} \mathrm{N}\right)$ regions. The non-parametric correlation analysis revealed that wet NEIMR conditions were significantly and positively correlated with SSTs over both of the Bay of Bengal (all pentads) and the equatorial western Indian Ocean (lag-2, -3 and -4 pentads) regions. However, significant LHF associations with the NEIMR conditions had positive correlations over the equatorial western Indian Ocean during the same and lag-1 and lag-2 pentads and they had negative correlations over the Bay of Bengal during the same and all the lagged pentads. The composite analysis confirmed that the SST anomalies significantly increased over the Bay of Bengal during all the time steps and over the equatorial western Indian Ocean region during the lag-2, -3 , and -4 pentads. The LHF anomalies significantly increased over the Indian Ocean, but decreased over the Bay of Bengal.

The different LHF associations with the wet NEIMR pentads between the equatorial western Indian Ocean and the Bay of Bengal regions were possibly related to the different atmospheric moisture demand over the two oceanic regions. As shown in the results, the specific humidity anomaly over the Indian Ocean region decreased during the lag-2, -3 and -4 pentads, which could cause increased moisture demand for the atmosphere. Additionally, enhanced wind speed during the same and lag-1 pentads could favor the evaporation processes, and thereby increased latent heat fluxes to the atmosphere. Over the Bay of Bengal, the decreased LHF anomaly with the wet NEIMR pentads could be due to the decreased atmospheric moisture demand, as there was abundant water vapor available in the atmosphere during the same and all the lagged pentads.

The analysis on moisture transport revealed that the lower atmospheric level up to $850 \mathrm{hPa}$ was critical in the moisture transport processes. The moisture from the equatorial 
western Indian Ocean was carried away by the strong westerly anomalies, linked to the anomalous cross-equatorial flow, to the moisture abundant Bay of Bengal region during the same and lag-1 time steps of wet NEIMR pentads. The moisture convergence was prominent and significant over the Bay of Bengal. The moisture over the Bay of Bengal, transported from the equatorial western Indian Ocean, was further carried to the southeastern peninsular of India by the stronger cyclonic circulations during the same and lag-1 pentads. Thus, NEIMR could be fed by the enhanced moisture over the Bay of Bengal with moisture from the equatorial western Indian Ocean through anomalous cyclonic circulations. The revealed ocean and atmosphere processes, associated with the wet NEIMR conditions, could help enhance the existing monsoon predictability and thereby improved rainfall forecast available for the southeastern peninsular India. The agriculture dependent population in the southeastern peninsular India could maximize the benefits of monsoon rain and reduce the risk of extreme rainfall events through the improved intra-seasonal forecast information for their agricultural and hydrological operations. 


\section{Lessons from the past for adapting to the monsoon variability in the future}

\subsection{Background}

Humans have altered terrestrial landscapes for agriculture for many thousands of years (Ruddiman 2003, Albert 2015). In some cases, these landscape changes have affected earth system functions and caused erratic climate patterns that pose serious threats to human society and to ecosystems (Opdam et al. 2009, Oldfield 2014). However, human societies have also implemented various adaptive practices, and despite the catalog of tales of collapse and destruction (Diamond 2005), the past also provides a library of examples of societal resilience suited to the needs of learning and innovating in response to climatic change (Endfield 2012, Oldfield 2014, Dearing et al. 2015). Studying the interactions between climate and humans in the historical past can thus provide some insight into preparing modern societies for the consequences of changing environments in the Anthropocene.

The paleoclimatic record derived from tree rings, lake or ocean sediments, cave speleothems, pollen spectra, and written sources has been useful to understand past climate variability and, likewise, at helping us to appreciate the forms, and lag times of societal response (Buckley et al. 2010, Pederson et al. 2014). Paleoclimatic records, archeology, and historical archives have been used for reconstructing regional histories (Dearing et al. 2015) and for inferring the contribution of climatic anomalies in the rise or collapse of human society in a region (Davis 2002, Buckley et al. 2010, Pederson et al. 2014). For example, the role of climate in the rise and collapse of civilizations has been proposed for the Akkadian Empire (Cullen et al. 2000), Mesoamerica (DeMenocal 2001), and particularly the collapse of Mayan civilization in the Yucatan Peninsula as a result of droughts ca. 800-900 CE (Curtis et al. 1996, Haug et al. 2003), Cambodia (Buckley et al. 2010), the Indus civilization (Berkelhammer et al. 2012, Dixit et al. 2014), the Mississippi lake region (Muñoz et al. 2014), and Mongol Empire at the time of Genghis Khan (Pederson et al. 2014). Western North America experienced more frequent and more severe droughts from 900 to $1300 \mathrm{CE}$ when compared with normal variability of the 
20th century (Cook et al. 2004), perhaps also explaining the collapse of the Anasazi culture and the disappearance of the Mill Creek Indians in the Great Plains (Bryson and Murray 1977).

Dearing et al. (2015) have highlighted the importance of understanding the socioecological system dynamics of the past for the sustainable management of modern landscapes. Bowden et al. (1981) had previously hypothesized that societies were likely to respond to climatic hazards in two alternative ways: lessening and catastrophe. The lessening hypothesis proposes that societies enhance their capacity to adapt to minor climatic stress through technological improvement and increased social organization. The catastrophe hypothesis suggests instead that societies become more vulnerable to major climatic stress as time progresses because of increasing vulnerability ascribable to ever heavier reliance on technology and to increasingly complicated social organization. Based on population and climatic data from North India, the US Great Plains, and the African Sahel, Bowden et al. (1981) found evidence for lessening strategies, but evidence for catastrophe was less clear partly because of spatial and temporal data limitations.

In South Asia, historians have documented the rise of the Chola Kingdom from a relatively small territory to becoming the dominant empire of South Asia between 850 and 1280 CE (Schwartzberg 1992, Subbarayalu 2012, Sastri 2014), a period which coincides with the Medieval Climate Anomaly (Mann et al. 2009, Graham et al. 2011). The role of climate as a contributing component to the rise of Chola Kingdom and to shifting southward the centre of gravity of Indian history has not, however, been previously investigated. Given that the rural Chola economy was heavily dependent on the monsoon (Srinivasan 1991), investigating the spatial and temporal variability of rainfall over South India in the past is likely to be important in understanding the growth of the Chola Kingdom in relation to its immediate neighbors.

Communities in various parts of the world have displayed complex adaptation strategies to deal with climatic variability by building water harvesting structures, water regulating structures, and by resorting to agricultural strategies such as crop diversification (Gunnell et al. 2007, Buckley et al. 2010, Wescoat 2011, Luzzader-Beach 
et al. 2012, Endfield 2012, Adamson 2014). For example, the Angkor kings of Cambodia built water-regulating structures such as canals and groundwater recharge reservoirs to irrigate their intensively managed agricultural landscape (Buckley et al. 2010). In South India, historians and archaeologists have documented the practice of constructing temples and man-made lakes (tanks) for the past 2000 years (Adiceam 1966, Balasubrahmanyam 1966, Dikshit et al. 1993, Champakalakshmi 1986, Srinivasan 1991, Rajan 2008, Subbarayalu 2012). The tanks in the southeastern parts of Tamil Nadu have been interpreted as adaptive strategies for managing the seasonal and internannual rainfall variability (Gunnell et al. 2007). Temple and tank construction in South India are also considered as primary indicators of political power and economic prosperity, because the purpose of the reservoirs is to harvest rainwater for enhancing agricultural productivity and ensuring food sovereignty (Subbarayalu 2010). Compilations of dated inscriptions on tank weirs have indicated that the construction rates of temples and tanks increased sharply during the Chola period (Srinivasan 1991, Rajan 2008). Investigating the chronology and spatial distribution of historical tank construction in the South Indian landscape would, therefore, help to (1) understand the response options to climatic variability in the region at the time of Chola rule, and (2) understand how pre-modern societies devised strategies for sustainable management of existing water harvesting structures as responses to climate change. Accordingly, in this chapter, I (1) examine Indian monsoon variability at seasonal time scales using a combination of modern and paleoclimatic data to understand the possible influence of climate on the rise of Chola Kingdom; (2) reconstruct the chronology and spatial patterns of tank construction in response to climatic variability as a means of understanding adaptive societal responses; and (3) explore the response of a complex hierarchical society to climate change during the last two centuries to understand how changes in social attitudes and resource management practices may have increased the vulnerability of southern India to extreme climatic events. 


\subsection{Study area}

\subsubsection{Brief history of the South Indian kingdoms}

In this study, the focus is on the historic region of South India, which roughly corresponds to the modern (and linguistically Dravidian) states of Tamil Nadu, Kerala, Andhra Pradesh, and Karnataka (Figure 4.1(a)) during the Ancient (560 BCE to $647 \mathrm{CE}$ ) and Early Medieval periods (647-1206 CE) of Indian history. From 250 CE, South India was shared by four major kingdoms (Figure 4.1(a); Sastri 1966, Schwartzberg 1992, Sastri 2014): the Early Pallava (250-550 CE) and Greater Pallava (550-930 CE) kingdoms (capital: Kanchipuram); the Pandya Kingdom (550-1320 CE; capital: Madurai); the Early and Later Chalukya kingdoms (1000-1200 CE; earlier capital: Badami; later capital: Taradavadi, a feudatory situated farther north); and the Chola Kingdom (846-1280 CE) (Figure 4.1(a)). During the 8th century CE, the Chola rulers established their capital city in Uraiyur (Niranjanadevi 2012) but moved it to Thanjavur in the 10th century, and then again to Gangaikondacholapuram in the $11^{\text {th }}$ century. The geographic extent of these kingdoms between 250 and $1500 \mathrm{CE}$ is based on Schwartzberg (1992) and shown in Figure 4.1(b). The Chola and Chalukya were among the 63 kingdoms in Indian history to attain superpower status (definition based on the size of their geographic footprint and span across several historic regions) for several consecutive centuries (Schwartzberg 1992). The Chalukya, Pandya, and Pallava were the dominant kingdoms in South India before $850 \mathrm{CE}$, with a short-lived overlap during early Chola expansion which began ca. $850 \mathrm{CE}$. The Hoysala and Vijayanagara kingdoms started to emerge after $1250 \mathrm{CE}$ following the decline and contraction of the Chola superpower. 
(a)

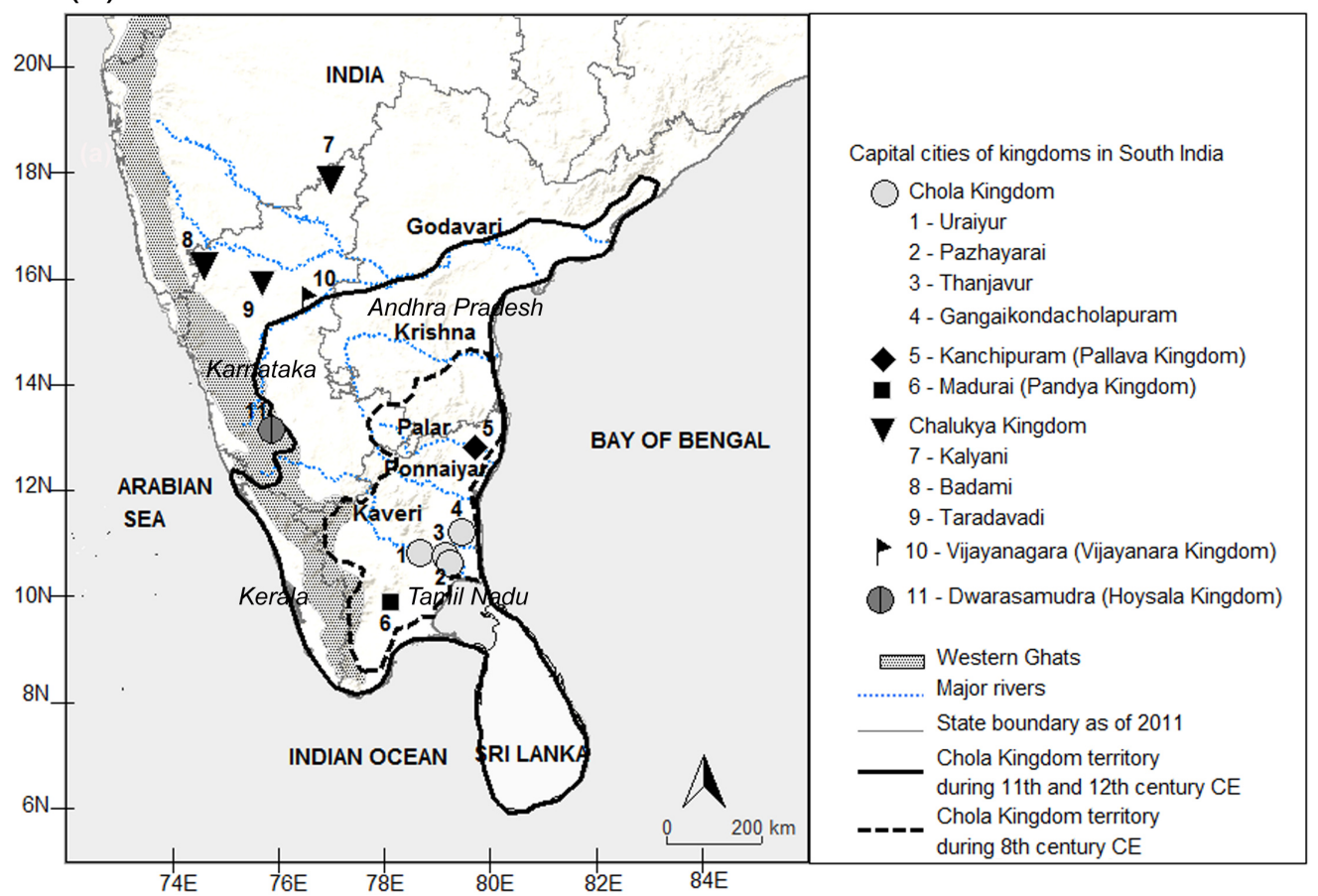

(b)

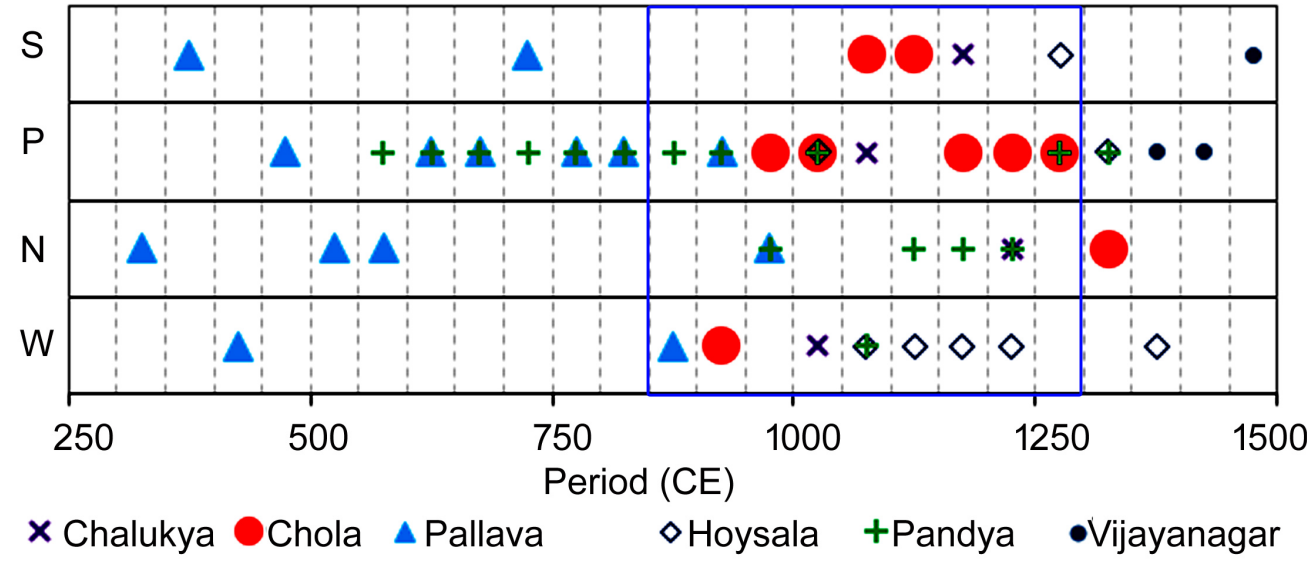

W (Weak) - Vassal state or some kind of dependency

$\mathrm{N}$ (Normal) - Commencement of a dynasty or having ephemeral power

$\mathrm{P}$ (Power) - Exercising power in one historical/cultural Indian region

S (Superpower) - Exercising power in at least two of the broad historical/cultural Indian regions

Figure 4.1 Geography and chronology of kingdoms in South India. (a) Map showing topography, rivers and capital cities of the South Indian kingdoms (compiled after Schwartzberg 1992), and (b) Status of South Indian kingdoms at 50-year intervals during the period 250-1500 CE (after Schwartzberg 1992). The blue rectangular box represents the golden age of the Chola Kingdom, between 850 and $1280 \mathrm{CE}$ 
The Chola rulers were famous for their administrative innovations and politically inclusive and centralizing strategies. They enforced a diversity of taxation rules, e.g. land tax from landowners, service tax from farmers, taxes on non-agricultural professions, miscellaneous taxes on tolls on merchandise, and judicial fines. From the beginning of the 11th century, agricultural land became classified into different categories, such as tank-irrigated, rain-fed, single- and double-crop, for taxation purposes. The revenue was periodically reassessed and the classification revised in accordance with changes in cropping patterns, yields, fertility, etc. (Subbarayalu 2012). Furthermore, the territorial cohesion between the Chola and Chalukya kings helped to minimize political fragmentation through a policy of robust corporate institutions involving local assemblies among merchant communities and in agrarian settlements (Schwartzberg 1992). In terms of size, the Chola Kingdom was the only political entity of South Asia to gain the status of a supra-regional imperial power at the beginning of the 11th century, carrying out a naval expansionist policy of foreign trade reaching Ceylon, southern Thailand, Sumatra (Indonesia), and Myanmar (Hall 1980, Champakalakshmi 1996, Subbarayalu 2012, Sastri 2014). The military expansion of the Chola Kingdom peaked during the earlier half of the 11th century and helped the Chola rulers to conduct large expeditions leading all of South India to be held united under his control (Subbarayalu 2012). Regional co-operation, taxation, trade, and military strategy may all be interpreted as political adaptations crafted by the Chola rulers to consolidate their economic prosperity.

\subsubsection{Landscapes of the Chola Kingdom: temples and tanks}

Agriculture was one of the major economic activities at the time of the Chola Kingdom (Srinivasan 1991, Subbarayalu 2012). The Chola kings are often considered great patrons of culture, art, and architecture, with historians sometimes referring to this period as the "Golden Age of tanks" because of the monumental architecture and multiplication of tanks in South India (Barah 1996). The Chola rulers during that time also promoted the construction or renovation of more than 400 temples (Balasubrahmanyam 1966, 1971, 1977, Balasubrahmanyam et al. 1979). The temples (Figure 4.2(a)) served as multipurpose community halls used for religious worship, for 
conducting educational activities, celebrating festivals, storing important records, and for sheltering communities during times of hardship (Balasubrahmanyam 1966).

(a)

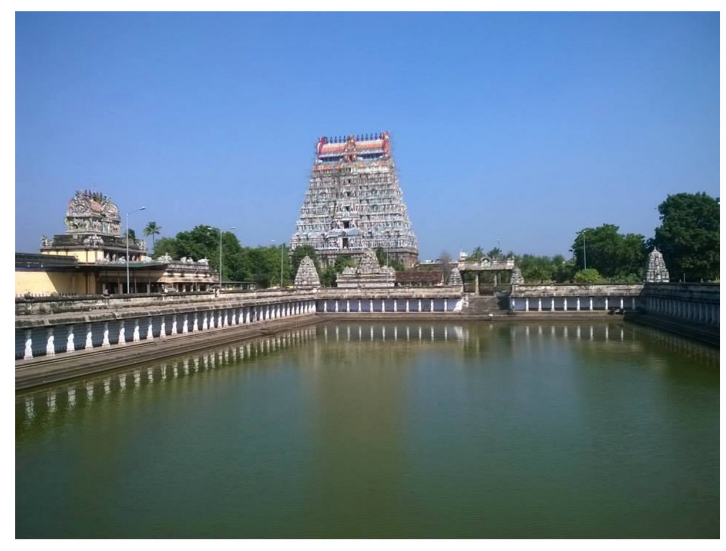

(b)

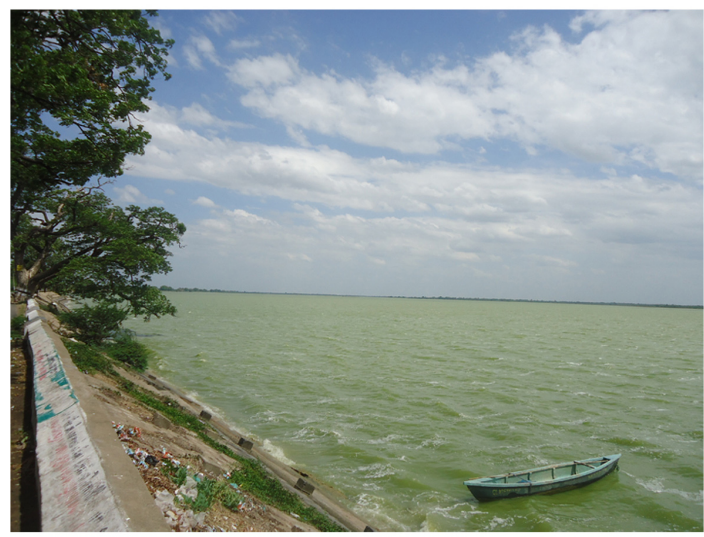

Figure 4.2 Temples and tanks in Cuddalore district, Tamil Nadu. (a) Nataraja temple and its tank in Chidambaram, and (b) Veeranam Lake in Sethiyathope (Photo by Shanmugasundaram Jothiganesh, 2015).

Temple tanks were built to harvest rainwater during the rainy season and supply it for domestic and agricultural use (Pandey et al. 2003, Ramachandran 2006, Rajan 2013, Meter et al. 2014). Today, temple tanks are part of the assets of the temple (Ganesan 2008). The tank typically exhibits surface areas ranging from 0.4 ha to 10 ha, and can hold 20 to $600 \mathrm{~m}^{3}$ of water. In addition to these temple tanks, the Chola rulers also promoted the development of multi-purpose man-made lakes, also called tanks (eri, in Tamil), mainly designed to harvest runoff for irrigation. Some of the larger artificial lakes of this kind in the Chola heartland are Veeranam Lake (capacity: $41.5 \cdot 10^{6} \mathrm{~m}^{3}$ ) (Figure 4.2(b)) and Chembarambakkam Lake (capacity: $88.0 \cdot 10^{6} \mathrm{~m}^{3}$ ) (WRO undated). Currently, the state of Tamil Nadu has 2,359 temple and 41,127 irrigation tanks - a clear sanction of their long-term sustainability as water harvesting devices. This population of extant reservoirs was an initiative entirely promoted by the four medieval kingdoms of South India, and the practice of tank irrigation was subsequently emulated by the successive rulers of South India until the mid-twentieth century (Adiceam 1966, Gunnell and Anupama 2003, Mialhe et al. 2008, DoS 2012, Prasanna Kumar 2013). 


\subsubsection{Climate and agriculture (1901-2010)}

There are two dominant rainfall seasons in peninsular India (Gunnell et al. 2007, Tyagi et al. 2008): the Southwest Indian monsoon rainfall (SWIMR) (June to September) and NEIMR (October to December) (Kripalani and kumar 2004, Prasanna et al. 2008, Rajeevan et al. 2012). During the SWIMR season winds are southwesterly (Figure 4.3(a)), and during the NEIMR season they blow from the northeast (Figure 4.3(b)). The Western Ghats, an elevated escarpment along the western boundary of peninsular India (see Figure 4.1(a)), influence the wind and rainfall patterns over southern India (Gunnell 1997), with the heavier SWIMR recorded over the Western Ghats (Figure 4.3(a)). In contrast, the heavier NEIMR occurs along the coastal fringe of Tamil Nadu (Figure 4.3(b)). The rainfall over southern India during these two monsoon seasons is episodic and is influenced by monsoon depressions, tropical cyclones and the transient characteristics of jet streams in the upper easterlies (Ramage 1971, Walsh et al. 1999).

(a)

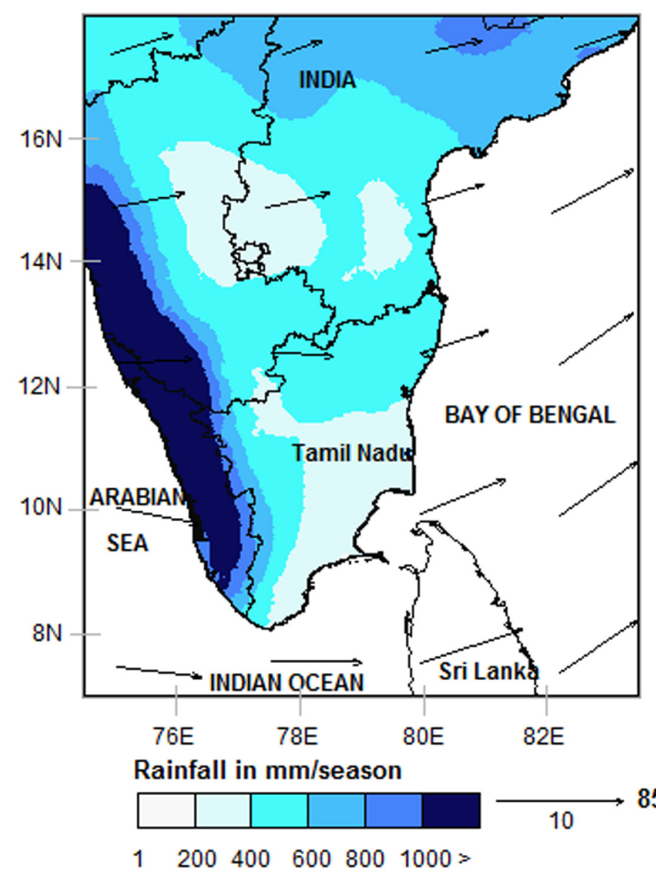

(b)

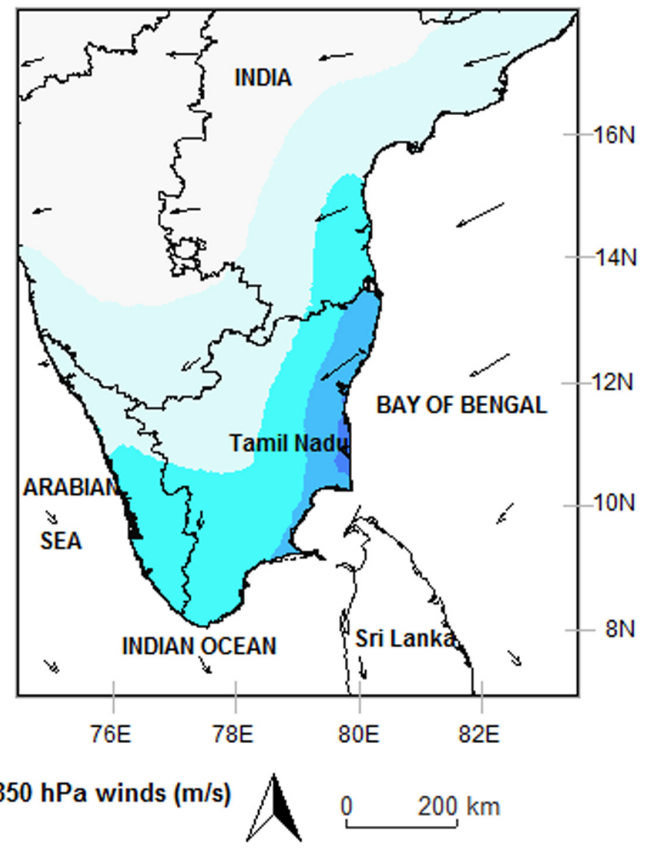

Figure 4.3 Modern rainfall distribution in peninsular India. (a) Seasonal mean of SouthWest Indian Monsoon Rainfall (1901 to 2010) and of $850 \mathrm{hPa}$ wind vectors (1948 to 2010) from June to September, and (b) Seasonal mean of North-East Indian Monsoon Rainfall (1901 to 2010) and of $850 \mathrm{hPa}$ wind vectors (1948 to 2010) from October to

December. Rainfall data (in units of $\mathrm{mm} / \mathrm{seas}$ ) were obtained from the Climate Research Unit (Harris et al. 2013) and wind vectors (in unit of $\mathrm{m} / \mathrm{s}$ ) were calculated 
using $\mathrm{u}-$ and v-winds from the National Center for Environmental Prediction (NCEP) reanalysis data (Kalnay et al. 1996).

The El Niño anomaly is one of the major climatic drivers behind SWIMR and NEIMR variability (Kumar et al. 2007, Zubair et al. 2008). El Niño conditions exert contrasting impacts on SWIMR and NEIMR because of the physical nature of the teleconnections that link the El Niño process with the two Indian monsoon systems. El Niño (as opposed to La Niña) conditions exacerbate NEIMR over Tamil Nadu because of two possible mechanisms: (1) stronger easterly wind and low-elevation moistureconvergence anomalies, along with associated changes in the circulation regime throughout the troposphere over Sri Lanka and the southern parts of India (Kumar et al. 2007); and (2) increased cyclonic activity caused by the warmer sea-surface temperatures (SSTs) in the northern Indian Ocean (Yadav 2012). The El Niño conditions favor NEIMR not only in South India, but also over the northeastern part of Sri Lanka (Suppiah 1989, 1996, Kane 1998, Zubair et al. 2008), which is also part of the tank civilization and exhibits very similar climatic conditions to those of southeastern India. In contrast, the intensity of SWIMR is attenuated during El Niño conditions (Ihara et al. 2007). These effects are associated with a decrease in the heat contrast between land and sea, which plays an important role in controlling SWIMR (Webster 1987, Lee et al. 2009) because of the warmer SSTs in the surrounding oceans during El Niño years (Krishna Kumar et al. 2006). The physical link between El Niño (warmer phases) and the Indian summer monsoon induces a decline in SWIMR on both interannual and interdecadal timescales due to an anomalous regional Hadley circulation and an eastward shift of Walker circulation patterns (Krishnamurthy and Goswami 2000, Krishna Kumar et al. 2006).

The rural population of South India today is heavily dependent on monsoon rainfall for meeting the water requirements of its agriculture (Parthasarathy et al. 1988, DoE 2006, Krishna Kumar et al. 2004). Approximately ca. 912 x $10^{3}$ ha of land area in the 1960 s and $518 \times 10^{3}$ ha in the 2000 s were still benefiting from dry-season tank irrigation (TNSPC 2012, UNDP 2013). Crop variety and crop yield are closely linked to rainfall regime (Krishna Kumar et al. 2004, Gadgil and Gadgil 2006, Prasanna 2014). For example, the correlation coefficient between the all-India food grains index and the 
Indian summer monsoon rainfall index between 1949 and 1998 was 0.79 (Krishna Kumar et al 2004).

\subsection{Data and methods}

\subsubsection{Modern climate data analysis, 1901 to 2010}

I calculated the total amounts and percentage contributions of SWIMR and NEIMR (the two major rainy seasons) to annual rainfall across South India as a basis for investigating the level of dependency of the respective kingdoms on each of the two monsoon systems for their water resources, and also as a means of acquiring deeper insight into why the Chola rulers moved their capital cities from Uraiyur to Thanjavur, then to Gangaikondacholapuram. In order to evaluate the chances stood by each of the six historical capital cities of South India of being exposed to the two monsoon systems, I used gridded monthly precipitation data at $0.5 \times 0.5$ degree resolution produced by the Climate Research Unit (CRU, Harris et al. 2013) and performed a temporal analysis of instrumental rainfall characteristics between 1901 and 2010. The monthly time series of CRU rainfall data for that period were obtained by extracting areal averages over South India $\left(75-82^{\circ} \mathrm{E}\right.$ and $\left.8-18^{\circ} \mathrm{N}\right)$ and were standardized by dividing rainfall anomaly by the standard deviation. These data were aggregated by season to obtain the June to September and October to December totals. The variation between monthly averaged SWIMR and NEIMR over the three Chola capitals (Uraiyur, Thanjavur and Gangaikondacholapuram) and those of their three neighboring kingdoms (Badami, Kanchipuram, Madurai) were described using box-and-whisker plot analysis (Chatfield 1985). A Student's $t$-test was carried out for a two-sample difference of means (Walpole et al. 1993) to examine the dependency of SWIMR and NEIMR over the six cities.

The annual Southern Oscillation Index (SOI) for 1901-2010 was obtained from the Australia Bureau of Meteorology (Bureau of Meteorology 2015a) and used to examine the associations between El Niño and the two Indian monsoons. I also tested whether SWIMR and NEIMR were correlated with the annually averaged 1901-2010 SOI (Chatfield 1985). The strength of association was estimated using the Pearson 
correlation coefficient. A chi-square test was carried out to assess the dependency between the monsoon indices and SOI values. The El Niño (SOI $<-7$ ), normal (SOI values between -7 to +7 ), and La Niña (SOI $>+7$ ) periods were classified based on the standard definitions published by the Australian Bureau of Meteorology (Bureau of Meteorology 2015b). The frequency of wetter and drier SWIMR and NEIMR years were also correlated with El Niño years. I selected all the years with SOI values less than -7 (El Niño conditions) and carried out composite difference analysis to determine the rainfall variations of SWIMR and NEIMR during El Niño years. A Student's $t$-test was used to quantify the statistical significance of observed differences $(95 \%$ confidence level) between the El Niño composite means and the climatological means.

\subsubsection{Historical climate data analysis, 500 to $1900 \mathrm{CE}$}

Paleoclimatic data for mainland India prior to the period of instrumental records are scarce. To understand longer-term SWIMR and NEIMR variability during the historical period of interest, I reviewed existing paleoclimatic evidence (NOAA Paleoclimatology 2015) from the following sources: (1) the South-Ist Indian Monsoon Index (SWIMI) - ${ }^{230}$ Th-dated stalagmite oxygen-isotope proxy record $\left(\delta^{18} \mathrm{O}\right)$ reconstructed from the Dandak cave deposits, which are located in the Indian state of Orissa (Sinha et al. 2007); (2) the South-Asian Monsoon Index (SAMI), which was constructed by tuning SOI time series to tree-ring data from South Asia (Shi et al. 2014); and (3) SOI time series constructed by correlating tree-ring and precipitation proxies (Yan et al. 2011). SOI reconstructions by Yan et al. (2011) were consistent with the proxies used by Conroy et al. (2010) for Tropical Pacific zonal SST gradients and for the Indo-Pacific Warm Pool over the period 800-1900 CE in capturing the dominant El Niño conditions during the period extending from 1000 to $1300 \mathrm{CE}$. For the purpose of this study, I implemented the SOI data from Yan et al. (2011) because they were reconstructed on the basis of proxies from Southeast Asia and South America, which are the two regions with the strongest El Niño-Southern Oscillation (ENSO) signals in recent records. 
The aforementioned datasets were available for different periods covering the last 2500 years, and there is agreement between them over the overlapping period 900-1500 CE. Time-series visualization plots were generated for all the reconstructed paleoclimate data (SOI, SAMI, and SWIMI) for the period between 500 and $1900 \mathrm{CE}$ and inferred the characteristics of the SWIMR from the SAMI and SWIMI graphs. The major assumption in this study is the uniformitarian principle (Hutton 1899), i.e. that climate characteristics and their relationship with climatic drivers during the modern instrumental period (1901 to 2010) were also valid during the broader historical period of interest (500 to $1900 \mathrm{CE}$ ) (e.g. Bocinsky and Kohler 2014, Bradley 2014). A number of studies on paleoclimate have suggested that this assumption is valid for monsoonal South Asia (Bradley 2014, Bocinsky and Kohler 2014), where the driving physical mechanisms that explain the annual-scale contrast between the monsoon season and the dry season during instrumental times (e.g. Gunnell et al. 2007) readily scales up to explain longer periods of contrast between drier and wetter periods during the Holocene (Gupta et al. 2003) and likewise during the glacial and interglacial periods of the Pleistocene (e.g., Duplessy 1982, Sarkar et al. 1990). The strength of ENSO has varied over the last two thousand years, but it appears that between 850 and $1280 \mathrm{CE}$, ENSO effects on rainfall patterns were stronger than immediately before or after that period (Sinha et al. 2007). While assuming that the association between 1901 and 2010 was also valid for past centuries and supported by similar driving physical mechanisms, I thus used modern instrumental relationships between the SOI and NEIMR to infer the characteristics of NEIMR from the SOI historical proxy between 500 and $1900 \mathrm{CE}$.

\subsubsection{Temple and tank data analysis}

The years of temple construction were compiled from the four volumes on Chola architecture by Balasubramanyam $(1966,1971,1977)$ and Balasubrahmanyam et al. 1979. Although this work does not contain a complete list of South Indian temples, it remains the most detailed survey available and provides extensive information on the Chola period. The periodization of Chola rulers was based on Sastri $(1966,2014)$, and was compared with Balasubramanyam $(1966,1971,1977)$, and Balasubrahmanyam et al. 
1979) to cross-correlate the period of rule and corresponding kingdom territories with the major peaks of temple construction. Every temple built by Chola rulers in South India had its own tanks to harvest and store rainwater. Therefore, the number of temples built under Chola rule provides an indication of the number of temple tanks. Given that the geographic coordinates of temples and tanks were not readily available, village locations obtained from district-level administrative units based on 2011 data from the Indian Survey Department were used instead.

The year of temple construction provided by the literature may not be systematically accurate, therefore I compiled the ruling period of each Chola king and the construction work commissioned under his rule. Each ruler was in power for approximately 30 to 50 years, and some ruled for a shorter time span (5 to 10 years). The Chola rulers were aggregated into nine chronological classes (Table 4.1) based on the number of temple construction works, assuming these clusters might have occurred during similar climatic conditions. The actual number of temples for each Chola time cluster was used for spatial analysis. To illustrate the district-wise spatial distribution of temples constructed by the nine Chola rulers, the temple and tank construction data were imported into SAVGIS, a freeware Geographic Information System (Souris 2002, Shanmugasundaram et al. 2012). The maps were prepared for each time slice in order to examine the spatio-temporal patterns of construction. 
Table 4.1 Chronology of Chola Kingdom rulers

\begin{tabular}{|c|c|c|c|c|}
\hline $\begin{array}{l}\text { Cluster } \\
\text { code }\end{array}$ & $\begin{array}{c}\text { Name of the } \\
\text { King }\end{array}$ & $\begin{array}{l}\text { Ruling period } \\
\text { in } C E\end{array}$ & $\begin{array}{c}\text { No. of temples } \\
\text { constructed or } \\
\text { renovated } \\
\end{array}$ & $\begin{array}{l}\text { Chola } \\
\text { Kingdom } \\
\text { period } \\
\end{array}$ \\
\hline \multirow[t]{2}{*}{$\mathrm{C} 1$} & Vijayalaya & & 22 & \multirow{6}{*}{$\begin{array}{l}\text { Early Chola } \\
\text { Kingdom }\end{array}$} \\
\hline & Aditya I & $850-907$ & 64 & \\
\hline $\mathrm{C} 2$ & Parantaka & $907-955$ & 48 & \\
\hline \multirow[t]{3}{*}{$\mathrm{C} 3$} & Sundara chola & \multirow[b]{3}{*}{$956-985$} & 6 & \\
\hline & Aditya II & & 2 & \\
\hline & Uttama chola & & 27 & \\
\hline $\mathrm{C} 4$ & Rajaraja I & $985-1014$ & 60 & \multirow{7}{*}{$\begin{array}{r}\text { Middle Chola } \\
\text { Kingdom }\end{array}$} \\
\hline $\mathrm{C} 5$ & Rajendra I & 1014-1044 & 25 & \\
\hline \multirow[t]{5}{*}{ C6 } & Rajadhiraja I & \multirow[b]{5}{*}{$1044-1070$} & 8 & \\
\hline & Rajendra Deva II & & 3 & \\
\hline & Raja Mahendra & & & \\
\hline & Vira Rajendra & & 1 & \\
\hline & Adhi Rajendra & & 1 & \\
\hline \multirow[t]{2}{*}{$\mathrm{C} 7$} & Kulonttunga I & & 51 & \multirow{8}{*}{$\begin{array}{r}\text { Later Chola } \\
\text { Kingdom }\end{array}$} \\
\hline & Vikrama Chola & $1070-1135$ & 22 & \\
\hline \multirow[t]{3}{*}{$\mathrm{C} 8$} & Kulottunga II & \multirow[b]{3}{*}{$1135-1182$} & 4 & \\
\hline & Rajaraja II & & 5 & \\
\hline & Rajadhiraja II & & 7 & \\
\hline \multirow[t]{3}{*}{ C9 } & Kulotunga III & \multirow[b]{3}{*}{$1182-1280$} & 29 & \\
\hline & Rajaraja III & & 19 & \\
\hline & Rajendra III & & 5 & \\
\hline
\end{tabular}

Source: Compiled from Balsubramaniam (1966, 1971, 1977), and Balasubrahmanyam et al. 1979

\subsubsection{Exploring the societal response to changing climate in the recent Anthropocene}

The evolving status of Chola tank systems in more recent times was investigated in order to highlight the relevance of this study to continuing changes in the climate and the landscapes. A perspective on societal resilience in the Anthropocene to extreme climatic events within the Chola historical region was gained by showcasing how these Medieval water harvesting structures played a role in either minimizing or worsening the impacts of well documented extreme climate events. The consequences of (1) the megadrought of 1876-1878 (Macleane 1885, Davis 2002), and (2) the major flood of 2015, 
which occurred after nearly 150 years of rapid population growth and substantial urban and rural landscape changes were identified for further study.

\subsection{Climatic variability during the modern and historical periods}

\subsubsection{Climatic variability, 1901-2010}

Interannual variations of NEIMR, as indicated by the range between the minimum and maximum in the box-and-whisker plots (Figure 4.4), are high compared to those of the SWIMR over each of the six historical capital cities of South India. The temporal variability and extreme seasonal totals of NEIMR were observed to be highest over the cities of Kanchipuram and Gangaikondacholapuram. The $t$-test results indicate that the monthly means of the NEIMR and SWIMR are significantly different ( $p$-value $<0.01)$ over all six cities. The NEIMR received in Uraiyur (Chola capital in the 8th c. CE) is much lower than that in Thanjavur (Chola capital in the 9-10th c. CE) and in Gangaikondacholapuram (capital during the 11th c. CE). NEIMR totals are much higher over Thanjavur and Gangaikondacholapuram than over the neighboring Chalukya and Pandya kingdoms. Table 4.2 shows the seasonally accumulated SWIMR and NEIMR and their percentage contributions to annual rainfall over those cities. The area corresponding to the Chola and Pallava kingdoms receives more than $50 \%$ of its annual rainfall during the NEIMR season. The highest NEIMR-receiving areas were Kanchipuram (Pallava Kingdom, $620 \mathrm{~mm}$ seasonal rainfall) and Gangaikondacholapuram (Chola Kingdom, 616 mm seasonal rainfall). Badami (Chalukya Kingdom) receives 58\% of its annual rainfall during the SWIMR season. 
Table 4.2 Rainfall characteristics over the capital cities of the kingdoms of South India

\begin{tabular}{|l|l|l|l|l|l|l|}
\hline Capital Cities & Kingdom & $\begin{array}{l}\text { Total } \\
\text { SWIMR } \\
(\mathbf{m m})\end{array}$ & $\begin{array}{l}\text { Total } \\
\text { NEIMR } \\
(\mathbf{m m})\end{array}$ & $\begin{array}{l}\text { Total } \\
\text { annual } \\
\text { rainfall } \\
(\mathbf{m m})\end{array}$ & $\begin{array}{l}\text { Ratio of } \\
\text { SWIMR } \\
\text { to annual } \\
(\mathbf{\%})\end{array}$ & $\begin{array}{l}\text { Ratio of } \\
\text { NEIMR to } \\
\text { annual } \\
(\%)\end{array}$ \\
\hline Badami & Chalukya & 340 & 154 & 589 & 58 & 26 \\
\hline Kanchipuram & Pallava & 452 & 620 & 1166 & 39 & 53 \\
\hline Madurai & Pandya & 291 & 446 & 894 & 33 & 50 \\
\hline Tiruchirapalli & Chola & 329 & 410 & 894 & 37 & 46 \\
\hline Tanjore & Chola & 317 & 568 & 1028 & 31 & 55 \\
\hline $\begin{array}{l}\text { Gangaikondac } \\
\text { holapuram }\end{array}$ & Chola & & & & & 52 \\
\hline
\end{tabular}

Source: Climate Research United rainfall gridded data sets

The Chola Kingdom received more benefits from the North-East monsoon winds (windward effect direct from the Bay of Bengal; see Figure 4.3(b)) than from the SouthWest monsoon winds (rainshadow effect generated by the Western Ghats escarpment; Figure 4.3(a)) (Srinivasan and Ramamurthy 1973, Gunnell 1997). The capital cities of the Chola Kingdom and their agricultural supply areas consequently received their water resources predominantly from the NEIMR, as shown in Table 4.2. The major river Kaveri and its tributaries flowing through the Chola Kingdom (see Figure 4.1(a)), however, also received perennial stream flow from the SWIMR regions situated in the upper catchments of the Kaveri drainage basin. Therefore, the power centers of the Chola Kingdom were in both a climatic and a hydrographic position to benefit directly from NEIMR and indirectly from SWIMR. 


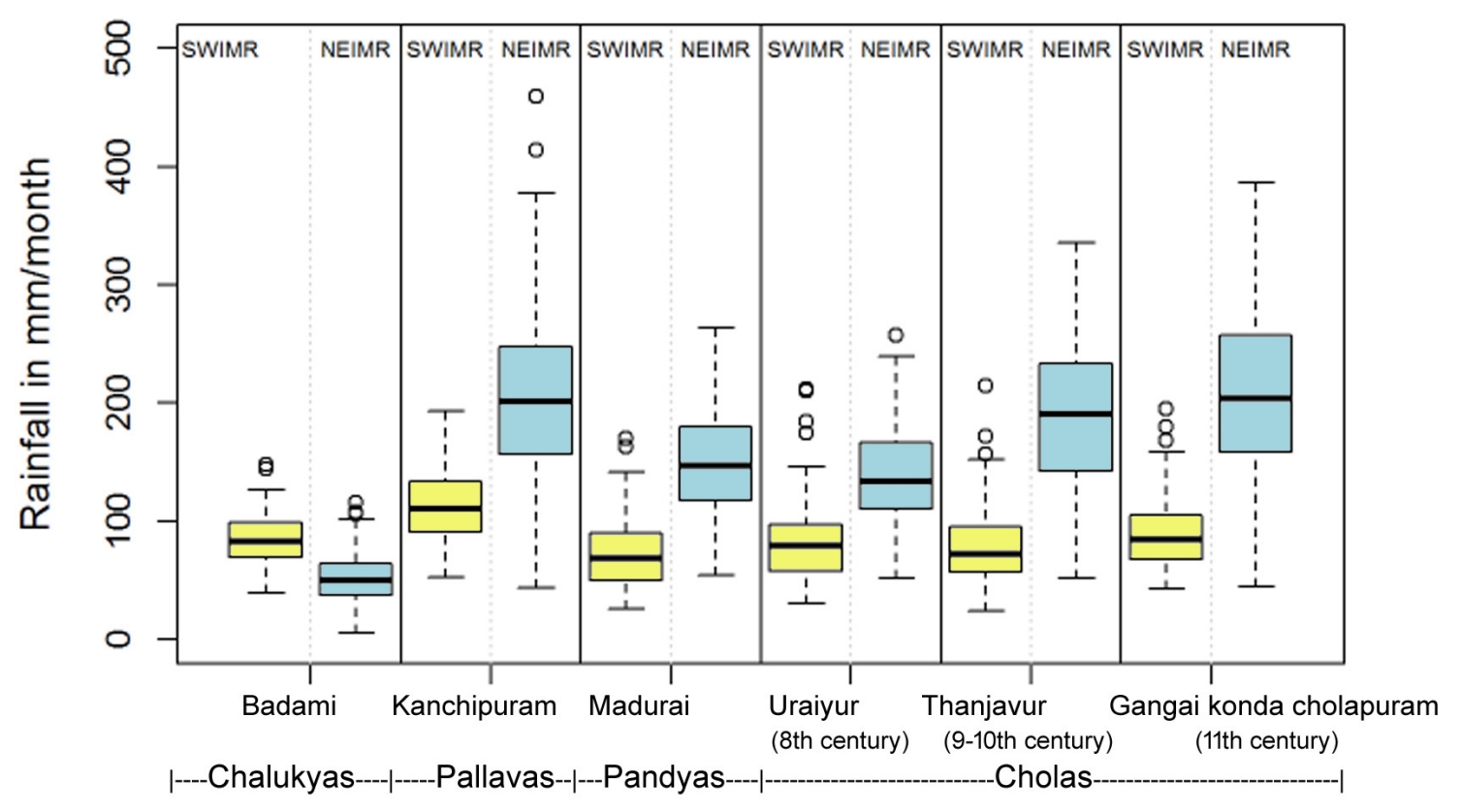

Capital cities of the Kingdoms of South India

Figure 4.4 Temporal variability of modern SWIMR and NEIMR over the capital cities of the Chola and other kingdoms of South India. Rainfall quantity (1901-2010 CE) is in $\mathrm{mm} /$ month. The t-test for a two-sample difference of the means in SWIMR and NEIMR time series rejects the null hypothesis (mean differences of SWIMR and NEIMR are equal to zero), and the p-values are significant at $99 \%$ for all six of the cities

In contrast to the Chola heartland, the neighboring kingdoms were predominantly dependent on one monsoon rainfall season (whether the SWIMR or NEIMR), and none of their capitals were situated on the Kaveri River - the only large perennial stream of South India. The Pandya Kingdom, which was ruled from Madurai, received water from NEIMR (at least $50 \%$ of annual rainfall), but the mean modern NEIMR amount in Madurai $(446 \mathrm{~mm})$ is not as high as in the capital cities of the Chola Kingdom (e.g., 616 $\mathrm{mm}$ in Gangaikondacholapuram). The Pallava Kingdom, ruled from Kanchipuram, also received water predominantly from NEIMR (53\% of annual rainfall). Water in the Chalukya region was predominantly supplied by SWIMR (Table 4.2). Out of the four South Indian kingdoms, the outlier is the Chalukya Kingdom, which was situated at higher elevations on the Deccan plateau in the semi-arid $(600 \mathrm{~mm}$ modern annual rainfall or less), South-West monsoon rain shadow of the Western Ghats escarpment. 


\subsubsection{Relationship between rainfall and the SOI, 1901-2010}

El Niño conditions (SOI values less than -7 ) are associated with enhanced (above average) NEIMR and attenuated (below average) SWIMR (Figure 4.5). The pattern of wetter periods indicates that clustering during El Niño years is detected in the NEIMRdominated (Figure 4.5(a)), but not in the SWIMR-dominated, regions (Figure 4.5(b)). Pearson's coefficients expressing the correlation between the SOI and the standardized SWIMR and NEIMR time series for the instrumental period 1901 to 2010 are +0.34 and -0.38 , respectively. The chi-square results (both $p$-values $<0.01$ ) indicate that the null hypothesis of no effect (of the SOI on the various monsoon indices) should be rejected, which means that these variables are interdependent. During the period of interest, there were 17 El Niño years, out of which $15(89 \%)$ recorded greater than average NEIMR and $12(71 \%)$ underwent attenuated SWIMR in South India. Results from the composite analysis confirm the suppressed SWIMR and enhanced NEIMR conditions during the El Niño years (Figure 4.6). These results are also consistent with results from previous studies based on different data sources, resolutions, geographical domains, and time periods (Krishnamurthy and Goswami 2000, Zubair and Ropelewski 2006, George et al. 2011).

(a)

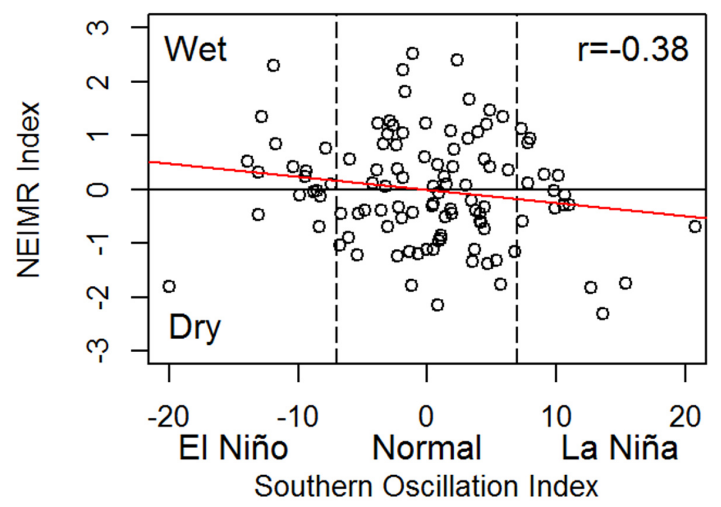

(b)

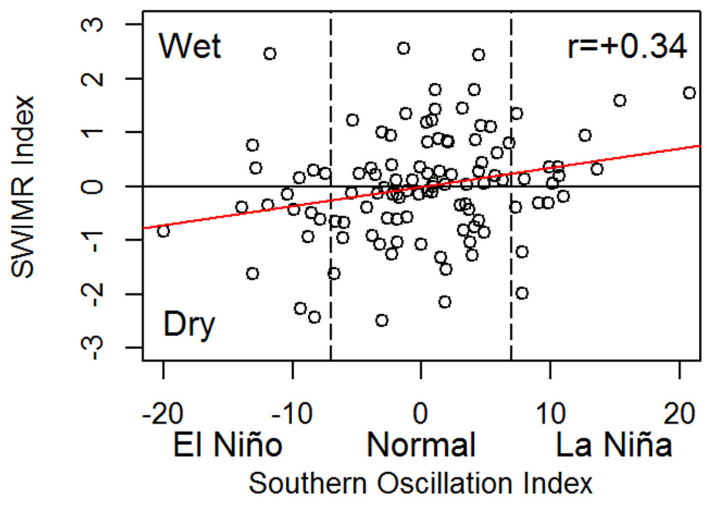

Figure 4.5 Scatterplots of (a) SOI vs. NEIMR index, and (b) SOI vs. SWIMR index (19012010). Positive values indicate a wetter, and negative values a drier, phase of NEIMR and SWIMR. Vertical dashed lines at -7 to 7 position the lower and upper limits of a normal period; values less than -7 indicate an El Niño period; values greater than 7 correspond to a La Niñ period. Red lines running diagonally in the plots represent the trend line of the data points. 
(a)

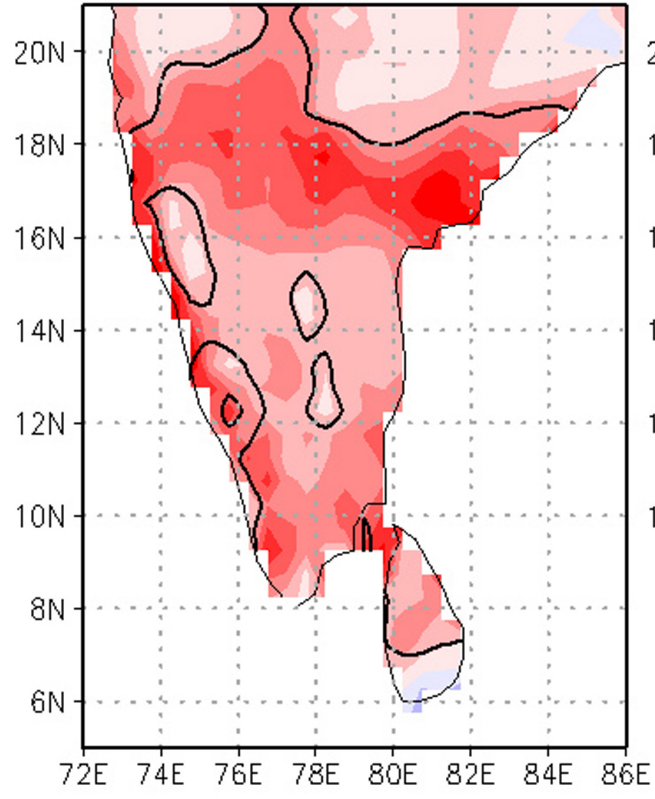

(b)

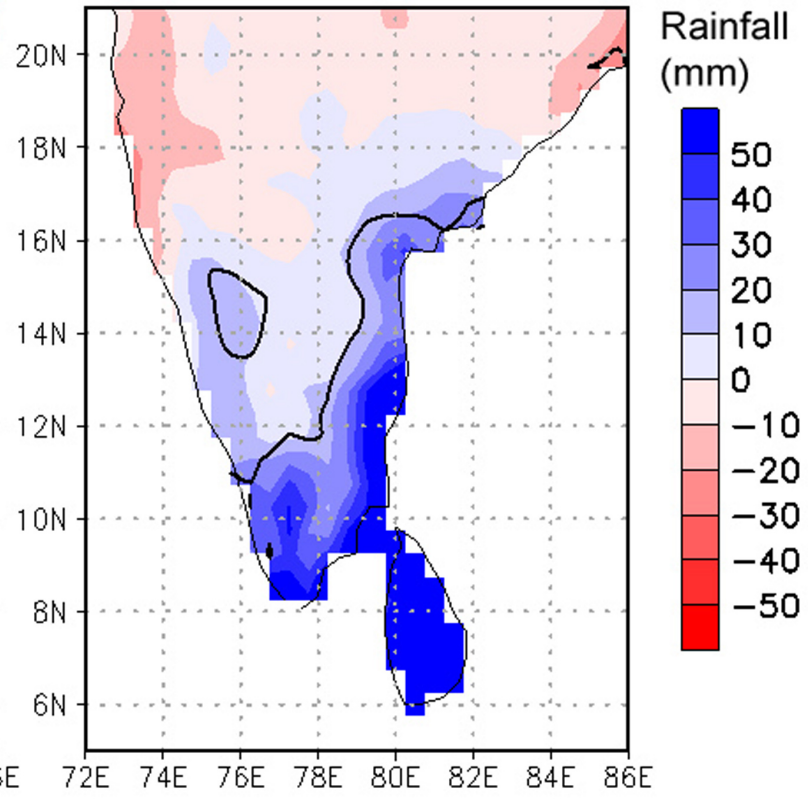

Figure 4.6 Rainfall deviation ( $\mathrm{mm} /$ month) during El Niño years from the climatological normal (a) SWIMR season, and (b) NEIMR season. Significant regions at the 95\% level were contoured.

\subsubsection{Climatic variability, 500-1900 CE}

Between 850 and $1280 \mathrm{CE}$, El Niño-like conditions (Figure 4.7(a)) and attenuated SWIMR conditions (Figure 4.7(b)) were recorded. During that period, the SAMI was also lower during the Chola rule and remained so until $1600 \mathrm{CE}$ compared to the period after $1600 \mathrm{CE}$ (Figure 4.7(c)). The SWIMI for the period 600-1500 CE (Figure 4.7(b)) indicates that decade-long droughts were recorded during the 9th to 12th centuries $\mathrm{CE}$ (Sinha et al. 2007, Chauhan et al. 2010, Tiwari et al. 2011). Yadava and Ramesh (2004) compared the reconstructed Indian Summer Monsoon rainfall record from the Gupteswar Stalactite with the marine sediment record from the eastern Arabian Sea (Von-Rad et al. 1999). Their comparisons also showed that the SWIMR was suppressed between the 9th and 12th centuries CE. The results of Figure 4.7(b) and all other available paleoclimatic records support the inference of attenuated SWIMR conditions during the period 8001200 CE. The SOI proxy data (Figure 4.7(a)) indicate more frequent El Niño-like conditions (i.e., negative SOI) during the period 850-1280 CE. 


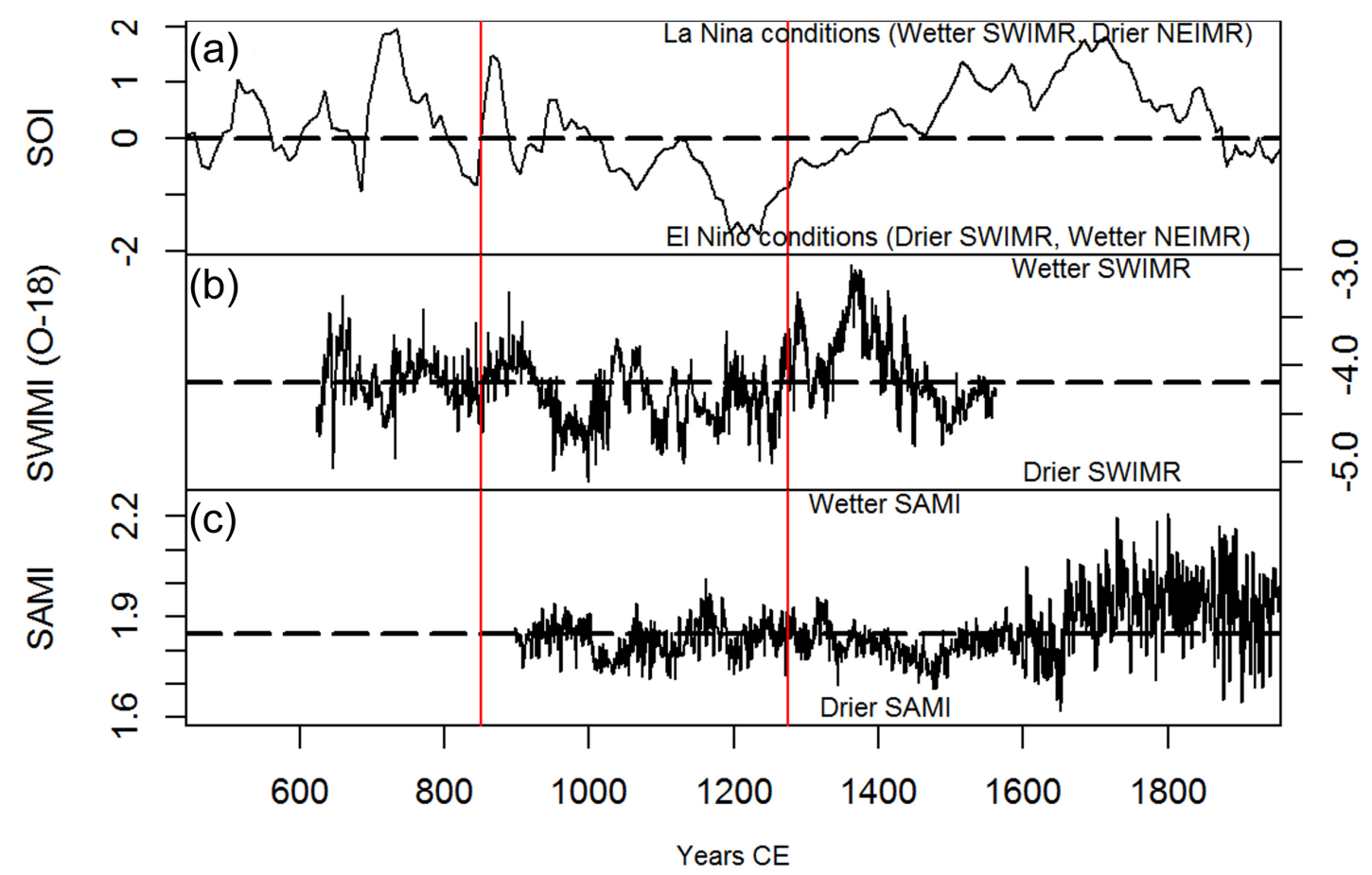

Figure 4.7 Time series of monsoon variability (500 to 1900 CE) based on three different geologic proxies. (a) SOI, after Yan et al. (2011), (b) Oxygen isotope values ( 1180$)$, a proxy for the South-West Indian Monsoon Index, as elaborated by Sinha et al. (2007) from speleothem geochemistry at Dandak caves, and (c) South Asian Monsoon Index after Shi et al. (2014). Vertical lines are lower and upper time brackets of the golden age of the Chola Kingdom (850-1280 CE) and horizontal dashed lines are means of each time series.

\subsection{Discussion}

\subsubsection{Potential causes for the rise of the Chola Kingdom}

Changes in land use and land cover are caused by a combination of variables such as climate, environmental catastrophes, land administration and planning, technological innovation, wars, and many other factors. From the results presented above on climate variability in peninsular India during the last 1500 years, three potential contributors to the rise of the Chola Kingdom between 850 and $1280 \mathrm{CE}$ are inferred: (1) enhanced rainfall conditions over Chola territory, (2) comparatively unfavorable climatic 
conditions in the neighboring Chalukya, Pallava and Pandya territories, and (3) technology-based adaptation strategies to the climate-induced opportunities. Many interdependent political aspects also contributed to the economic and territorial strength of the Chola kingdom as discussed in section 4.2.1.

Comparatively unfavorable climatic conditions in the neighboring kingdoms. The attenuated SWIMR and prolonged drought conditions are likely to have put agricultural productivity under stress due to rainfall deficits in the Chalukya Kingdom, which is located in the SWIMR-dominated regions. Today, crop yields are strongly associated with monsoon regime (Krishna Kumar et al. 2004). Similarly, Prasanna (2014) inferred that an increase (decrease) in Indian summer monsoon rainfall is generally associated with an increase (decrease) in national food grain yield (period of interest: 1967-2010). The relationship between agriculture and monsoon rainfall variability in modern times indicates that past climatic variability, particularly conditions of attenuated SWIMR, could have affected the agricultural sector to a similar or even greater extent. In the case of the Pandya Kingdom, the capital city (Madurai) was located in the NEIMR region, with its limited agricultural lands to the west and southwest of Madurai receiving more water resources from SWIMR rather than from NEIMR. Attenuated SWIMR might, therefore, have put Pandyan territory to some disadvantage, although less so than the Chalukya Kingdom given the dense network of tank storage systems in this NEIMRdominated Pandyan region already at that time (Mialhe et al. 2008, Gunnell et al. 2007).

The weaker SWIMR (Dhavalikar 2002, Gupta et al. 2003) during the Medieval Climate Anomaly, which implied diminished discharge in SWIMR-supplied Deccan rivers, made water resources less dependable in Chalukya territory. However, between 1150 and $1200 \mathrm{CE}$ the SWIMR was above average (Figures 7(b, c)), which could be one of the reasons why the Chalukya Kingdom briefly regained "superpower" status during this period. Kanchipuram, the capital city of the Pallava Kingdom, was located in the NEIMR-dominated region. As such it would have received surplus NEIMR, with large interannual variability (see the large temporal variation in Figure 4.4) and additional exposure to cyclone hazards because of its relative proximity to the coast (Gunnell et al. 2007, UNDP 2013, Indian Meteorological Department 2012). The majority of water 
harvesting structures in Pallava territory were built under the patronage of Chola rulers from 850 to $1280 \mathrm{CE}$ (Figure 4.8, Balasubramanyam 1966, Srinivasan 1991), which indicates that the Pallava Kingdom might not have initially possessed a sufficient base of water harvesting structures to optimize runoff harvesting and flood control during highrainfall cyclonic years and to manage the consequences of extreme climatic hazards through sovereign or independent means.

Enhanced rainfall conditions at the core of the Chola Kingdom. The Chola landscape benefited directly from NEIMR and indirectly from SWIMR via the perennial Kaveri River. Even when one monsoon failed, rural and urban communities would have the second monsoon system on which to rely during the subsequent season. Instrumental data for the 20th century have shown that it is unusual for both monsoons to fail during successive seasons. For instance, deficits $(-20 \%$ deviation from the climatological normal, as defined by the Indian Meteorological Department (2015a)) of SWIMR and NEIMR occurring in the same year were recorded only twice between 1901 and 2010 CE. In an essentially agrarian society (e.g., Subbarayalu 2012), the availability of rainand riverwater distributed across two seasons throughout a landscape equipped with a vast water storage capacity would have been advantageous in terms of increasing food production. On decadal to centennial time scales, the Chola Kingdom would have benefited most from NEIMR during the attenuated SWIMR conditions, i.e. under the enhanced El Niño-like conditions between 850 and $1280 \mathrm{CE}$. Because of the surplus water resources from NEIMR, the Chola Kingdom appears to have attained relatively high food production. Subbarayalu (2012) has provided a rough estimate of 1300 villages existing in the heartland of Chola territory during the 11th century. Each village of 1000 households would have produced an average grain output of 87,000 metric tons each year (Subbarayalu 2012), confirming the hypothesis inference of a large food capacity subsistence base. In summary, the long-term and above-normal NEIMR conditions, supplemented by capital cities strategically situated in the floodplains of the SWIMR-fed Kaveri River and its canals and delta distributaries, would have secured surplus food production in the Chola Kingdom to emerge as a prosperous, superpower after $850 \mathrm{CE}$, peaking during the 11 th century $\mathrm{CE}$. 
Adaptation strategies to capture optimum benefits from NEIMR. The spatial patterns of temple construction for each time slice of Chola rule indicate that construction works were heavily focused on the NEIMR-dominated regions (southeastern coastal belt of Tamil Nadu) (Figure 4.8). South Indian society appears to have acquired a deep empirical understanding of the South Indian climate (Gunnell et al. 2007). Chola rulers maintained their capital cities within the NEIMR-dominated regions while devising strategies based on building resilient rain- and river-fed tank systems that could adapt to climatic variability involving extremes from droughts to cyclones. For example, the Cholas experienced devastating floods in their erstwhile capital city, Uraiyur, which stood in the Kaveri River floodplain near Tiruchirappalli during the 8th century (Niranjanadevi 2012). However, SWIMR became unreliable from the 9th century (Figure 4.7(b)). Apparently as a result of these drier SWIMR conditions, the Chola Kingdom strategically moved its administration to Thanjavur by the 10th century, and then again to Gangaikondacholapuram in the 11th century CE (both situated at safe distances from the active Kaveri floodplain) — thus perhaps chasing after the shifting wetter epicenters of the NEIMR-dominated coastal hinterland (see Figure 4.1(a)).

Overall, the spatial pattern of temple and tank construction between 850 and 1280 $\mathrm{CE}$ indicates that greater preference was given to NEIMR-dominated southeastern India rather than any other climatic subregion (Figure 4.8). Although the tanks are primarily designed to buffer drought conditions and operate as useful runoff harvesting structures even during normal rainfall years, they are also effective flood-mitigation devices. Given the high intensity of NEIMR meteorology, a succession of interconnected, dammed reservoirs along a slope will break the kinetic energy of runoff, delay the conveyance of overland flow, and contain water (Meter et al. 2014). Given that the Chola heartland receives up to $50-60 \%$ of its annual rainfall during the NEIMR season (Balachandran et al. 2006, Rajeevan et al. 2012), the tanks would have received maximum water from the heavy downpours (including cyclones) that occur during the NEIMR season.

The rules of Rajaraja I (985-1014 CE) and Rajendra I (1014-1044 CE) marked the pinnacle of Chola rule in terms of temple construction rate (see Table 4.1) and 
territorial extent. The Chola rulers not only built the tanks but also laid down principles for maintaining and managing them. These principles underwent changes during the successive periods, but they are still ingrained in rural culture and finely tuned to the ecology of water flow and other environmental constraints (Pandey et al. 2003, Mosse 2003). For example, the Chola kings gifted land to the temple authorities, who were exempted from land tax for the maintenance of temples and tanks (Srinivasan 1991, Subbarayalu 2012). In addition, army garrisons were stationed near the larger temples (Subbarayalu 2012). Therefore, various political and financial measures involving the concentration of power around temples and tanks were implemented to promote these water-harvesting structures as ways of improving agriculture in a region largely untouched by the SWIMR regime. Gunnell et al. (2007) hypothesized that the multiplication of water-harvesting structures could have resulted from either of two opposite causes: a response to increasing drought or, conversely, the conscious choice to capitalize on wetter times in order to increase agricultural yields and production, and hence to accelerate economic growth. Depending on how the problem is viewed, tank construction was thus either a risk-mitigating or a wealth-enhancing strategy-with nonetheless win-win outcomes in both cases. 
(a) C1 - 850 to $907 \mathrm{CE}$

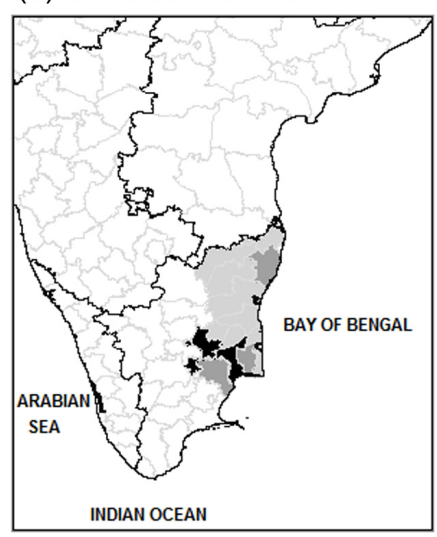

(d) C4 - 985 to $1014 \mathrm{CE}$

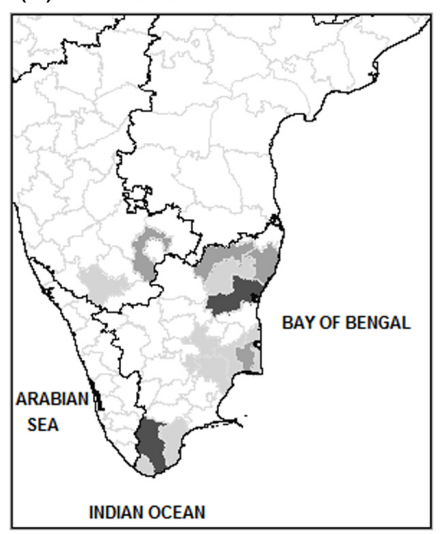

(g) C7 - 1070 to $1135 \mathrm{CE}$

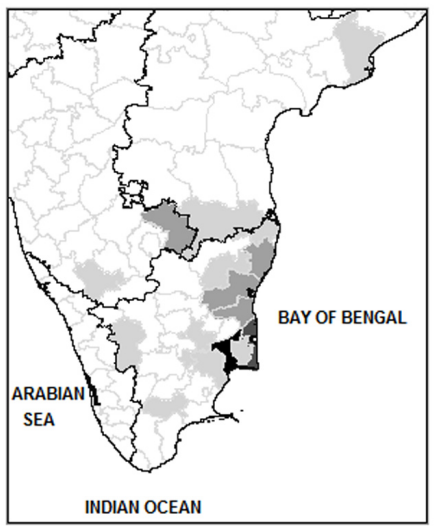

No. of temples by district

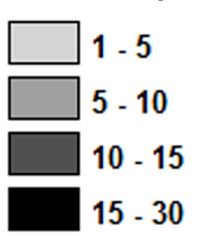

(b) $\mathrm{C} 2-907$ to $955 \mathrm{CE}$

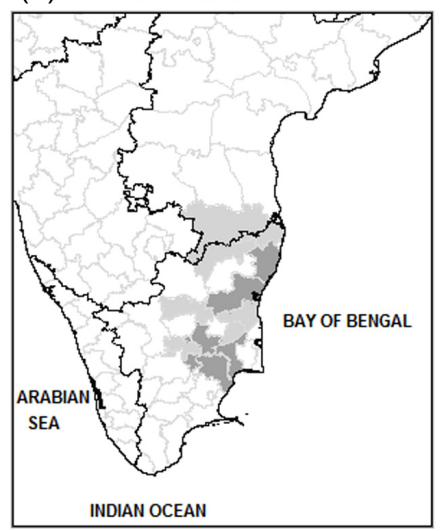

(e) C5 - 1014 to $1044 \mathrm{CE}$

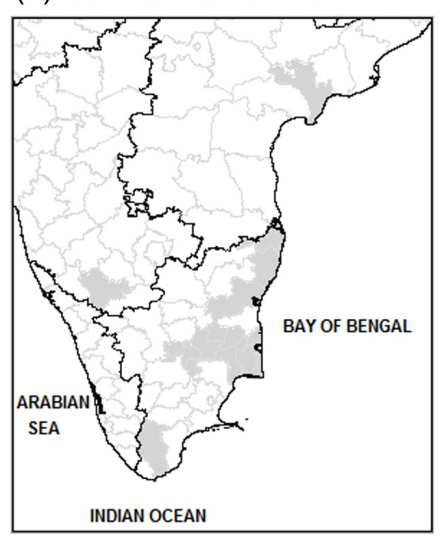

(h) $\mathrm{C} 8-1135$ to $1182 \mathrm{CE}$

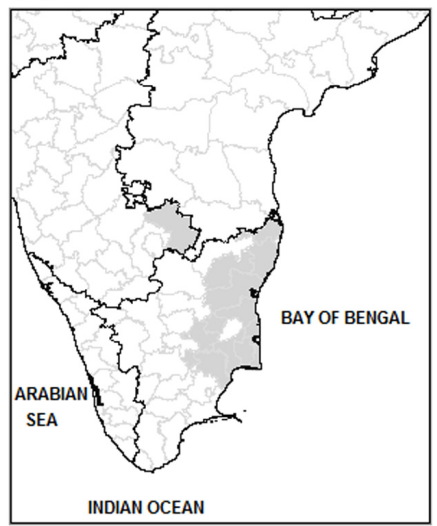

A (c) $\mathrm{C} 3-955$ to $985 \mathrm{CE}$

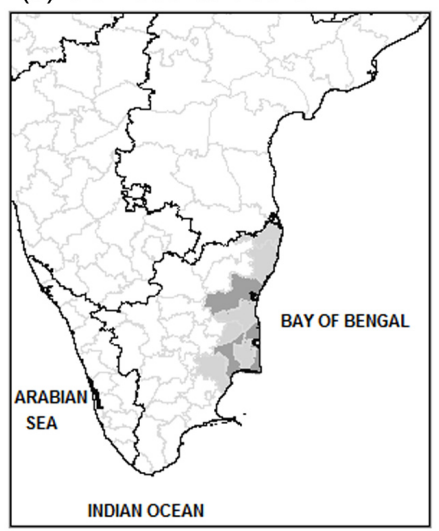

(f) $\mathrm{C} 6-1044$ to $1070 \mathrm{CE}$

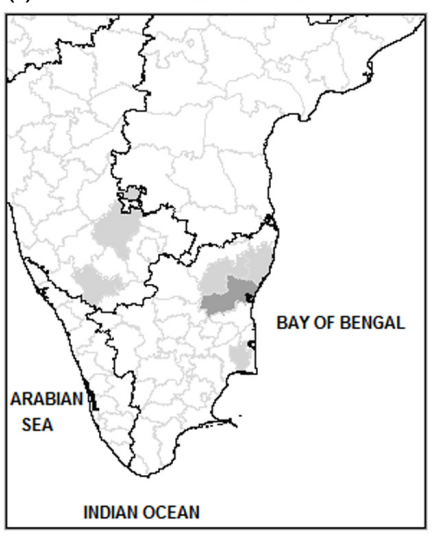

(i) C9 - 1182 to $1280 \mathrm{CE}$

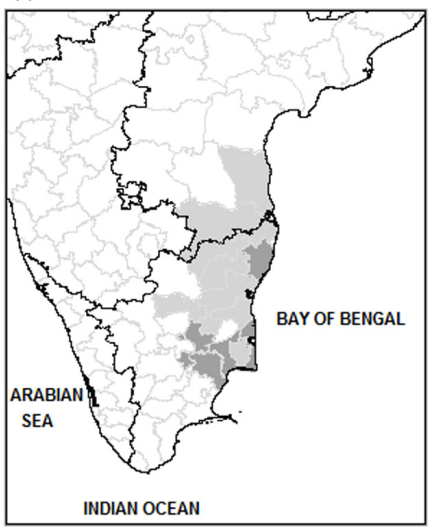

State boundary

District boundary

Figure 4.8 Spatial distributions of temple and tank construction works in South India. Maps show the number of temples constructed in each modern district between 850 and 1280 CE. C1 to C9: successive Chola periods as given in Table 4.1. 


\subsubsection{Societal response to climatic challenges during the Anthropocene}

The majority of global and regional economic crises during El Niño years have been well documented for post-Medieval times (Davis 2002) and suggest that vulnerability to El Niño events would have hampered socioeconomic resilience through recovery processes. On the other hand, the success of the Chola Kingdom supports the increasingly well-documented idea that ancient societies responded to short- and longerterm climatic change and developed adaptive strategies to cope with climatic variations, thus confirming the "lessening" hypothesis discussed by Bowden et al. (1981). Resulting technological adaptations, such as the temples, tanks and man-made lakes built by Chola laborers, have endured, and many are still functional today (Mialhe et al. 2008). The worst mega-drought of the modern era, caused by a strong El Niño, occurred in 1878 (Davis 2002, Cook et al. 2010). It affected crop production in the Madras Presidency (areas including the four South Indian States-Andhra Pradesh, Kerala, Karnataka, and Tamil Nadu, i.e. a territory roughly similar to the Chola superpower, Figure 4.1), where it resulted in the death of 1.5 million people (Davis 2002). However, three administrative districts situated in the heartland of the former Chola Kingdom (i.e. Thanjavur, Thiruvarur, and Nagapattinam) were less severely affected by famine and mass mortality than many other parts of the British Raj (Macleane 1885), chiefly because the well capacitated tank system helped to buffer the impacts of acute monsoon failure. This suggests that innovation and adaptation strategies based on time-tested indigenous knowledge can have long-lasting benefits for societies when they provide resilience for managing the impacts of climate variability.

The proportion of irrigated lands through the traditional tank irrigation system at the beginning of the 21 st century was $46 \%$ less than it was in the 1960 s because of poorly predictable rainfall patterns and changes in agricultural practices (TNSPC 2012). In the wake of the Green Revolution, groundwater irrigation was deemed more dependable for farmers than gravity-driven irrigation. Along with the shift toward more energy-hungry, often pump-driven irrigation practices, maintenance of the traditional waterways and common-property water harvesting structures declined as a result of this growing 
privatization of water management (Gunnell and Anupama 2003, Jegadesan and Fujita 2011, UNDP 2013).

Against the backdrop of substantial landscape changes resulting from the growing dereliction of village-scale tank irrigation system in favor of farm-scale pump irrigation in the last 30 or so years, the consequences of landscape-scale tank mismanagement can be observed in the context of extreme events such as the heavy cyclone rainfall of late 2015 in the NEIMR region of Tamil Nadu. On 01-02 December 2015, a rainfall station at Tambaram (Kanchipuram district) recorded $490 \mathrm{~mm} /$ day, and Chembarambakkam (Thiruvallur district) recorded $140 \mathrm{~mm}$ /day (Indian Meteorological Department 2015b). The torrential rains were a historical maximum for those areas. This succession of meteorological events caused substantial material destruction, including significant loss of life, in the coastal districts of Tamil Nadu, with widespread flooding and waterlogging. Many assessments of the damage caused by this intense, but not exceptional, event ascribed the aggravated vulnerability of the region to such meteorological conditions to the dereliction of the interconnected tank network constructed by the Chola rulers during the Chola and Pallava periods, and to its failing capacity to serve as a flood-hazard mitigation system (The Hindu 2016, The Indian Express 2016, BBC 2016).

Increasing greenhouse gas emissions, warming climate, and changes in precipitation pattern have been emphasized by the Intergovernmental Panel on Climate Change (IPCC) as key features of the Anthropocene epoch (Stocker et al. 2013, IPCC 2014, Field et al. 2014). Some of the climate-altering changes in land use and land cover have been documented in India (e.g. Douglas et al. 2006, Lee et al. 2009). Likewise, the 2015 flood in Tamil Nadu provides another example of how changes in land use and how ignoring indigenous water management practices can aggravate the potentially harmful impacts of natural hazards on human livelihoods. Current climate adaptation plans tend to focus on 20th century experience because of data limitations. For southeast India, this study suggests it is critical to reach farther back in time and pay attention to the "natural experiments of history" (Diamond and Robinson 2010) during the last two thousand years or more. If past centuries featuring wetter episodes, such as recorded for example during Medieval time, recur without appropriate preparedness and adaptation, recent 
signs indicate that the situation could be threatening for densely populated southeast India, with impacts perhaps much worse than the impacts observed during the 2015 flood. Planning adaptation strategies for southeast India should gain from a holistic examination of human history and its responses to climate change.

Water harvesting structures are as relevant to the Anthropocene as they were to their Chola initiators, not just for the purpose of irrigating agricultural lands but also for supplying drinking water and enabling groundwater recharge. Furthermore, South Indian tanks contain water but also sediment, flora and fauna. They thus support fish livestock, aquatic plants (some edible), pottery and brickmaking activities, all of which provide additional income to certain sections of the village population (Gunnell and Anupama 2003, Asian Development Bank 2006). Tanks in southern India also provide a place for forestry activities, from which timber, fruits, fuel, and habitat for wildlife (particularly birds: some South Indian tanks are natural reserves for resident and migratory bird situated on the Central Asian Flyway: Islam and Rahmani 2005). Another resource is land, given that during the dry season the tank foreshore typically becomes pasture for the village herd, often overgrown by scrub vegetation used for fuelwood (particularly when runs of consecutively drier years fail to fill the tank and, therefore, to irrigate its command area), and even simple runoff agriculture in the tank bed itself. These commonproperty tanks serve as floodwater retention areas that can store huge amounts of the stormwater runoff and thereby minimize the flooding risk during the cyclone season (Balasubramanian undated). The restoration and rehabilitation of these multi-purpose "no regrets" water harvesting structures of the Chola period in southern India and Sri Lanka (Gilliland et al. 2013) is of resounding relevance to the environmental uncertainties of the Anthropocene - not just as fascinating cultural heritage but as functional man-made environmental capital suited to sustaining long-term agricultural and societal resilience.

\subsection{Summary}

This chapter reveals a coincidence between long-term rainfall variability and the rise of the Chola Kingdom during the Early Medieval Period of Indian history. Climatic 
data analysis for the modern instrumental period (1901-2010) indicates that the SOI is one of the influencing factors in SWIMR and NEIMR variability, and more so during El Niño years. Although the impacts of drought on earlier societies cannot be assessed with the same methods as the modern era, some useful lessons can nonetheless be learned for the Anthropocene from an understanding of premodern paleodrought impacts. The identified modern relationships allow existing historical records to be deciphered in a paleoclimatologically relevant perspective. These records indicate that El Niño-like conditions occurred more frequently during the period between 850 and $1280 \mathrm{CE}$ than during any time prior (500-850 CE) or subsequent (1280-1900 CE) to it. The enhanced NEIMR over the Chola territory and comparatively unfavorable climatic conditions over the neighboring kingdoms from 850 to $1280 \mathrm{CE}$ (El Niño-dominant period) were advantageous to the Chola Kingdom. The Chola strategy of building tanks in the NEIMR regions helped them to harvest and store water for domestic and agricultural purposes. Their effective adaptation strategies to a variable climate, combined with robust governance practices and a cohesive allegiance to the king, would have helped them to develop substantial agricultural surpluses, and to provide the necessary economic purchase to rise even further as a powerful empire ruling over SWIMR-dominated regions in South India, Sri Lanka, and parts of Southeast Asia. The spatial diffusion of their construction technologies indicates that the Chola Kingdom was able to expand its territory to a greater extent and replicate its strategies by building more temples and tanks beyond its heartland, eventually carrying the technology over from Tamil Nadu into Karnataka, which entered its own "golden age of tanks" under Vijayanagar rule after the 13th century CE (Morrison 2015), when climatic fortunes turned and SWIMR began to strengthen its hold on that region to new advantage. The Chola rulers also deployed a variety of administrative strategies which also contributed to their supremacy in South India. However, I suggest that this political dimension was an enhancing ingredient crafted by the successive Chola rulers to capitalize on the climate-related economic opportunities of the time rather than a purely "sui generis" feature of civilizational genius - disconnected from the environmental context of the time.

This case study illuminates how, for example, the Chola historical heartland proved more resilient that other regions of the Indian subcontinent during the El Niño-driven 
mega-droughts of 1876-1878, when famine killed millions in India and around the world. Likewise, the consequences of chronic mismanagement of the extant Chola tank system were illustrated in 2015 by the devastating impacts on human livelihoods and infrastructure of extreme-yet fairly typical, by historical standards-meteorological events. One key conceptual value of the Anthropocene lies in the importance of learning from the lessons of the past in order to prepare for the future. A recurrence of centuries of wetter NEIMR periods, or of intense rainfall events such as those of 2015, is a possibility of the future. If historical knowledge is ignored, this is likely to increase the vulnerability of human communities in an era of changing climate and accelerated land-use change, where the capacity of the landscape (whether natural or man-made) to behave in predictable ways becomes modified beyond the response and stewardship capacity of land managers. The tanks serve as an effective mitigation option to manage the negative impacts of flood and drought in South India. Growing water demand from a growing human population in highly variable rainfall zones of South India thus calls for continued rehabilitation of existing tanks. Given further that the region has reached peak groundwater extraction, the restoration and perhaps expansion of these tank systems is of great importance for assisting with groundwater recharge. The proper maintenance of this water harvesting infrastructure also supports rural livelihoods in many other ways, such as raising livestock, fish farming, pottery-related crafts, and brickmaking work. Natural hazard mitigation and economic prosperity and social well-being (which partly hinge on avoiding the loss of crops, buildings and human lives as a consequence of extreme climatic events) are two sides of the same coin. The Cholas understood this and invested in a "no regrets" system of its time where a second, tank-irrigated cropping season was a vehicle for shorter-term enrichment, but where the infrastructure and its wide spread across the landscape also became a long-term insurance system against famine (illustrated by the 1878 ENSO famine) and flood damage. Planners and policymakers should thus gain from restoring value to the existing tank system as a means of managing climatic risk in South India, and for ensuring the related goals of food security, food sovereignty, and urban flood hazard in a suitably managed, "capable" landscape. 


\section{Dissertation conclusion}

\subsection{Summary}

In the first research question, the spatio-temporal variations of NEIMR at pentad time step were examined and the probability of its occurrence during 1982-2014 were identified using the Hidden Markov Model (HMM). Three rainfall states were identified during the NEIMR season, which were the wet (State-1), the coastal wet (State-2), and the dry (State-3) states. Seasonal total NEIMR was significantly and positively correlated with the frequency of State-1, whereas it was negatively correlated with that of State-3, indicating the crucial role of the rainfall states in determining water requirements in the southeastern peninsular India. The rainfall states were associated with distinctive atmospheric circulation and temperature patterns, particularly the wet (State-1) and the dry (State-3) conditions. The wet conditions were characterized by enhanced cyclonic activities and increased moisture convergence at $850 \mathrm{hPa}$ over the southeastern peninsular India and its neighboring oceanic regions (Bay of Bengal and Indian Ocean). In contrast, the dry conditions were associated with the anticyclonic circulation and the reduced moisture convergence at $850 \mathrm{hPa}$. The plausible physical mechanisms behind the wet (dry) condition could be that anomalous warmer (cooler) land temperature above $20^{\circ} \mathrm{N}$ induced lower (higher) sea level pressure anomalies and drove anomalous southwesterly (northeasterly) surface winds over the NEIMR region. These anomalous surface winds and the associated lower-level cyclonic (anticyclonic) circulations could enhance (suppress) moisture transport from the convergence regions over the Bay of Bengal and northern Indian Ocean into the southern peninsular of India. Overall, the findings reveal that the pentad variability of NEIMR with the classified three rainfall states and the key atmospheric circulation and temperature patterns linked to these rainfall states.

In the second research question, the associations between the pentad NEIMR over the southeastern peninsular India with the ocean and atmospheric conditions over the surrounding oceanic regions during the months of October to December for the period 1985-2014 were identified. The non-parametric correlation and composite analyses were carried out for simultaneous and lagged time steps (up to four lags) of oceanic and 
atmospheric variables with pentad NEIMR. The results indicate that NEIMR was significantly correlated: 1) positively with both sea surface temperature (SST) during the lag-2, lag-3 and lag-4 time steps and latent heat flux (LHF) during the same and lag-1 time steps, over the equatorial western Indian Ocean region, 2) positively with SST and negatively with LHF during all the simultaneous and lag time steps, over the Bay of Bengal region. During the wet NEIMR pentads over the southeastern peninsular of India, SST significantly increased over the Bay of Bengal during all the time steps and the equatorial western Indian Ocean during the lag-2, -3 , and -4 time steps, while the LHF decreased over the Bay of Bengal (all time steps) and increased over the Indian Ocean (same and lags-1 and -2). The investigation on ocean-atmospheric interaction revealed that the enhanced LHF over the equatorial western Indian Ocean was related to increased atmospheric moisture demand and increased wind speed, whereas the reduced LHF over the Bay of Bengal was associated with decreased atmospheric moisture demand. The vertical integrated moisture flux and moisture transport vectors from 1000 to $850 \mathrm{hPa}$ exhibited that the moisture was carried away from the equatorial western Indian Ocean to the strong moisture convergence regions of the Bay of Bengal during the same and lag-1 time steps of wet NEIMR pentads. Further, the moisture over the Bay of Bengal was transported to the southeastern peninsular through stronger cyclonic circulations, which was confirmed by the moisture transport vectors and positive vorticity. The identified ocean and atmospheric processes, associated with the wet NEIMR conditions over the southeastern peninsular of India, could be a valuable scientific contribution for enhancing rainfall predictability, which has a huge socioeconomic value to the agricultural and water resource management sectors in the southeastern peninsular India.

In the third research question, the lessons drawn from how the societies in South India adapted to varying climate in the past was examined. An investigation of instrumental and proxy climatic datasets between 500 and $2010 \mathrm{CE}$ indicates that the period between $\sim 850$ and $\sim 1300 \mathrm{CE}$, a time of frequent El Niño-like conditions, was associated with a substantial increase in NEIMR, whereas South-West Indian monsoon rainfall (SWIMR) suffered substantial deficits. The spatial pattern and chronology of water-harvesting infrastructure development under Chola rule indicate that these features were concentrated in the NEIMR-receiving regions of southeastern India and that their 
construction peaked during El Niño-dominated intervals. Overall, enhanced NEIMR conditions and adaptation strategies practiced in the Cholas territory, combined with less favorable climatic conditions over the neighboring kingdoms, appears to have underpinned the well-documented political and economic strengths of the Chola superpower. It is inferred that the water management infrastructure promoted by the Chola rulers helped to buffer the consequences of climatic extremes in later history, whether droughts (e.g. the El Niño-related mega-drought of 1876-1878) or floods (because the reservoirs can contain surplus runoff). More recently, however, a preference for groundwater irrigation and other landscape changes driven by population pressure has made the region more vulnerable to the incidence of heavy NEIMR episodes, as illustrated by the severe floods of 2015. Future climate adaptation planning in South Asia should appreciate the merits of restoring and expanding the currently decaying legacy of Chola-style "no regrets" water management infrastructures.

\subsection{Future works}

The farmers, decision makers from the agriculture sector, and other planning agencies in the southeastern peninsular of India are lacking reliable longer lead-time (more than a week time) rainfall forecast information, but it is critical for decisionmaking in the agricultural sector to manage climate associated risks. This dissertation revealed the persistence of three distinct rainfall states and the key atmospheric circulation and temperature patterns linked to these rainfall states. In addition, the driving forces behind ocean and atmospheric conditions and moisture transport processes associated with the wet NEIMR conditions were identified with a temporal evolution (various lags). The identified driving ocean and atmospheric conditions could be used to develop an intra-seasonal statistical forecasting model. The reanalyses data set used in this study was at lower resolution, however if there are data sets available with better spatial resolution, that could create improved chances for better understanding synoptic patterns and physical processes associated with the regional NEIMR variability. As the seasonal NEIMR variability was associated with the inter-annual climate indicator of Southern Oscillation Index (SOI), the relationship could be used in the forecasting model 
to predict the seasonal characteristics of NEIMR. Further, the intra-seasonal ocean and atmospheric drivers could be used to predict the intra-seasonal NEIMR variability. Tamil Nadu State Planning Commission's 2012-2017 planning document highlighted that there is a willingness to incorporate climate forecast information at various time scales to minimize the climate associated losses in Tamil Nadu (GoT, 2012). The policy makers in Tamil Nadu welcome such initiative as a positive sign for developing new tools and practices of climate risk management in the future. Developing forecast tools will be helpful to convince the policy makers for developing programs and projects to benefit millions of rice cultivating households at-risk in Tamil Nadu.

An intermediate complexity global circulation model (PlaSim; Fraedrich et al. 2005) was used to investigate the sensitivity of NEIMR over the southeastern peninsular India to the changed SSTs over the Bay of Bengal and the equatorial western Indian Ocean regions. The observed interactions between ocean and atmosphere over the two oceanic regions described in section 3 could not be simulated successfully. The modeling results highlighted that the parameterization for the ocean and atmosphere interactions over the Indian Ocean might need to be improved in climate models. The identified ocean and atmospheric processes, associated with the wet NEIMR conditions over the southeastern peninsular India from this dissertation, could be a valuable scientific input for enhancing the rainfall simulations not only at intra-seasonal but also potentially at seasonal and longer term in climate models. A modeling experiment could be designed with a more complex global circulation model with improved spatial resolution to evaluate how the dynamics of ocean and atmospheric interactions over the Bay of Bengal and Indian Ocean are simulated and how they are associated with wet conditions over the southeastern peninsular India.

The role of land on the NEIMR was not investigated in this dissertation. However, the land could have a role on the monsoon circulation and rainfall distribution. Meehl et al. (1994) proposed an internal feedback mechanism that highlighted that increased evaporation and transpiration increased the upward latent heat fluxes, and further increased the moisture in the atmosphere conducive for convective activities over 
land. The preliminary investigation on land parameters at pentad time step did not show any clear results. Probably, the land might have a role on influencing the diurnal variability of NEIMR. The land surface temperature and soil moisture conditions could provide a favorable or unfavorable environment for cyclones to make landfall and propagation in to the interior landmass. For example, the warmer landmass over China attracted more super typhoons, which originated in the South China Sea and made landfall over China (Xu et al. 2013). Similarly, for the SWIMR season, the antecedent ground wetness over the Indian subcontinent provided a favorable condition for monsoon depression and cyclonic storms to penetrate deeper into the Indian landmass (Kishtawal et al. 2013). As the ocean-atmosphere condition indicated about the stronger cyclonic circulations contribution to the wet NEIMR conditions over the southeastern peninsular India, exploring the roles of land conditions on influencing the cyclonic events crossing the southeastern India would address some of the scientific gaps identified from the past studies. 


\section{Bibliography}

Adamson G (2014) Institutional and community adaptation from the archives: A study of drought in western India, 1790-1860. Geoforum 55: 110-119.

Adiceam E (1966) La géographie de l'irrigation dans le Tamil Nadu. Pondicherry: École Française d'Extrême Orient (in French).

Albert RM (2015) Anthropocene and early human behavior. The Holocene 25(10): 15421552.

Asian Development Bank (2006) Rehabilitation and management of tanks in India-A study of select States. Available at https://thinkasia.org/bitstream/handle/11540/5073/rehabiliation-managementtanks.pdf?sequence=1 (accessed 15 August 2016).

Balachandran S, Asokan R, Sridharan S (2006) Global surface temperature in relation to Northeast Monsoon Rainfall over Tamil Nadu. Journal of Earth System Science 115(3): 349-362. doi:10.1007/BF02702047.

Balasubrahmanyam SR (1966) Early Chola art. New Delhi: Asia Publishing House. Balasubrahmanyam SR (1971) Early Chola temples: Parantaka I to Rajaraja (AD 907985). Mumbai: Orient Longman.

Balasubrahmanyam SR (1977) Middle Chola temples: Rajaraja I to Kulottunga I (AD 985-1070). Kolkata: Oriental Press.

Balasubrahmanyam SR, Natarajan B, Ramachandran B (1979) Later Chola temples: Kulottunga I to Rajendra III (AD 1070-1280). Chennai: Mudgala Trust.

Balasubramanian (undated) Institutional landscapes in common pool resource management: a case study of Irrigation tanks in South India. Available at https://dlc.dlib.indiana.edu/dlc/bitstream/handle/10535/1742/Balasubramanian_R. pdf? sequence $=1$ (accessed 15 August 2016)

Banacos PC, Schultz DM (2005) The use of moisture flux convergence in forecasting convective initiation: Historical and operational perspectives. Weather and Forecasting 20(3): 351-66. doi:10.1175/WAF858.1.

Barah BC (1996) Traditional water harvesting systems: an ecological economic survey. New Delhi: New Age International Limited. 
Barradas RA, Nigam S (2013). Atmosphere - Land-surface Interactions over the Southern Great Plains: Characterization from Pentad Analysis of DOE-ARM Field Observations and NARR Reanalysis. Journal of Climate 26(3): 875-886. doi:10.1175/JCLI-D-11-00380.1.

BBC (2016) Why is India's Chennai flooded? Available at http://www.bbc.com/news/world-asia-india-34992004 (accessed 02 August 2015).

Berkelhammer M, Sinha A, Stott L, Cheng H, Pausata FSR, Yoshimura K (2012) An abrupt shift in the Indian monsoon 4000 years ago. In: Giosan L, Fuller D, Nicoll K, Flad RK, Clift, PD (Eds), Climates, Landscapes, and Civilizations. Geophysical Monograph Series 198, American Geophysical Union, Washington D.C., pp. $75-87$.

Bocinsky RK, Kohler TA (2014) A 2,000-year reconstruction of the rain-fed maize agricultural niche in the US Southwest. Nature Communications 5: 5618, doi: 10.1038/ncomms6618.

Bowden MJ, Kates RW, Kay PA, Riebsame WE, Warrick RA, Johnson DL, Gould HA, Weiner D (1981) The effect of climate fluctuations on human populations: two hypotheses. In: Wigley TML, Ingram MJ, Farmer G (eds.) Climate and History. Cambridge: Cambridge University Press, pp. 479-513.

Bracken C, Rajagopalan B, Zagona E (2014) A hidden Markov model combined with climate indices for multidecadal streamflow simulation, Water Resour. Res. 50: 7836-7846. doi:10.1002/2014WR015567.

Bradley RS (2014) Paleoclimatology: reconstructing climates of the Quaternary. San Diego: Academic Press.

Bryson RA, Murray TJ (1977) Climates of Hunger. Madison: University of Wisconsin Press.

Buckley BM, Anchukaitis KJ, Penny D, Fletcher R, Cook ER, Sano M, Hong TM (2010) Climate as a contributing factor in the demise of Angkor, Cambodia. Proceedings of the National Academy of Sciences 107: 6748-6752. 
Bureau of Meteorology (2015a) S.O.I. (Southern Oscillation Index) Archives-1876 to present. Available at http://www.bom.gov.au/climate/current/soihtm1.shtml (accessed 23 May 2015).

Bureau of Meteorology (2015b) Southern Oscillation Index. Available at http://www.bom.gov.au/climate/enso/\#tabs=SOI (accessed 23 May 2015).

Champakalakshmi R (1986) Urbanization in Medieval Tamil Nadu. In: Bhattacharya S, Gopal S, Thapar R. (eds) Situating Indian history. New Delhi: Oxford University Press, pp. 35-68.

Champakalakshmi R (1996) Trade, Ideology and Urbanization: South India 300 BC to $A D$ 1300. New Delhi: Oxford University Press.

Charlotte BV, Simon EK, George G, Yesodharan S, Ruchith RD ( 2012) Intra-seasonal oscillation of northeast monsoon over southern peninsular India-an investigation. International Journal of Scientific and Research Publications 2(8): 1-22.

Chatfield C (1985) The initial examination of data. Journal of the Royal Statistical Society, Series A (General) 148(3): 214-253.

Chauhan OS, Dayal AM, Basavaiah N, Kader U (2009) Indian summer monsoon and winter hydrographic variations over past millennia resolved by clay sedimentation. Geochemistry, Geophysics, Geosystems 11(9). doi:10.1029/2010GC003067.

Clemens S, Prell W, Murray D, Shimmield G, Weedon G (1991) Forcing mechanisms of the Indian Ocean monsoon. Nature 353(6346): 720-725. doi:10.1038/353720a0.

Conroy JL, Overpeck JT, Cole JE (2010) El Niño/Southern Oscillation and changes in the zonal gradient of tropical Pacific sea surface temperature over the last $1.2 \mathrm{ka}$. PAGES news 18(1): 32-34.

Cook ER, Anchukaitis KJ, Buckley BM, D'Arrigo RD, Jacoby GC, Wright WE (2010) Asian monsoon failure and megadrought during the last millennium. Science 328: 486-489.

Cook ER, Woodhouse CA, Eakin CM, Meko DM, Stahle DW (2004) Long-term aridity changes in the western United States. Science 306: 1015-1018. 
Cullen HM, DeMenocal PB, Hemming S, Brown FH, Guilderson T, Sirocko F (2000) Climate change and the collapse of the Akkadian empire: evidence from the deep sea. Geology 28: 379-382.

Curtis JH, Hodell DA, Brenner M (1996) Climate variability on the Yucatan Peninsula (Mexico) during the last 3500 years, and implications for Maya cultural evolution. Quaternary Research 46: 37-47.

Davis M (2002) Late Victorian holocausts: El Niño famines and the making of the third world. London: Verso Books.

Dearing JA, Acma B, Bub S, Chambers FM, Chen X, Cooper J, Crook D, Dong XH, Dotterweich M, Edwards ME, Foster TH, Gaillard M-J, Galop D, Gell P, Gil A, Jeffers E, Jones RT, Anupama K, Langdon PG, Marchant R, Mazier F, McLean CE, Nunes LH, Sukumar R, Suryaprakash I, Umer M, Yang XD, Wang R, Zhang K (2015) Social-ecological systems in the Anthropocene: the need for integrating social and biophysical records at regional scales. The Anthropocene Review 2: $220-246$.

DeMenocal PB (2001) Cultural responses to climate change during the late Holocene. Science 292(5517):667-673.

Department of Agriculture and Cooperation. 2003. Drought 2002. Ministry of Agriculture: New Delhi, India.

Department of Environment (2006) State of environment of Tamil Nadu—2005. Available at http://envfor.nic.in/sites/default/files/SoE\%20report\%20of\%20Tamilnadu_0.pdf (accessed 23 May 2015).

Department of Statistics (2012) The statistics of Tamil Nadu-year 2011. Government of Tamil Nadu, Chennai.

Dhavalikar MK (2002) Environment and Culture: A Historical Perspective. Pune: Oriental Research Institute.

Diamond J (2005) Collapse: how societies choose to fail or succeed. New York: Viking Penguin.

Diamond J, Robinson JA (eds) (2010) Natural experiments of history. Cambridge: Harvard University Press. 
Dikshit GS, Kuppuswamy GR, Mohan SK (1993) Tank irrigation in Karnataka.

Bangalore: Gandhi Sahitya Sangha.

Dixit Y, Hoddell DA, Petrie CA (2014) Abrupt weakening of the summer monsoon in northwest India 4100 yr ago. Geology 42: 339-342.

Dommenget D, Latif M (2002) A cautionary note on the interpretation of EOFs. Journal of Climate 15(2): 216-225. doi:10.1175/1520442(2003)016<1087:COACNO >2.0.CO;2.

Douglas EM, Niyogi D, Frolking S, Yeluripati JB, Pielke RA, Niyogi N, Vörösmarty CJ, Mohanty UC (2006) Changes in moisture and energy fluxes due to agricultural land use and irrigation in the Indian Monsoon Belt. Geophysical Research Letters 33(14), doi:10.1029/2006GL026550.

Duplessy JC (1982) Glacial to interglacial contrasts in the northern Indian Ocean. Nature, 295: 494-498.

Endfield GH (2012) The resilience and adaptive capacity of social-environmental systems in colonial Mexico. Proceedings of the National Academy of Sciences 109(10): 3676-3681.

Evans JL (1993) Sensitivity of tropical cyclone intensity to sea surface temperature. Journal of Climate 6(6): 1133-1140. doi:10.1175/15200442(1993)006<1133:SOTCIT>2.0.CO;2.

Field CB, Barros VR, Dokken DJ, Mach KJ, Mastrandrea MD, Bilir TE, Chatterjee M, Ebi KL, Estrada YO, Genova RC, Girma B (2014) IPCC, 2014: Climate change 2014, impacts, adaptation, and vulnerability. Part A: Global and sectoral aspects. Contribution of Working Group II to the Fifth Assessment Report of the Intergovernmental Panel on Climate Change.

Fraedrich K, Jansen H, Kirk E, Luksch U, Lunkeit F (2005) The Planet Simulator: Towards a user friendly model. Meteorologische Zeitschrift 14(3):299-304.

Forney GD Jr (1978) The Viterbi algorithm. Proceedings of the IEEE 61: 268-278. Fujinami H, Yasunari T, Morimoto A (2014) Dynamics of distinct intra-seasonal oscillation in summer monsoon rainfall over the Meghalaya-Bangladesh-western Myanmar region: covariability between the tropics and mid-latitudes. Climate dynamics 43(7-8):2147-66. 
Gadgil S, Gadgil S (2006) The Indian monsoon, GDP and agriculture. Economic and Political Weekly 47: 4887-4895.

Gadgil S. 2003. The Indian monsoon and its variability. Annual Review of Earth and Planetary Sciences 31(1): 429-467. doi:10.1146/annurev.earth.31.100901.141251.

Ganesan M (2008) The temple tanks of Madras, India: rehabilitation of an ancient technique for multipurpose water storage. Indian Journal of Science and Technology 1: 1-8.

George G, Charlotte BV, Ruchith RD (2011) Interannual variation of northeast monsoon rainfall over southern peninsular India. Indian Journal of Marine Sciences 40(1): 98-104.

Gilliland K, Simpson IA, Adderley WP, Burbidge CI, Cresswell AJ, Sanderson DC, Coningham RA, Manuel M, Strickland K, Gunawardhana P, Adikari G (2013) The dry tank: development and disuse of water management infrastructure in the Anuradhapura hinterland, Sri Lanka. Journal of Archaeological Science 40(2): $1012-1028$.

Graham NE, Ammann CM, Fleitmann D, Cobb KM, Luterbacher J (2011) Support for global climate reorganization during the "Medieval Climate Anomaly". Climate Dynamics 37(5-6):1217-45.

Greene AM, Robertson AW, Kirshner S (2008) Analysis of Indian monsoon daily rainfall on subseasonal to multidecadal time-scales using a hidden Markov model. Quaterly Journal of the Royal Meteorological Society 134: 875-887. doi:10.1002/qj.

Gunnell Y (1997) Relief and climate in south Asia: The influence of the Western Ghats on the current climate pattern of peninsular India. International Journal of Climatology 17: 1169-1182. doi:10.1002/(SICI)10970088(199709)17:11<1169::AID-JOC189>3.0.CO;2-W.

Gunnell Y, Anupama K (2003) Past and present status of runoff harvesting systems in dryland peninsular India: a critical review. Ambio: A Journal of the Human Environment 32: 320-324.

Gunnell Y, Anupama K, Sultan B, Jussieu P, Ird-cnrs-upmc UMR, Curie M (2007) Response of the South Indian runoff-harvesting civilization to northeast monsoon 
rainfall variability during the last 2000 years: instrumental records and indirect evidence. The Holocene 2: 207-216. doi:10.1177/0959683607075835.

Gupta AK, Anderson DM, Overpeck JT (2003) Abrupt changes in the Asian southwest monsoon during the Holocene and their links to the North Atlantic Ocean. Nature 421: 354-357.

Guttorp P, Minin VN (1995) Stochastic modeling of scientific data. CRC Press: London, UK.

Hall K (1980) Trade and Statecraft in the Age of the Colas. New Delhi: Abhinav Publishers.

Harris I, Jones PD, Osborn TJ, Lister DH (2013) Updated high-resolution grids of monthly climatic observations. International Journal of Climatology 34: 623-642.

Haug GH, Gunther D, Peterson LC, Sigman DM, Hughen KA, Aeschlimann B (2003) Climate and the collapse of the Maya civilization. Science 299: 1731-1735.

He Y, Lee E (2016) Empirical relationships of sea surface temperature and vegetation activity with summer, Earth Interactions 20: 1-18. doi:10.1175/EI-D-15-0028.s1.

Heitzman J (1987) State formation in South India, 850-1280. Indian Economic Social History Review 24: 34-61.

Hu, Y., Zhong, Z., Liu, X. and Zhu, Y., 2012. Influence of air-sea interaction on the simulation of East Asian summer monsoon: a case study. Dynamics of Atmospheres and Oceans, 53, pp.1-16.

Hutton J (1899) Theory of the Earth: with proofs and illustrations. London: Geological Society.

Ihara C, Kushnir Y, Cane A, Pe VHDL (2007) Indian summer monsoon rainfall and its link with ENSO and Indian Ocean climate indices. International Journal of Climatology 27: 179-187.

Indian Meteorological Department (2012) Cyclone e-atlas. Available online at http://www.rmcchennaieatlas.tn.nic.in/login.aspx?ReturnUrl=\%2f (accessed 23 May 2015).

Indian Meteorological Department (2015a) Terminologies and Glossary. Available at http://www.imd.gov.in/doc/termglossary.pdf (accessed 23 May 2015). 
Indian Meteorological Department (2015b) Weekly rainfall update. Available at http://www.imd.gov.in (accessed 15 December 2015).

Indrapala K (1985) The overseas campaigns of Rajaraja I. Tamil Civilization 2(3): 48-85. International Research Institute. 2007. Hidden Markov Model Tools. Available online http://iri.columbia.edu/our-expertise/climate/tools/hidden-markov-model-tool/. (accessed 22 June 2015)

IPCC (2014) Climate Change 2014: synthesis report. Contribution of Working Groups I, II and III to the Fifth Assessment Report of the Intergovernmental Panel on Climate Change [Core Writing Team, R.K. Pachauri and L.A. Meyer (eds.)]. IPCC, Geneva, pp.151.

Islam MZ, Rahmani AR (eds) (2005) Important bird areas in India: priority sites for conservation. Mumbai and New Delhi: Bombay Natural History Society and Oxford University Press.

Jegadesan M, Fujita K (2011) Deterioration of the informal tank institution in Tamil Nadu: caste-based rural society and rapid economic development in India. Southeast Asian Studies 49(1): 99-123.

Joseph PV, Sijikumar S (2004) Intra-seasonal variability of the low-level jet stream of the Asian summer monsoon. Journal of Climate 17(7): 1449-1458. doi: 10.1175/1520-0442(2004)017<1449:IVOTLJ>2.0.CO;2.

Kalnay E, Kanamitsu M, Kistler R, Collins W, Deaven D, Gandin L, Joseph D (1996) The NCEP/NCAR 40-year reanalysis project. Bulletin of the American Meteorological Society 77(3): 437-471.

Kanamitsu M, Ebisuzaki W, Woollen J, Yang SK, Hnilo JJ, Fiorino M, Potter GL (2002) NCEP-DOE AMIP-II Reanalysis (R-2). Bulletin of the American Meteorological Society 83(11): 1631-1643. doi:10.1175/BAMS-83-11-1631.

Kanamitsu M, Ebisuzaki W, Woollen J, Yang SK, Hnilo JJ, Fiorino M, Potter GL (2002) NCEP-DOE AMIP-II Reanalysis (R-2). Bulletin of the American Meteorological Society 83(11): 1631-1643. doi:10.1175/BAMS-83-11-1631.

Kane RP (1998) ENSO relationship to the rainfall of Sri Lanka. International Journal of Climatology 18(8): 859-871. 
Koteswaram P (1958) The Easterly Jet stream in the tropics. Tellus 10(1): 43-57.

doi:10.1111/j.2153-3490.1958.tb01984.x.

Kripalani RH, Kumar P (2004) Northeast monsoon rainfall variability over south peninsular India vis-a-vis the Indian Ocean dipole mode. International Journal of Climatology 24(10): 1267-1282. doi:10.1002/joc.1071.

Krishna Kumar K, Kumar RK, Ashrit RG, Deshpande NR, Hansen JW (2004) Climate impacts on Indian agriculture. International Journal of Climatology, 24(11): $1375-1393$.

Krishna Kumar K, Rajagopalan B, Hoerling M, Bates G, Cane M (2006) Unraveling the mystery of Indian monsoon failure during El Niño. Science 314(5796): 115-119.

Krishnamurthy V, Goswami BN (2000) Indian monsoon-ENSO relationship on interdecadal timescale. Journal of Climate 13: 579-595.

Krishnamurthy V, Kinter III JL (2003) The Indian monsoon and its relation to global climate variability. In Rodo X, Francisco CA (Eds.), Global Climate (pp. 186236). Springer-Verlag: Berlin Heidelberg, Germany. doi:10.1007/978-3-66205285-3_10.

Krishnamurthy V, Shukla J (2000) Intra-seasonal and interannual variability of rainfall over India. Journal of Climate, 13(24): 4366-4377.

Krishnamurti TN, Tewari M, Rajendran K, Gadgil S (2002) A heavy winter monsoon rainfall episode influenced by easterly waves, a westerly trough, blocking and the ITCZ. Weather 57(10): 367-70. doi:10.1256/wea.37.02.

Kumar KK, Rajagopalan B, Cane MA (1999) On the weakening relationship between the Indian monsoon and ENSO. Science 284(5423): 2156-2159. doi:10.1126/science.284.5423.2156.

Kumar P, Kumar KR, Rajeevan M, Sahai AK (2007) On the recent strengthening of the relationship between ENSO and northeast monsoon rainfall over South Asia. Climate Dynamics 28(6): 649-60. doi:10.1007/s00382-006-0210-0.

Lau KM, Peng L (1987) Origin of low-frequency (intra-seasonal) oscillations in the tropical atmosphere. Part I: Basic theory. Journal of the Atmospheric Sciences 44(6): 950-972. doi: 10.1175/1520-0469(1987)044<0950:OOLFOI >2.0.CO;2 
Lee E, Chase TN, Rajagopalan B, Barry RG, Biggs TW, Lawrence PJ (2009) Effects of irrigation and vegetation activity on early Indian summer monsoon variability. International Journal of Climatology 29: 573-581. doi:10.1002/joc.1721.

Lee E, Barford CL, Kucharik CJ, Felzer BS, Foley JA (2011) Role of turbulent heat fluxes over land in the monsoon over East Asia. International Journal of Geosciences 2 (4): 420-431. doi:10.4236/ijg.2011.24046.

Lekshmy PR, Midhun M, Ramesh R (2015) Spatial variation of amount effect over peninsular India and Sri Lanka: Role of seasonality. Geophysical Research Letters 42(13): 5500-5507.

Lélé MI, Leslie LM, Lamb PJ (2015) Analysis of Low-Level Atmospheric Moisture Transport Associated with the West African Monsoon. Journal of Climate 28:4414-4430

Lewis SL, Maslin MA (2015) Defining the Anthropocene. Nature 519(7542): 171-180.

Li R, Lü S, Han B, Gao Y (2015) Connections between the South Asian summer monsoon and the tropical sea surface temperature in CMIP5. Journal of Meteorological Research 29:106-18.

Li S, Baizhu S, Zongting G, Bo S, Bai L, Shen-Hung W, Gang A, Jian L (2007) The Impacts of Moisture Transport of East Asian Monsoon on Summer Precipitation in Northeast China, Advances in Atmospheric Sciences, 24(4): 606-618.

Luzzadder-Beach S, Beach TP, Dunning NP (2012) Wetland fields as mirrors of drought and the Maya abandonment. Proceedings of the National Academy of Sciences 109(10): 3646-3651.

Macleane CD (1885) Manual of the Administration of the Madras Presidency, Volume 2. Chennai: E. Keys.

Mann ME, Zhang Z, Rutherford S, Bradley RS, Hughes MK, Shindell D, Ammann C, Faluvegi G, Ni F (2009) Global signatures and dynamical origins of the Little Ice Age and Medieval Climate Anomaly. Science 326(5957): 1256-1260.

Meter KJV, Basu NB, Tate E, Wyckoff J (2014) Monsoon harvests: the living legacies of rainwater harvesting systems in South India. Environmental Science and Technology 48(8): 4217-4225. 
Mialhe F, Gunnell Y, Mering C (2008) Synoptic assessment of water resource variability in reservoirs by remote sensing: General approach and application to the runoff harvesting systems of south India. Water Resources Research 44, W05411, doi:10.1029/2007WR006065.

Mo KC, Chelliah M, Carrera ML, Higgins RW, Ebisuzaki W (2005) Atmospheric moisture transport over the United States and Mexico as evaluated in the NCEP regional reanalysis. Journal of Hydrometeorology 6(5):710-728

Morrison KD (2015) Archaeologies of flow: water and the landscapes of Southern India past, present, and future, Journal of Field Archaeology 40(5): 560-580.

Mosse D (2003) The rule of water: statecraft, ecology, and collective action in South India. New Delhi: Oxford University Press.

Muñoz SE, Schroeder S, Fike DA, Williams JW (2014) A record of sustained prehistoric and historic land use from the Cahokia region, Illinois, USA. Geology 42: 499502.

National Oceanic Atmospheric Administration (NOAA) Paleoclimatology (2015) Paleoclimate data sets. http://www.ncdc.noaa.gov/data-access/paleoclimatologydata (accessed 23 May 2015).

Niranjanadevi E (2012) Karikal Cholan. Chennai: Vikatan Publication.

Novick KA, Ficklin DL, Stoy PC, Williams CA, Bohrer G, Oishi AC, Papuga SA, Blanken PD, Noormets A, Sulman BN, Scott RL (2016) The increasing importance of atmospheric demand for ecosystem water and carbon fluxes. Nature Climate Change. 6(11):1023-1027.

Oldfield F, Barnosky AD, Dearing J, Fischer-Kowalski M, McNeill J, Steffen W, Zalasiewicz J (2014) The Anthropocene Review: Its significance, implications and the rationale for a new transdisciplinary journal. The Anthropocene Review 1(1): 3-7.

Opdam P, Luque S, Jones KB (2009) Changing landscapes to accommodate for climate change impacts: a call for landscape ecology. Landscape Ecology 24(6): 715-721.

Pal I, Robertson AW, Lall U, Cane M (2015) Modeling winter rainfall in Northwest India using a hidden Markov model: understanding occurrence of different states and 
their dynamical connections. Climate Dynamics 44(3): 1003-1015.

doi:10.1007/s00382-014-2178-5.

Pandey DN, Gupta AK, Anderson DM (2003) Rainwater harvesting as an adaptation to climate change. Current Science 85(1): 46-59.

Parthasarathy B, Munot AA, Kothawale DR (1988) Regression model for estimation of Indian food grain production from summer monsoon rainfall. Agricultural and Forest Meteorology, 42(2): 167-182.

Pederson N, Hessl AE, Baatarbileg N, Anchukaitis KJ, Di Cosmo N (2014) Pluvials, droughts, the Mongol Empire, and modern Mongolia. Proceedings of the National Academy of Sciences 111: 4375-4379.

Prakash S, Gairola RM (2013) Natural Hazards 68: 763-774. doi:10.1007/s11069-0130651-9

Prasanna Kumar JVS (2013) Temple tanks of Tamil Nadu. Deccan Chronicle, 13 December 2013. Available at http://www.deccanchronicle.com/131213/newscurrent-affairs/article/massive-efforts-revive-temple-tanks-tamil-nadu (accessed 23 May 2015).

Prasanna V (2014) Impact of monsoon rainfall on the total foodgrain yield over India. Journal of Earth System Science 123(5): 1129-1145. doi:10.1007/s12040-0140444-x.

Prasanna V, Yasunari T (2008) Interannual variability of atmospheric water balance over South Peninsular India and Sri Lanka during northeast monsoon season. International Journal of Climatology 28(15): 1997-2009.

Raj YEA (2012) Indian Northeast Monsoon. In Tyagi A, Asnani GC, De US, Hatwar HR, Mazumdar AB (Eds.), Monsoon Monographs - Volume 1 (1st ed., pp. 606-677). Indian Meteorological Department: New Delhi, India.

Rajan K (2008) Ancient irrigation technology: sluice technology in Tamil Nadu. Heritage India Trust, Thanjavur, $326 \mathrm{p}$.

Rajan P (2013) Irrigation system, water management and agrarian system in southern Pennar valley under the Cholas. Indian Streams Research Journal 2(12): 3-8. 
Rajeevan M, Bhate J, Kale JD, Lal B (2006) High resolution daily gridded rainfall data for the Indian region: Analysis of break and active monsoon spells. Current Science 91(3): 296-306. doi:10.1.1.559.6989.

Rajeevan M, Bhate J, Kale JD, Lal B (2006) High resolution daily gridded rainfall data Rajeevan M, Unnikrishnan CK, Bhate J, Niranjan Kumar K, Sreekala PP (2012) Northeast monsoon over India: Variability and prediction. Meteorological Applications 19(2): 226-236. doi:10.1002/met.1322

Ramachandran K (2006) The sacred spaces of a water culture: the temple tanks of South India. In: Third World Water Forum - Water and Cultural Diversity - 2003, Tokyo: United Nations Educational Scientific and Cultural Organization: pp. $113-130$.

Ramage CS (1971) Monsoon meteorology. New York: International Geophysics series. Ramaswamy C (1962) Breaks in the Indian summer monsoon as a phenomenon of interaction between the easterly and the sub-tropical westerly jet streams. Tellus 14(3): 337-349. doi:10.1111/j.2153-3490.1962.tb01346.x

Rao YP (1976) Southwest monsoon. Vol. 1. India Meteorological Department: New Delhi, India

Robertson AW, Kirshner S, Smyth P, Charles SP, Bates BC (2006) Subseasonal to interdecadal variability of the Australian monsoon over North Queensland. Quarterly Journal of the Royal Meteorological Society 132(615): 519-42. doi:10.1256/qj.05.75

Ruddiman WF (2003) The anthropogenic greenhouse era began thousands of years ago. Climatic Change 61(3): 261-293.

Ruddiman WF (2013) The Anthropocene. Annual Review of Earth and Planetary Sciences 41: 45-68.

Sarkar A, Ramesh R, Bhattacharya SK, Rajagopalan G (1990) Oxygen isotope evidence for a stronger winter monsoon current during the last glaciation. Nature 343: 549551.

Sastri KAN (1966) The Later Cholas. Chennai: University of Madras Press. 
Sastri KAN (2014) A history of South India from prehistoric times to the fall of

Vijayanagar. Chennai: Oxford University Press (Original work published in 1955).

Schwartzberg JE (Ed.) (1992) A historical atlas of South Asia. New York: Oxford University Press.

Schwarz G. 1978. Estimating the dimension of a model. The Annals of Statistics 6(2): 461-464. doi:10.1214/aos/1176344136.

Shanmugasundaram J, Soulalay V, Chettiyappan V (2012) Geographic information system-based healthcare waste management planning for treatment site location and optimal transportation routing. Waste Management and Research 30(6): 587595.

Shi F, Li J, Wilson RJS (2014) A tree-ring reconstruction of the South Asian summer monsoon index over the past millennium. Scientific Reports 4(6739), doi:10.1038/srep06739

Sikka DR, Gadgil S (1978) Large-scale rainfall over India during the summer monsoon and its relation of the lower and upper tropospheric vorticity. Indian Journal of Meteorology, Hydrology and Geophysics 29: 219-31.

Singh OP (1995) Influence of Bay of Bengal on winter monsoon rainfall, Mausam 46(3): 307-312.

Sinha A, Cannariato KG, Stott LD, Cheng H, Edwards RL, Yadava MG, Ramesh R, Singh IB (2007) A 900-year (600 to 1500 A.D.) record of the Indian summer monsoon precipitation from the core monsoon zone of India. Geophysical Research Letters 34, L16707, doi:10.1029/2007GL030431.

Souris M (2002) Les principes des systèmes d'information géographique - Principes, algorithmes et architecture du système Savane. Available at http://www.savgis.org/SavGIS/Etudes_realisees/SOURIS_these_2002.pdf (accessed 23 June 2015).

Sreekala PP, Rao SVB, Rajeevan M (2011) Northeast monsoon rainfall variability over south peninsular India and its teleconnections. Theoretical and Applied Climatology 108(1-2): 73-83. doi:10.1007/s00704-011-0513-x. 
Srinivasan TM (1991) Irrigation and water supply: South India, 200 B.C.-1600 A.D.

Chennai: New Era Publications.

Srinivasan V, Ramamurthy K (1974) Comprehensive articles on selected topics, Northeast monsoon. Pune: India Meteorological Department

Steffen W, Crutzen PJ, McNeill JR (2007) The Anthropocene: are humans now overwhelming the great forces of nature? Ambio: A Journal of the Human Environment 36(8): 614-621.

Stocker TF, Qin D, Plattner GK, Tignor M, Allen SK, Boschung J, Nauels A, Xia Y, Bex B, Midgley BM (2013) IPCC, 2013: climate change 2013: the physical science basis. Contribution of working group I to the fifth assessment report of the intergovernmental panel on climate change.

Subbarayalu Y (2010) Changes in agrarian relations in the Kaveri delta c. 900-1300. Social Scientist 38: 44-52.

Subbarayalu Y (2012) South India under the Cholas. New Delhi: Oxford University Press.

Suppiah R (1989) Relationships between the southern oscillation and the rainfall of Sri Lanka. International Journal of Climatology 9(6): 601-618.

Suppiah R (1996) Spatial and temporal variations in the relationships between the Southern Oscillation phenomenon and the rainfall of Sri Lanka. International Journal of Climatology 16(12): 1391-1407.

Tamil Nadu State Planning Commission (2012) Working group document on "Assessing the subsector contribution of state income and its potential'. Available at http://www.tn.gov.in/spc/app_studies/app1.pdf (accessed 23 June 2015).

The Hindu (2016) Flash floods in Kancheepuram. Available at http://www.thehindu.com/news/national/tamil-nadu/flash-floods-inkancheepuram/article7875065.ece (accessed 02 April 2016).

The Indian Express 2016. Explained: Why is Chennai under water? Available at http://indianexpress.com/article/explained/why-is-chennai-under-water/ (accessed 02 April 2016).

Tiwari M, Singh AK, Ramesh R (2011) High-resolution monsoon records since Last Glacial Maximum: a comparison of marine and terrestrial paleoarchives from 
South Asia. Journal of Geological Research 2011: 1-12, doi:10.1155/2011/765248.

Tyagi A, Hatwar HR, Pai DS (2009) Monsoon 2008-a report. IMD Met Monograph/Synoptic Meteorology, New Delhi: Indian Meteorological Department.

United Nations Development Programme (2013) Climate risk management for agriculture sector in Tamil Nadu State of India. New York: United Nations Development Programme, Bureau for Crisis Prevention and Recovery (UNDPBCPR).

Von Storch H and Zwiers FW (2001). Statistical analysis in climate research. Cambridge: Cambridge university press.

Von-Rad U, Schaaf M, Michels KH, Schulz H, Berger WH, Sirocko F (1999) A 5000-yr record of climate change in varved sediments from the oxygen minimum zone off Pakistan, Northeastern Arabian Sea. Quaternary Research 51(1): 39-53.

Wallace JM (2000) North Atlantic Oscillation/annular mode: Two paradigms - one phenomenon. Quaternary Journal Royal Meteorological Society 126: 791-805. doi:10.1002/qj.49712656402.

Walpole RE, Myers RH, Myers SL, Ye K (1993) Probability and statistics for engineers and scientists. New York: Macmillan.

Walsh RP, Glaser R, Militzer S (1999) The climate of Madras during the eighteenth century. International Journal of Climatology 19(9): 1025-1047.

Wang B, Rui HL (1990) Synoptic climatology of transient tropical intra-seasonal convection anomalies Meteorology and Atmospheric Physics 44(1-4): 43-61.

Wang B, Wu R, Li T (2003) Atmosphere-warm ocean interaction and its impacts on the Asian-Australian monsoon variation. Journal of Climate 16(8):1195-121

Wang B, Xu X (1997) Northern Hemisphere summer monsoon singularities and climatological intra-seasonal oscillation Journal of Climate 10:1071-1085.

Water Resource Organization (WRO undated) Details of Reservoirs in Tamil Nadu. Available at http://www.wrd.tn.gov.in/Reservoir_details.pdf (accessed 02 April 2016). 
Webster PJ (1987) The Elementary Monsoons. In Fein JS, Stephens PL (Eds.), Monsoons (1st ed., 3-32). National Science Foundation: Washington, DC, USA.

Wescoat JL (2011) Water, Climate, and the Limits of Human Wisdom: HistoricalGeographic Analogies Between Early Mughal and Modern South Asia. The Professional Geographer 66: 382-389

Wilks DS (2011). Statistical methods in the atmospheric sciences (Vol. 100). Cambridge: Academic press.

Wu R and Kirtman BP (2006). Two Types of Dry Indian Summer Monsoons. Maryland: Center for Ocean-Land-Atmospheric Studies and George Mason University

Wu R, Kirtman BP, Pegion K (2005) Local air-sea relationship in observations and model simulations. Maryland: Center for Ocean-Land-Atmospheric Studies and George Mason University.

Wu R, Kirtman BP, Pegion K (2017) Surface latent heat flux and its relationship with sea surface temperature in the National Centers for Environmental Prediction Climate Forecast System simulations and retrospective forecasts. Geophysical Research Letters 34(17):1-6 doi:10.1029/2007GL030751

Yadav RK (2013) Emerging role of Indian Ocean on Indian northeast monsoon. Climate Dynamics 41(1): 105-116. doi:10.1007/s00382-012-1637-0.

Yadav RK. 2012. Why is ENSO influencing Indian northeast monsoon in the recent decades? International Journal of Climatology 32(14): 2163-2180. doi:10.1002/joc. 2430 .

Yadava MG, Ramesh R (2005). Monsoon reconstruction from radiocarbon dated tropical Indian speleothems. The Holocene 15(1): 48-59.

Yan H, Sun L, Wang Y, Huang W, Qiu S, Yang C (2011) A record of the Southern Oscillation Index for the past 2,000 years from precipitation proxies. Nature Geoscience 4: 611-614.

Zhou LT, Chen G, and Wu R (2015). Change in surface latent heat flux and its association with tropical cyclone genesis in the western North Pacific. Theoretical and Applied Climatology 119(1-2):221-227. 
Zubair L, Ropelewski CF (2006) The strengthening relationship between ENSO and northeast monsoon rainfall over Sri Lanka and southern India. Journal of Climate 19: $1567-1575$.

Zubair L, Siriwardhana M, Chandimala J, Yahiya Z (2008) Predictability of Sri Lankan rainfall based on ENSO. International Journal of Climatology 28(1): 91-101.

Zucchini W, Guttorp P (1991) A Hidden Markov Model for Space-Time Precipitation.

Water Resources Research 27(8):1917-23. doi:10.1029/91WR01403. 